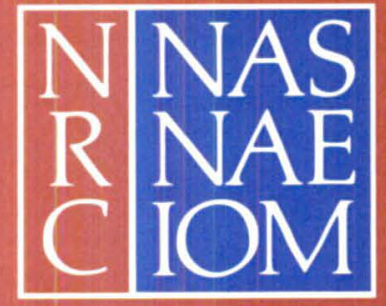

Nasa $=C R-176,322$

NASA-CR-176322

19860003767

\title{
Aeronautical Technology 2000: A Projection of Advanced Vehicle Concepts
}

\section{FOR REFERENCE}

NOT TO BE TAKEN PROM THIS ROOM

Panel on Vehicle Applications

Aeronautics and Space Engineering Board

Commission on Engineering and Technical Systems

National Research Council 


\section{Aeronautical Technology 2000: A Projection of Advanced Vehicle Concepts}

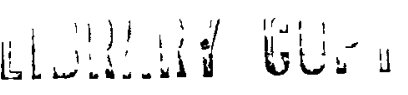

JUL 28980

Report of the

Panel on Vehicle Applications

Aeronautics and Space Engineering Board

Commission on Engıneerıng and Technical Systems

Natıonal Research Councıl
LANGLEY RESEARCH CENTER

LIBRARY, NASA

HAMPTON, VIRGINIA

FOR REFERENCE

NOT TO BE TAKEN FROM THIS ROOM

NATIONAL ACADEMY PRESS

Washıngton, D C. 1985 
NOTICE: The project that is the subject of this report was approved by the Governing Board of the National Research Council, whose members are drawn from the councils of the National Academy of Sciences, the National Academy of Engineering, and the Institute of Medicine. The members of the committee responsible for the report were chosen for their special competences and with regard for appropriate balance.

This report has been reviewed by a group other than the authors according to procedures approved by a Report Review Committee consisting of members of the National Academy of Sciences, the National Academy of Engineering, and the Institute of Medicine.

The National Research Council was established by the National Academy of Sciences in 1916 to associate the broad community of science and technology with the Academy's purposes of furthering knowledge and of advising the federal government. The Council operates in accordance with general policies determined by the Academy under the authority of its congressional charter of 1863 , which establishes the Academy as a private, nonprofit, self-governing membership corporation. The Council has become the principal operating agency of both the National Academy of Sciences and the National Academy of Engineering in the conduct of their services to the government, the public, and the scientific and engineering communities. It is administered jointly by both Academies and the Institute of Medicine. The National Academy of Engineering and the Institute of Medicine were established in 1964 and 1970, respectively, under the charter of the National Academy of Sciences.

This report and the study on which it is based were supported by Contract No. NASW-3455 between the National Aeronautics and Space Administration and the National Academy of Sciences.

Copies of this publication are available from:

Aeronautics and Space Engineering Board

National Research Council

2101 Constitution Avenue, N.W.

Wash ington, D.C. 20418

Printed in the United States of America 
PANEL ON VEHICLE APPLICATIONS

Members

ARMAND SIGALlA, CHAIRMAN, Chief Engineer, Technology for New Products, Boeing Commercial Airplane Company

PAUL A. CZYSZ, McDonne11 Aircraft Company, McDonne11 Douglas Corporation

RICHARD R. HEPPE, President, Lockheed-California Company

JOHN D. LOUTHAN, Retired Director, Advanced Programs Engineering, LTV Aerospace and Defense Company, Vought Aeroproducts Division JOSEPH MALLEN, President, Boeing-Vertol Company

IRWIN MENDELSON, President, Engineerıng Division, Pratt \& Whitney Aircraft Group

JAN ROSKAM, Ackers Distinguished Professor of Aerospace Engineering and Director, Flight Research Laboratory, University of Kansas RONALD SAMBORSKY, Manager, Turbo-Propulsion Programs, Marine and Industrial Systems, Aerojet Techsystems Company

ROGER D. SCHAUFELE, Vice President, Engineering, Douglas Aircraft Company, McDonnell Douglas Corporation

A. D. WELLIVER, Boeing Military Airplane Company

\section{Liaison Representatives}

WILLIAM S. AIKEN, Director, Aeronautical Systems Division, NASA Headquarters

HAROLD ANDREWS, Associate Technical Director, Naval Air Systems Command

RICHARD L. BALLARD, Associate Division Chief and Technical Monitor, Headquarters Department of the Army, The Pentagon

LAURENCE H. FISHBACH, Head, Unconventional Systems Section, NASA Lewis Research Center

DOMINIC MAGLIERI, NASA Langley Research Center

G. KEITH RICHEY, Chief Scientist, AFWAL, Flight Dynamics Laboratory Wright Patterson AFB

JOHN ZUK, Chief, Aeronautics Systems Branch, NASA Ames Research Center

\section{ASEB Staff}

ROBERT J. BURGER, Study Director

MARLENE R. VEACH, Project Assistant 
Members

JOSEPH F. SHEA, CHAIRMAN, Senior Vice President, Engineering, Raytheon Company

MAX E. BLECK, Consul tant

BERNARD BUDIANSKY, Professor of Structural Mechanics, Harvard University

W. BOWMAN CUTTER III, Coopers and Lybrand

R. RICHARD HEPPE, President, Lockheed-California Company

RICHARD W. HESSELBACHER, Manager, Division Advanced Development and

Information Systems, Space System Division, and President,

Management and Technical Services Company, General Electric Company

KENNETH F. HOLTBY, Senior Vice President, The Boeing Company

JAMES J. KRAMER, Manager, Advanced Technology Programs, General

Electric Company

PETER W. LIKINS, President, Lehigh University

DONALD J. LLOYD-JONES, Consultant

STEPHEN F. LUNDSTROM, Associate Professor in Electrical Engineering

(Research), Stanford University

ARTUR MAGER, Consultant

STANLEY MARTIN, JR., Vice President, V-22 Engineering, Bell

Helicopter Textron

JOHN F. MCCARTHY, JR., Northrop Corporation

JOHN L. McLUCAS, Executive Vice President, Communications Satellite Corporation

IRWIN MENDELSON, President, Engineering Division, Pratt \& Whitney Aircraft Group

JAN ROSKAM, Ackers Distinguished Professor of Aerospace Engineering and Director, Flight Research Laboratory, University of Kansas

ROGER D. SCHAUFELE, Vice President, Engineering, Douglas Aircraft

Company, McDonnell Douglas Corporation

RICHARD S. SHEVELL, Professor, Department of Aeronautics and Astronautics, Stanford University

ROBERT E. SKELTON, Professor of Aeronautics Engineering, Purdue University

ALTON D. SLAY, President, Slay Enterprises, Incorporated

MORRIS A. STEINBERG, Vice President, Science, Lockheed Corporation

LAURENCE R. YOUNG, Professor of Aeronautics and Astronautics

Massachusetts Institute of Technology

$\underline{\text { Staff }}$

ROBERT H. KORKEGI, Executive Director

A. J. EVANS, Staff officer

BERNARD MAGGIN, Staff Officer

LAURA D'SA, Administrative Secretary

JULIE A. FERGUSON, Senior Secretary 
CONTENTS

1. INTRODUCTION . . . . . . . . . . . . . . . . . 1

2. SUMMARY . . . . . . . . . . . . . . . . . 5 General Observations, 5

Assessments of Aircraft Classes, 9

Related Activities--Program Development, 21

3. DISCUSSION OF SPECIFIC AIRCRAFT CLASSES . . . . . . . . 25

MILITARY AIRCRAFT . . . . . . . . . . . 25

Subsonic Strike, 25

Supersonic Short Takeoff-Vertical Landing, 29

Advanced Fighter, 39

Hypersonic Vehicles, 45

TRANSPORT AIRCRAFT . . . . . . . . . . . . 59

Subsonic Transport, 59

Commuter Aircraft, 65

Supersonic Transport, 74

ROTORCRAFT . . . . . . . . . . . . . . 81

EXTREMELY HIGH ALTITUDE AIRCRAFT . . . . . . . . . . 94

TRANSATMOSPHERIC VEHICLE . . . . . . . . . . 100 
TABLES AND FIGURES

Tables

TABLE 1 Possible Representative Aircraft . . . . . . . . . 2

TABLE 2 Essential Technologies for Representative Aircraft Types . . 6

TABLE 3 Performance Gains and New Capability . . . . . . . . 7

TABLE 4 Enhancing/Supporting Propulsion Technology Needs

for Subsonic Strike Aircraft . . . . . . . . . . . . . 31

TABLE 5 Basic Characteristics of the Subsonic Strike Aircraft • 31

TABLE 6 Performance Projections for STOVL . . . . . . . . . 39

TABLE 7 Performance Projections for Advanced Fighter . . . . . . 46

TABLE 8 Hypersonic Technology Activity . . . . . . . . . . 56

TABLE 9 Cryogenic Fuel Program Elements . . . . . . . . . 56

TABLE 10 Propulsion System Technology Needs . . . . . . . . 67

TABLE 11 Performance Projections for Subsonic Transport Aircraft $~ 67$

TABLE 12 Performance Projections for Commuter Aircraft . . . . . 73

TABLE 13 Performance Projections for Supersonic Transport . . . 80

TABLE 14 Supersonic Cruise Aircraft Comparison . . . . . . . 81

TABLE 15 Performance Projections for Rotorcraft . . . . . . . 93

TABLE 16 Projected Performance Gains, Future Advanced Rotorcraft 99

TABLE 17 Performance Projections for Extremely High

Altitude Aircraft ..................... 100

TABLE 18 Performance Projections for Transatmospheric Aircraft . . 108

\section{Figures}

FIGURE 1 Subsonic Strike Aircraft . . . . . . . . . . . 10

FIGURE 2 Supersonic Short Takeoff-Vertical Landing Aircraft . • 10

FIGURE 3 Advanced Fighter Aircraft . . . . . . . . . . . . . 11

FIGURE 4 Hypersonic Interceptor . . . . . . . . . . . . . . 12

FIGURE 5 Hypersonic Cruise Missile . . . . . . . . . . . 13

FIGURE 6 Hypersonic Transport . . . . . . . . . . . . . 13

FIGURE 7 Advanced Subsonic Transport . . . . . . . . . . . . 14

FIGURE 8 Assault Transport . . . . . . . . . . . . . . 15

FIGURE 9 Long-Haul Airlifter . . . . . . . . . . . . 15

FIGURE 10 Commuter Aircraft ............... 17

FIGURE 11 Supersonic Transports ............... 18

$\mathbf{v i}$ 
FIGURE 12 Next-Generation Helicopters, year 2000 . . . . . 20

FIGURE 13 Advanced High-Speed Rotorcraft . . . . . . . . . 20

FIGURE 14 Extremely High Altitude Aircraft, Solar Powered . . . . 22

FIGURE 15 Extremely High Altitude Aircraft, Microwave Powered . - 22

FIGURE 16 Transatmospheric Aircraft ............. 23

FIGURE 17 Next Generation Shuttle .............. 23

FIGURE 18 Technology matrix, Subsonic Strike Aircraft . . . . 28

FIGURE 19 Technology matrix, Advanced Fighter propulsion systems . 30

FIGURE 20 Technology matrix, Supersonic STOVL . . . . . . . 37

FIGURE 21 Technology matrix, Supersonic STOVL propulsion . . . . 38

FIGURE 22 Turbojets for the Advanced Fighter . . . . . . . . 42

FIGURE 23 Technology matrix, Advanced Fighter Aircraft . . . . . 46

FIGURE 24 Hypersonic Airbreathing Missile . . . . . . . . 48

FIGURE 25 Military Penetrator Aircraft . . . . . . . . . . 48

FIGURE 26 Hypersonic Accelerator Vehicle . . . . . . . . . . 50

FIGURE 27 Hypersonic Transport Aircraft . . . . . . . . . . 50

FIGURE 28 Propulsion system fuel efficiency . . . . . . . . . 52

FIGURE 29 Propulsion system, materials, and Mach number

relationship . . . . . . . . . . . . . . . . 52

FIGURE 30 Technology matrix, Hypersonic Vehicles . . . . . . . 58

FIGURE 31 Technology matrix, Hypersonic Vehicle propulsion systems 58

FIGURE 32 Technology matrix, Subsonic Transports . . . . . . 66

FIGURE 33 Technology matrix, Commuter Aircraft . . . . . . . . 72

FIGURE 34 Technology matrix, Commuter Aircraft propulsion systems 73

FIGURE 35 Technology matrix, commercial Supersonic Transport . . 79

FIGURE 36 Technology matrix, Supersonic Transport

propulsion systems .................... 80

FIGURE 37 Technology matrix, Rotorcraft ........... 85

FIGURE 38 Technology matrix, Rotorcraft propulsion systems . . . 87

FIGURE 39 Technology matrix, Extremely High Altitude Aircraft • 98

FIGURE 40 Technology matrix, Extremely High Altitude

Aircraft propulsion systems . . . . . . . . . . . . 99

FIGURE 41 Aircraft sizing for various power systems for

operation at 60,000 feet . . . . . . . . . . . . . 99

FIGURE 42 TAA/Aerospace Vehicle, vertical-takeoff concept. . . . 101

FIGURE 43 TAA/Aerospace Vehicle, air-launched concept . . . . 101

FIGURE 44 Technology matrix, Transatmospheric Aircraft . . . . . 106

FIGURE 45 Technology matrix, Transatmospheric Aircraft

propulsion systems ...................... 107 
INTRODUCTION

In January 1984, at the request of the National Aeronautics and Space Administration (NASA), the Aeronautics and Space Engineering Board (ASEB) of the National Research Council conducted a Workshop on Aeronautical Technology: a Projection to the Year 2000 (Aerotech 2000 Workshop) at the University of Texas at Austin. The workshop brought together a group of more than 80 experts from various fields of aeronautics. The participants were organized into eight panels to address the areas of aerodynamics; materials; structures; guidance, navigation, and control; human factors; propulsion; computer and information technology; and systems integration.

The panels were asked to project advances in aeronautical technologies that could be available by the year 2000, conceptualize types of advanced aircraft, and identify performance gains that could evolve from the application of the advanced technologies. The projections were not to be constrained by consideration of resource availability or other factors involved in decisions to commit to design and development. Details of the workshop and its findings are contained in the ASEB report entitled Aeronautics Technology Possibilities for 2000: Report of a Workshop, National Academy Press, October 1984.

As the workshop was drawing to a close, it became evident that a more comprehensive investigation of advanced air vehicle concepts than was possible in the limited time available at the workshop would be valuable. Thus, a special panel on vehicle applications was organized. The new panel was directed to consider more fully the integrated effects of technological advances projected at the workshop and to describe in some detail examples of future air vehicles and capabilities that could result from application of the projected technology. Membership of the Vehicle Applications Panel was comprised of experts from the workshop and others carefully selected from industry who were skilled and experienced in the design and development of advanced aeronautical systems.

The Vehicle Applications Panel, after defining and describing advanced vehicle concepts based on projected technologies, was 
requested to identify specific technology developments required for each of the selected vehicle types. The major features of each class of aircraft were described according to a set of descriptive elements agreed on by the panel.

In the course of two meetings, the panel identified and described representative types of aircraft judged possible with the workshop's technology projections. A list of these representative aircraft is shown in Table 1. The list includes, but is not limited to, the vehicles identified at the Aerotech 2000 Workshop.

The panel was organized into subgroups which addressed each of the selected aircraft classes. For each of the classes, the subgroups identified improvements in performance, efficiency, and operational characteristics possible through the application of the workshop's year 2000 technology projections. The subgroups also identified the technologies considered essential and enhancing or supporting to achieve the projected aircraft improvements. Finally, an assessment was made of the integrated performance benefits perceived to be attainable through the application of appropriate technology.

TABLE 1 Possible Representative Aircraft

Military Aircraft

- Subsonic Strike

- Supersonic Short Takeoff-Vertical Landing

- Advanced Fighter

- Hypersonic

Transport Aircraft

- Subsonic Transport

-- Short-/Medium-Range (Commercial)

-- Long-Range (Commercial)

-- Long-Haul Airlifter (Military)

-- Assault (Military)

-- Short Haul (Military)

- Commuter Transport

- Supersonic Transport (Commercial)

Rotorcraft (Commercial and Military)

- Next Generation Helicopters

- Advanced High Speed Rotorcraft

Extremely High Altitude Aircraft (Commercial and Military)

Transatmospheric Aircraft (Commercial and Military) 
In the judgment of the panel, essential technology represents those technologies, reduced to practice, required for the projected advancements in performance and/or capability of future aircraft.

Enhancing/supporting technology encompasses those technologies that are deemed desirable and contributory, but are not in themselves required to attain the necessary improvements that make the vehicle class of special interest.

The panel's deliberations were not constrained by market factors, documented requirements, or certification or political considerations.

It is recognized that resource limitations do not allow the pursuit of unlimited programs of research and technology development and associated support activities. Realistically, selection of the technology to be pursued must result from sound requirements based on consideration of factors such as the needs, benefits, costs, and the likelihood of successful design and development. This study by the ASEB Vehicle Applications Panel, therefore, represents a first step toward prioritization of the aeronautical technology projections developed at the Aerotech 2000 Workshop.

A further prioritization of the projected essential technologies will require at least another step beyond this study to take into account the practical needs and requirements for the projected aircraft. Results of such an effort would provide a basis for judging the nature of the research and technology program required to support future aircraft design and development.

Subsequent to the ASEB's Aerotech 2000 Workshop and prior to the publication of the present report of the Vehicle Applications Panel, the President's Office of Science and Technology Policy (OSTP) published a special study, National Aeronautical R\&D Goals: Technology for America's Future. The OSTP report presented three time-phased goals*:

- Subsonic Goal: To Build Trans-Century Renewal (near-term advancement in technology for a new generation of subsonic tranports);

- Supersonic Goal: To Attain Long-Distance Efficiency (development of technologies for efficient, long-range supersonic cruise); and

- Transatmospheric Goal: To Secure Future Options (assurance that timely options will be available for exploitation of the air and space interface).

Each of these aircraft technology development goals and others were identified as possible by the earlier ASEB Aerotech 2000 Workshop. The workshop report identifies 10 vehicle classes (which include the three selected in the OSTP study) that could be developed with the application of the technology developments identified as possible by the year

*See pages 21-24 for further description of the OSTP goals. 
2000. As noted, this report describes the technology advancements needed for these aircraft developments and thereby the realization of the goals identified by OSTP.

However, more work is needed to develop specific plans for maturing the technologies and establishing time-frames for their application if the OSTP goals are to be realized.

The next chapter summarizes the findings of the Vehicle Applications Panel. It includes: (1) general observations regarding key areas of technology and their implications for the aircraft classes considered in this study; (2) assessments of the aircraft classes listed in Table 1 (discussed in detail in the last chapter of this report); and (3) a brief discussion of the OSTP goals and their relationship to this activity. 
The findings of the Vehicle Applications Panel result from judgments based on the specialized knowledge and experience of the participants, rather than special detailed analyses.

Potential new or greatly improved performance capabilities of twenty-first century aircraft will be dependent on advances projected to be possible in most of the aeronautical disciplines addressed at the Aerotech 2000 Workshop. Some of the technology advances deemed essential for the various classes of aircraft are summarized in Table 2. Their effective integration is assumed to make possible the performance gains and new capabilities identified in Table 3. Significant technical advances are projected to be possible in all the classical technology areas--propulsion, aerodynamics, structures and materials, and guidance and control.

In identifying essential technologies, the panel found that some technologies are essential to several aircraft classes and, therefore, are especially important. Prime examples of such areas of commonality include materials and structures, airframes, and propulsion. Comments on these technologies follow.

\section{Materials and Structures}

In this area, composites (plastic and metal matrices) are considered to be cost competitive with aluminum in the construction of Short- to Medium-Range Subsonic Commercial Transport Aircraft, Commuter Aircraft, and, to some extent, Extremely High Altitude Aircraft. Another example is high temperature materials (i.e., metal matrix composite, rapid solidification materials, and ceramics) that can be fabricated into large airframe structures for Supersonic Transports, Hypersonic Aircraft, and the Transatmospheric Aircraft, which in the later cases will require special attention to reusability. 
TABLE 2 Essential Technologies for Representative Aircraft Types

Military Aircraft

- Subsonic Strike Aircraft

-- Reduced observability

-- Aero-propulsion integration

-- Reliable engines

- Supersonic STOVI

-- Thrust management \& vectoring

-- Integrated concepts and

-- operations

-- Engine materials

- Advanced Fighter

-- Supersonic propulsion

-- High-temperature materials and structures

-- Supersonic h1gh $L / D$ and maneuvering 1 ift

-- Low observability

- Hypersonic Vehicles (a)

-- Multicycle turbo and ramjet propulsion

-- Integrated avionics

-- Controls

-- Cryogenics

-- Materials and thermal protection

-- Lightweight structures

Transatmospheric Aircraft

Propulsion

Aerodynamics/structures

-- Thermal protection systems

-- Lightweight structures

-- Materials

Controls and integrated avionics
Transport Aircraft

- Subsonic Transport Aircraft(b)

-- Propulsion systems

-- Drag reduction

-- Materials and structures

-- High lift

-- Flight control (low speed)

-- Noise reduction (civil)

- Commuter Aircraft

-- Propulsion systems

-- Laminar flow

- Supersonic Transport Aircraft

-- Propulsion systems

-- Lightweight/temperature tolerant materials/ structures

- Noise and sonic boom reduction

Rotorcraft

Noise/vibration reduction

Drag reduction

Control/stabilization

New propulsion system concepts

System validation

Extremely High Altitude Aircraft Energy storage and energy system integration

Ultra-light structures

(a) Airplanes and missiles.

(b) Civil and military; short- and long-haul. 
TABLE 3 Performance Gains and New Capability

\begin{tabular}{|c|c|c|}
\hline Aircraft & Performance Gains & New Capability \\
\hline Subsonic Strike & $\begin{array}{l}\text { Low observability; high } \\
\text { manuverability at sub- } \\
\text { sonic speeds }\end{array}$ & \\
\hline $\begin{array}{l}\text { Supersonic Short } \\
\text { Takeoff-Vertical } \\
\text { Landing }\end{array}$ & $\begin{array}{l}\text { STOVL with high manu- } \\
\text { verability; Mach 2; all } \\
\text { weather }\end{array}$ & \\
\hline Advanced Fighter & $\begin{array}{l}\text { Supersonic crusse at Mach } 3 \\
\text { to } 4 \text { and maneuvering } 2 \mathrm{~g} \text {; } \\
\text { altitude above } 70,000 \mathrm{ft} \text {; } \\
\text { zoom climb to } 100,000 \mathrm{ft} \\
\text { maneuver of } 4 \text { to } 5 \mathrm{gs} \text { at } \\
\text { Mach } 2 \text { and } 40,000 \mathrm{ft}\end{array}$ & $\begin{array}{l}\text { Radius of action of } 1,000 \\
\text { miles with } 2,0001 \mathrm{~b} \\
\text { payload and takeoff } \\
\text { weight of } 100,0001 \mathrm{bs} \\
\text { reduced detectability }\end{array}$ \\
\hline Hypersonic & $\begin{array}{l}\text { Hypersonic aircraft and } \\
\text { missiles; } 80,000-145,000 \mathrm{ft} \text {; } \\
\text { Mach } 4 \text { to } 12\end{array}$ & \\
\hline $\begin{array}{l}\text { Subsonic Transports } \\
\text { (Short-/Medium- } \\
\text { Range, Long- } \\
\text { Range/Long-Haul) }\end{array}$ & $\begin{array}{l}\text { Aerodynamic drag, } 15-20 \% \\
\text { reduction arcraft weight; } \\
\text { aircraft weight, 15-25\% } \\
\text { reductron, operation eff }- \\
\text { ciency, } 20-30 \% \text { improvement; } \\
\text { maintenance requirements, } \\
30-50 z \text { reduction }\end{array}$ & \\
\hline Assault Transport & $\begin{array}{l}\text { Terrain/threat avoidance; } \\
\text { vertical/short takeoff; all } \\
\text { weather, day/night operation }\end{array}$ & \\
\hline Commuter & $\begin{array}{l}\text { Aerodynamic drag, } 10 \% \text { reduction; } \\
\text { specific fuel consumption, } 20- \\
30 \% \text { reduction; aircraft weight, } \\
10-15 \% \text { reduction; maintenance } \\
\text { requirements, 30-50\% reduction }\end{array}$ & \\
\hline $\begin{array}{l}\text { Supersonic } \\
\text { Transport }\end{array}$ & $\begin{array}{l}\text { Speed of Mach } 2.2 \text { to } 3.2 \text {; aero- } \\
\text { dynamic drag, } 30-50 \% \text { reduction; } \\
\text { specific fuel consumption, 5-15\% } \\
\text { reduction; aircraft weight, } \\
\text { 15-20\% reduction; passenger } \\
\text { mles per gallon of fuel, } \\
150-350 \% \text { improvement }\end{array}$ & \\
\hline Rotorcraft & $\begin{array}{l}\text { Nolse, vibration reduction; } \\
\text { specific fuel consumption, } 40 \% \\
\text { reduction; aircraft weight, } \\
30 \% \text { reduction; operation, all } \\
\text { weather; payload, higher } \\
\text { fractions }\end{array}$ & $\begin{array}{l}\text { Vertical takeoff and } \\
\text { landing with horizontal } \\
\text { alrcraft-like flight }\end{array}$ \\
\hline $\begin{array}{l}\text { Extremely High } \\
\text { Altitude }\end{array}$ & & $\begin{array}{l}\text { Very high altitude, very } \\
\text { long duration operations }\end{array}$ \\
\hline Transatmospheric & & $\begin{array}{l}\text { Extension of hypersonic } \\
\text { aircraft to hypervelocity; } \\
\text { unrestricted aircraft speed } \\
\text { from ramp to orbit, Cruise/ } \\
\text { loiter in atmosphere; or- } \\
\text { bital operations; on-demand } \\
\text { launch basing flexibility } \\
\text { through horizontal takeoff; } \\
\text { affordable, space presence. }\end{array}$ \\
\hline
\end{tabular}




\section{Airframes}

Airframe and propulsion integration is an important common area for achleving major advancements for many of the aircraft types identified by the panel. It is particularly significant in the design of higher Mach number aircraft where advanced technology will permit the integration of the propulsion system, aircraft system, and human operators with airframe-engine control systems, and, for military aircraft, vehicle weaponry, high maneuverability, and special flight functions. Examples of aircraft in which integrated flight control technology will help to make possible significant performance gains are: the Short Takeoff-Vertical Landing (STOVL) Tactical Fighter with its complex engine control requirements, the Advanced Fighter Aircraft with its advanced weaponry, and the High-Speed Rotorcraft with convertible engines. Advanced programmable controls also will increase mission flexibility and the utility of Hypersonic and Transatmospheric, Subsonic Strike, and Extremely High Altitude Aircraft.

\section{Propulsion}

The performance of all vehicles could be greatly enhanced by improved engine thrust-to-weight ratios. The propulsion subgroup concluded that increasing the thrust was not as important as lowering the weight of the engine through the application of advanced low-weight, high-strength materials. In fact, of the 10 vehicles considered, advanced materials were deemed essential to 5 propulsion systems and enhancing to 4 others.

Advanced and/or combined engıne cycles were judged to be essential to six of the vehicle classes, ranging from variable cycle and geometry engines for the supersonic vehicles to the convertible engine for rotorcraft. In some cases, it was difficult to decide whether a technology was essential or enhancing. For example, counter rotating propfan or ductless fan engines can offer a 20 to 40 percent reduction in fuel consumption for Mach 0.8 long haul transports. However, these aircraft, even without the propfan, should prove to be highly efficient transports in the year 2000 .

Many of the essential technology rankings in propulsion are assigned to projected Supersonic and Hypersonic aircraft. Technology advancements in airframe and propulsion integration, control systems, and combustors were deemed essential for a number of aircraft classes. Combustor design varies greatly from short, low-pressure ratio and low-temperature remote burners for STOVL to very high temperature burners for the Mach 3.5 fighter, and to controlled high temperature supersonic combustors for Hypersonic Aircraft. 


\section{ASSESSMENTS OF AIRCRAFT CLASSES}

\section{Subsonic Strike Aircraft}

A critical design feature of a representative Subsonic Strike Aircraft (Figure 1) will be reduced observability by radar and other detection techniques to improve mission survivability. If detected, high maneuverability will be important. This characteristic will be realized through technology developments in materials, configuration shaping (including integration of the airframe and propulsion system), advanced aerodynamic control techniques, and engine cycle design. Advanced technology will make possible a moderately sized aircraft with a combat radius exceeding 1,000 nautical miles and a capability for long-range deployment without in-flight refueling. Advanced controls integrating both aerodynamic and propulsion system controls will allow terrain following. Integration of weapon and flight control systems will provide improved weapon delivery effectiveness.

The engines and engine installation for this vehicle will stress low exhaust temperature (nonaugmented), no visible smoke, a conformal inlet, and a vectorable exhaust nozzle. To achieve high subsonic maneuverability with the nonaugmented engine, main combustor outlet temperatures approaching stoichiometric values are essential and will be possible.

Because the propulsion system can be a principal contributor to radar, infrared, and visual signatures, special attention will be given to inlet configurations and exhaust nozzle development. In addition, propulsion features such as the variable cycle engine, deemed essential for other vehicles, can be available to enhance Subsonic Strike Aircraft performance.

Airframe and weapon integration is critical to good performance. Internally carried (or conformal) weapons will be essential and careful attention must be given to this technology development.

\section{Supersonic Short Takeoff-Vertical Landing Aircraft}

The Supersonic Short Takeoff-Vertical Landing (STOVL) Aircraft (Figure 2) is a fighter-interceptor aircraft that will be able to operate from short or damaged runways or from appropriate Navy ships. Maximum speed in the range of Mach numbers of 2.0 to 2.5 will be possible. Vertical Takeoff and Landing (VTOL) and STOVL airplanes have been described as flying propulsion systems wrapped in an aerodynamic shape. The STOVL airplane is one of the vehicles critically dependant on engine development. High thrust-to-weight-ratio engines, propulsion and airframe integration, controls, ground effects, and nozzle technology advances are all essential to this class of vehicle. Many fighters today have engine thrust to aircraft gross weight ratios greater than 1.0 , yet they are not designed to achieve STOVL

performance. 


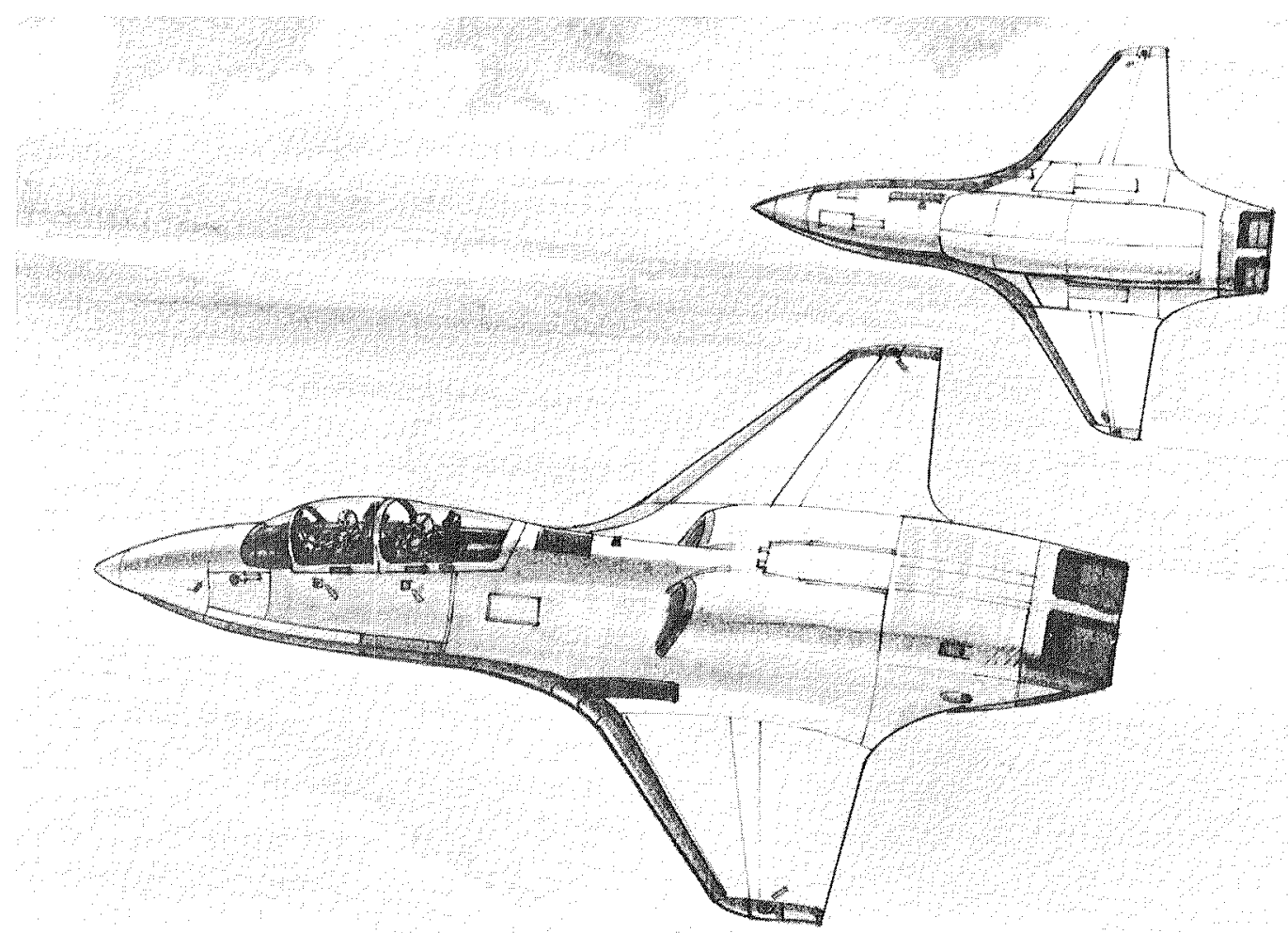

FIGURE 1 Subsonic Strike Aircraft.
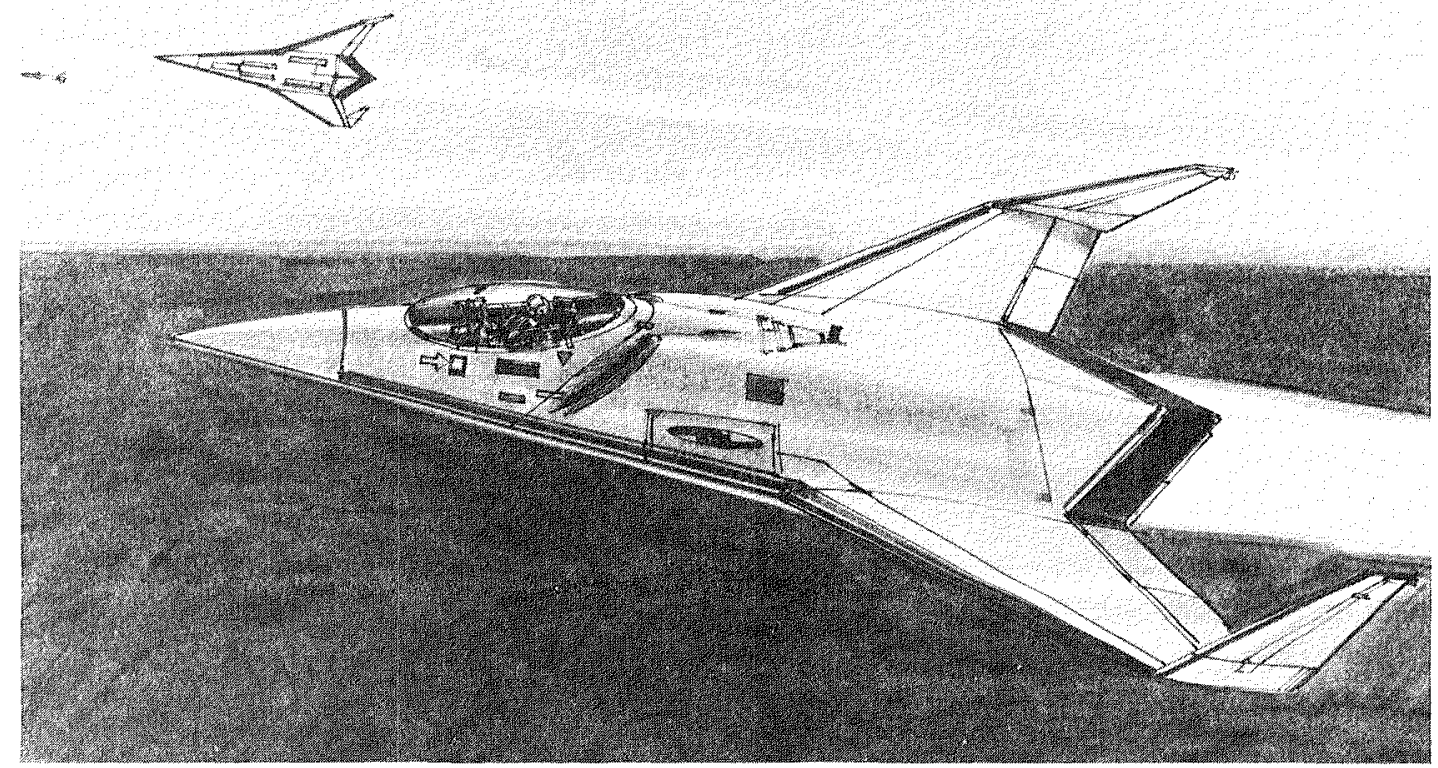

FIGURE 2 Supersonic Short Takeoff-Vertical Landing Aircraft. 
Thrust vectoring combined with aerodynamic controls will enhance maneuvering capability. Advanced digital control systems will provide appropriate mixing of controls throughout the aircraft's flight envelope. Included will be thrust management and vectoring for low speed takeoff and landing and for supersonic flight control. In addition to a high thrust-to-weight-ratio propulsive system and a fully integrated control system, a lightweight airframe will be especially important.

\section{Advanced Fighter}

With successful pursuit of selected technologies, the Advanced Fighter Aircraft (Figure 3) could cruise at speeds above Mach 3.5 at a1titudes in excess of 70,000 feet. It will be possible to maneuver at $2 \mathrm{gs}$ or more at this cruise condition. Because of the power loading, zoom climbs to 100,000 feet to avoid threats would be possible. At lower supersonic speeds and altitudes, 4 to 5 g maneuvers would be possible. Improved efficiency will allow a radius of action of 1,000 nautical miles with a disposable payload of 2,000 pounds. The realization of these flight characteristics will depend on the development of advanced aerodynamic shapes, efficient variable geometry propulsion systems, and high strength/lightweight materials and structures that can withstand sustained temperatures of $1,000^{\circ} \mathrm{F}$ for wing leading edges, air inlets, and exhaust nozzles.

A unique feature of this class of aircraft will be its ability to operate controllably through very high angles of attack to evade attacking missiles and to bring its weapons quickly on target. These

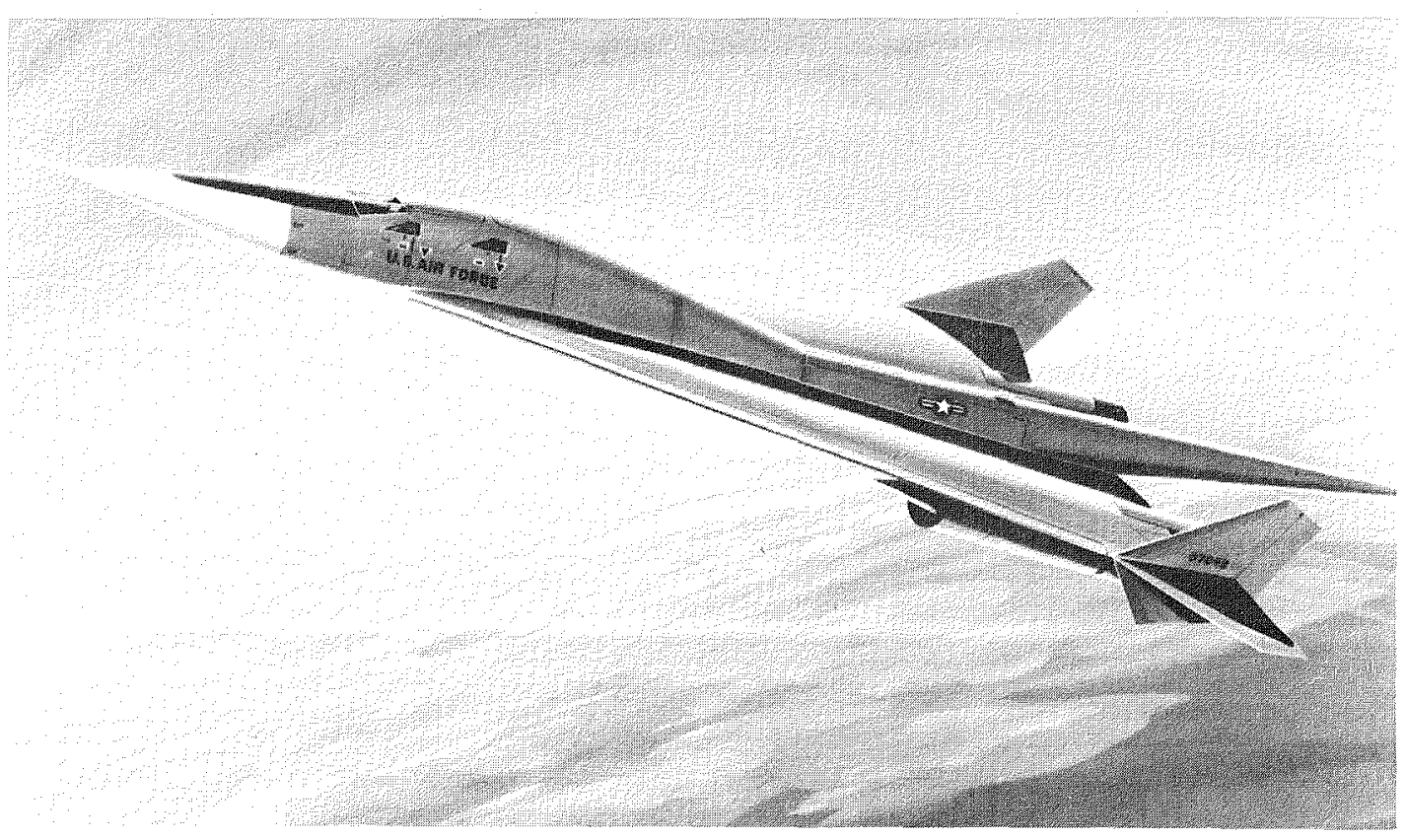

FIGURE 3 Advanced Fighter Aircraft. 
characteristics will be possible through the use of advanced aerodynamic and thrust-vectoring devices and associated avionics to provide extended range and maneuvering capability, and through advanced propulsion systems integrated with flight controls. The full effectiveness of the Advanced Fighter will depend on parallel development of compatible extended-range, highly maneuverable weapons. The propulsive system could be a low-bypass ratio turbojet, with or without variable cycle features, or a turboramjet. Combustor exit temperatures will approach $3,600^{\circ} \mathrm{F}$ or higher. Overall engine pressure ratios of 9 to 16 (compared with present values of 8) will be attainable and would be accomplished in one spool. High unaugmented specific thrust will be required for efficient cruise, with the afterburner used only for acceleration and maneuvering.

\section{Hypersonic Aircraft}

Hypersonic Aircraft, both manned and unmanned, operating in the sensible atmosphere at speeds up to Mach numbers of 12 will be possible. For such vehicles, propulsion, aerodynamics, structures, and control integration technologies could be developed by the year 2000. These developments are absolutely essential. The technology to provide routine, rapid cryogenic fuel handling could be available and will be required. The Hypersonic Interceptor, Hypersonic Cruise Missile, and Hypersonic Transport (Figures 4 through 6) are reflections of potential interest to both the military and civil market places. These aircraft would make use of multicycle propulsion systems for high total flight envelope efficiency.

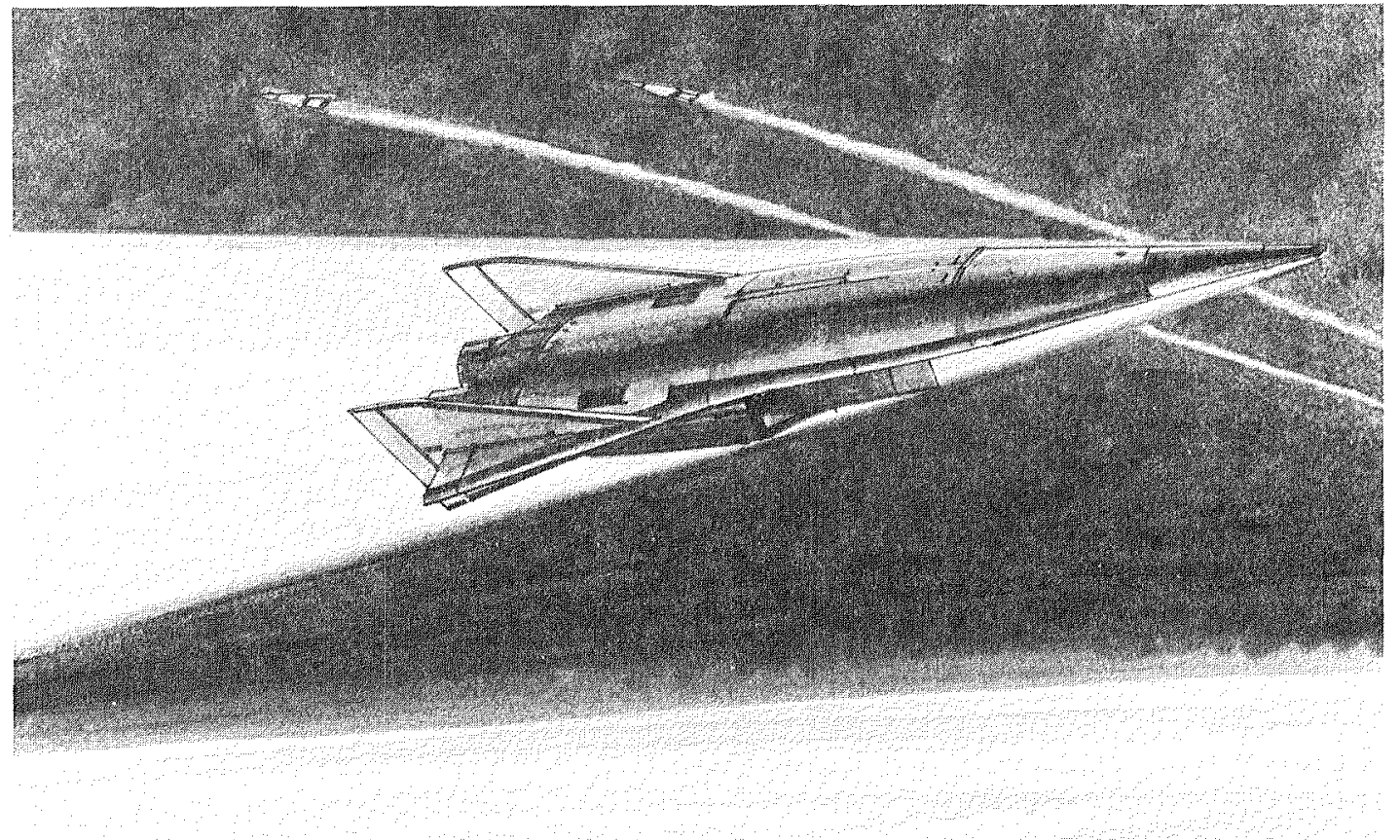

FIGURE 4 Hypersonic Interceptor. 


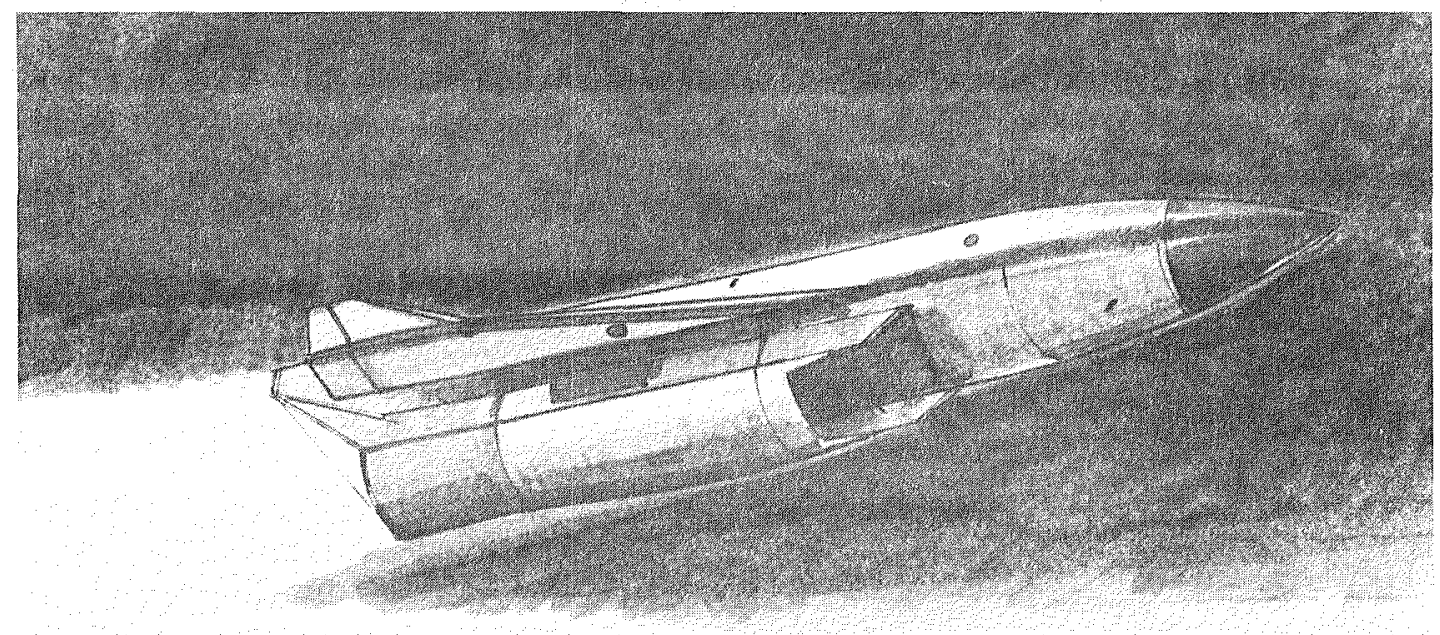

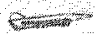

FIGURE 5 Hypersonic Cruise Missile.

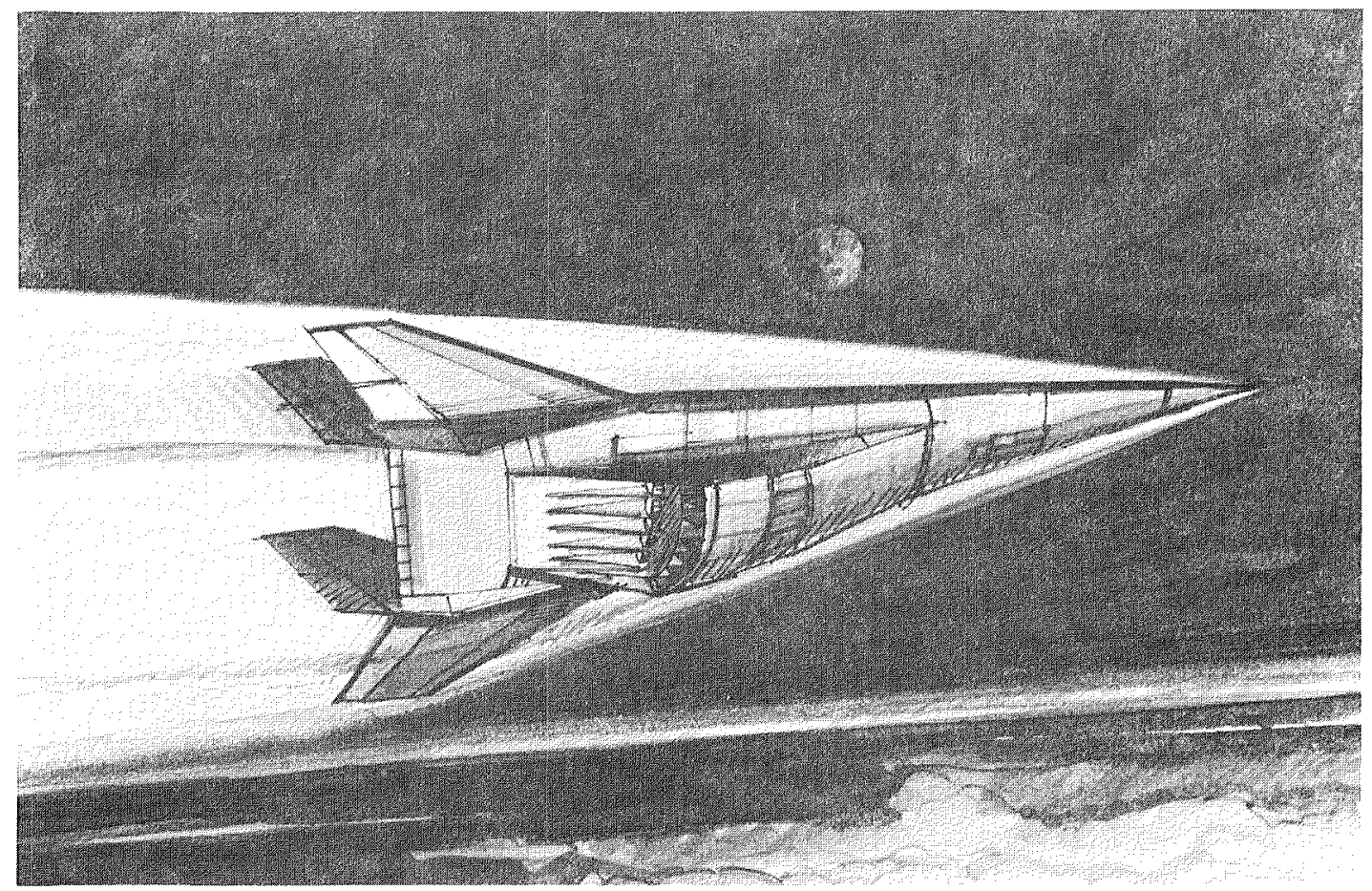

FIGURE 6 Hypersonic Transport. 
New and in-development materials, structures, and thermal management techniques will allow design of high heat load, low weight, durable airframes and engines. Cruise speeds of Mach 6 to 8 would be realized with ranges of hundreds of miles for the interceptors to thousands of miles for the other aircraft. The propulsion concepts include an airturbo ramjet, hydrogen-fueled ramjet, and a hydrogen expansion cryojet for the lower hypersonic speeds. For higher hypersonic speeds above Mach 6 to 8 , a supersonic combustion ramjet (scramjet) would be utilized.

Integration of the airframe and propulsion system are critical for low total vehicle drag and volume. For example, engine inlets will be fully integrated with and inseparable from the airframe.

\section{Subsonic Transport Aircraft}

Figures 7,8, and 9 are illustrations of an Advanced (short- to medium-range) Subsonic Transport Aircraft, an Assault Transport, and a Long-Haul (military) Airlifter, respectively. The civil Short- to Medium-Range Transport, powered by advanced turboprops, will be highly efficient through the use of advanced aerodynamics, structural materials, and propulsion and will have low noise. It will provide a high level of ride comfort through automated flight controls and will be capable of cruise speed in the range of Mach 0.7 to 0.8 .

Compared with current designs, advanced long-range commercial subsonic turbofan jet-powered transports (not illustrated) are projected

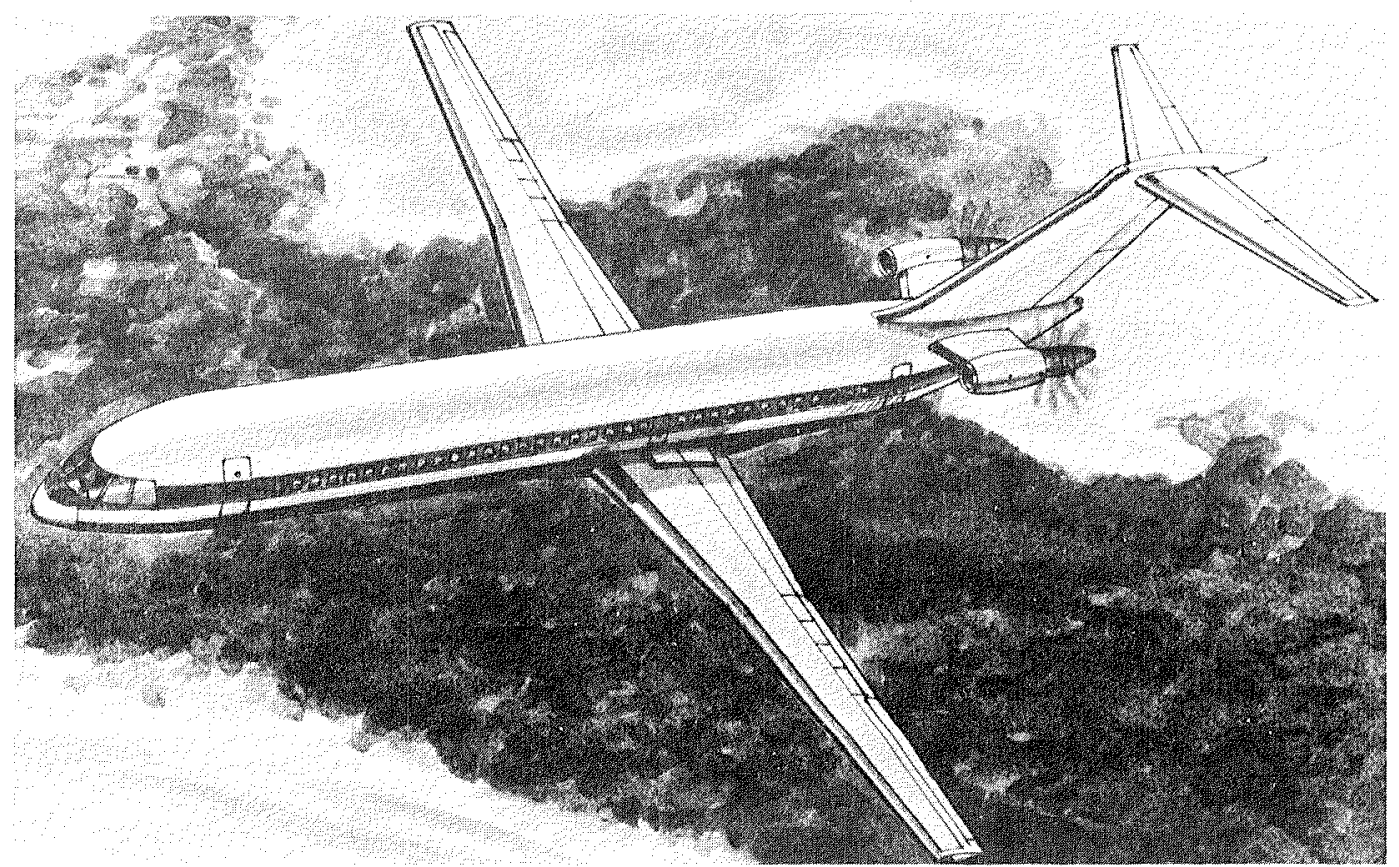

FIGURE 7 Advanced Subsonic Transport. 


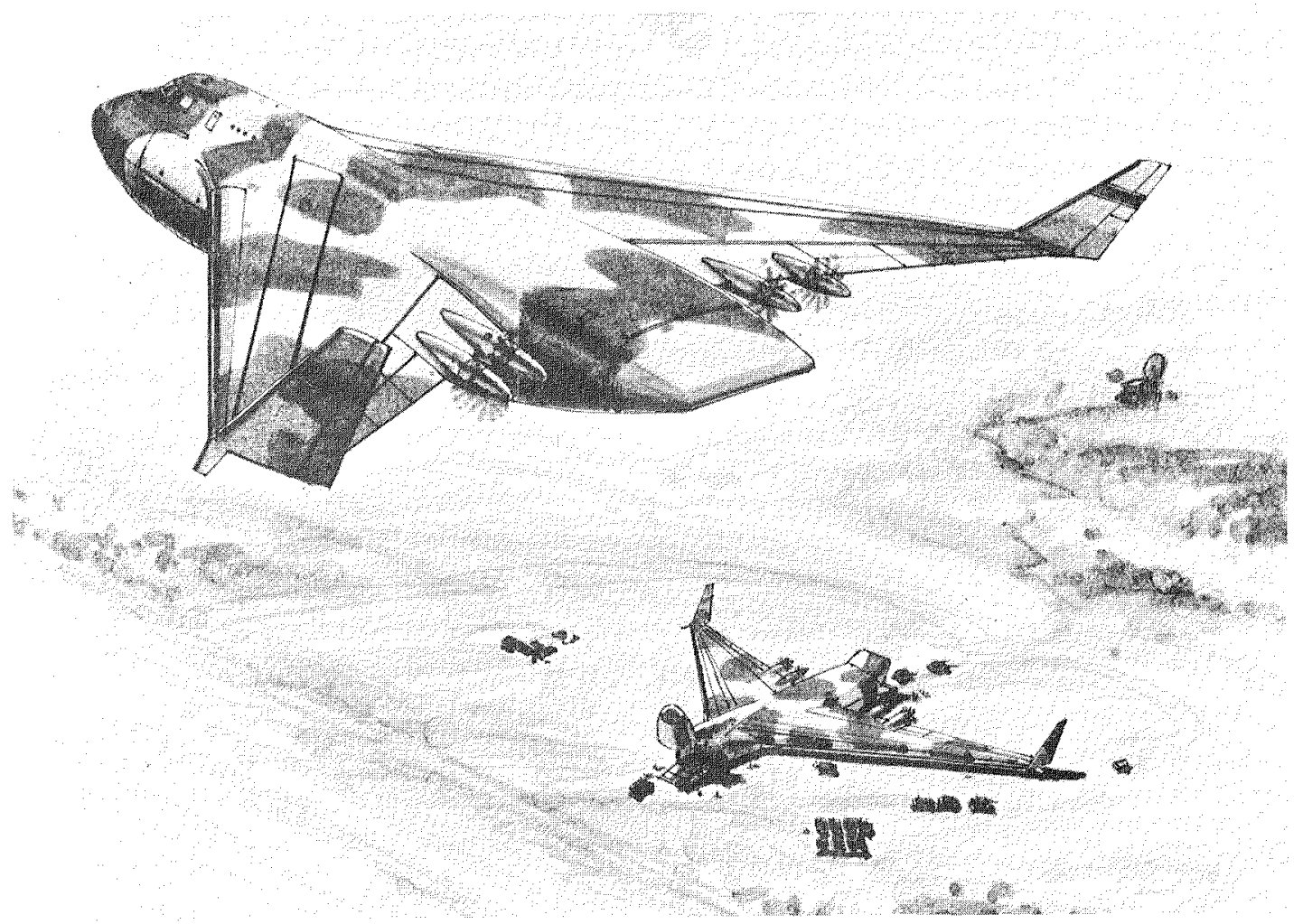

FIGURE 8 Assault Transport.

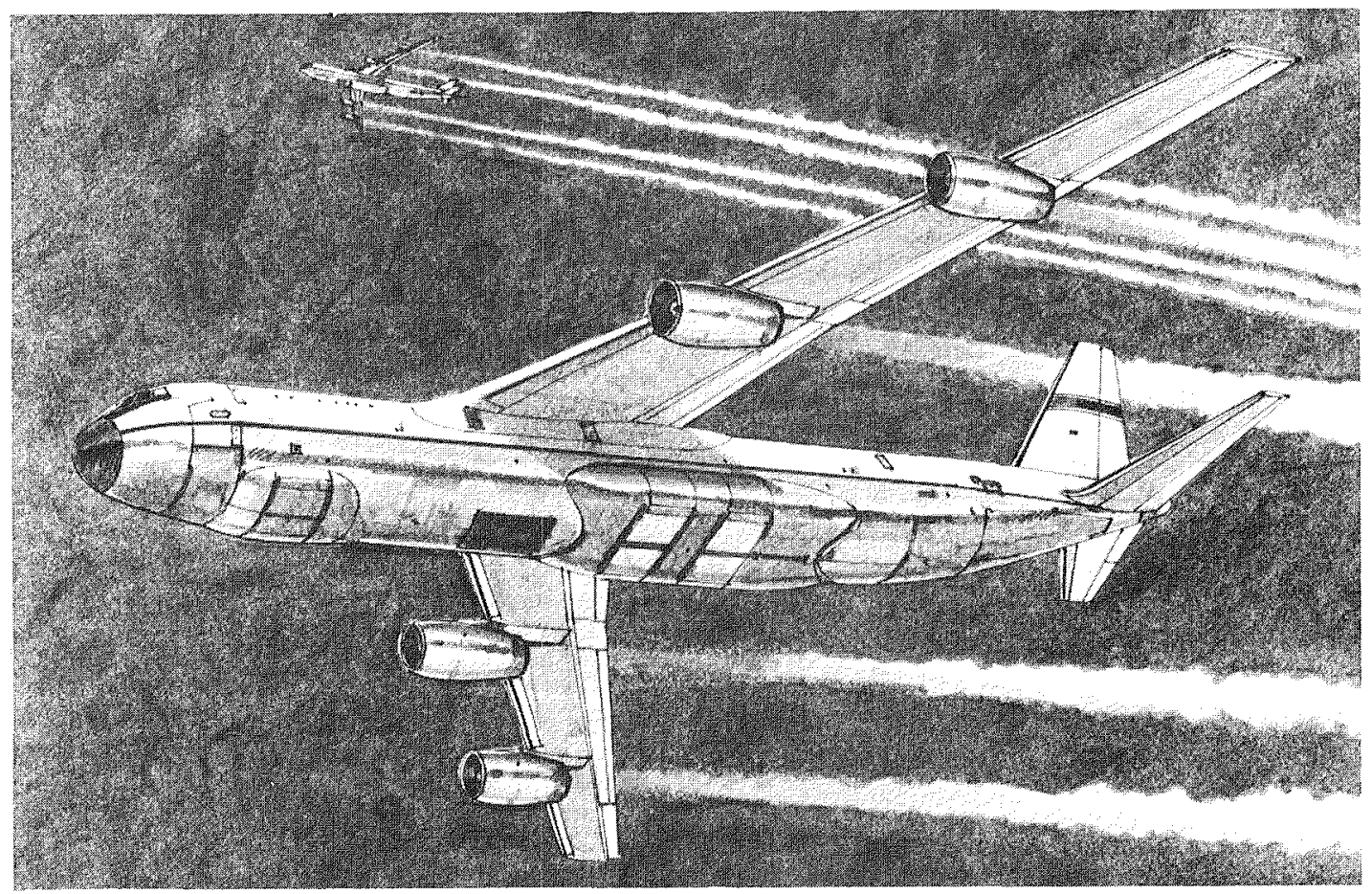

FIGURE 9 Long-Haul Airlifter. 
payload capability while using less fuel. This higher efficiency will be achieved by the application of new, low-weight materials and structures, lower overall drag due to more extensive laminar flow, and improved propulsive efficiency. These aircraft will have greater community acceptability because of low noise during takeoff and approach maneuvers.

Propulsion for the Subsonic Transport, long thought to be a somewhat mature technology, can be improved significantly in terms of fuel consumption, relative to turbofan engines of today. Since the cost of fuel represents an important part of the direct operating costs of airlines (according to major and commuter airline cost analyses), more efficient engines are important to future air transportation economics. Improvements in fuel consumption of 20 percent relative to today's engines are envisioned for an advanced high-bypass turbofan. The potential for advanced turboprops is even greater, approaching 40 percent improvement over today's short-haul turbofans for single rotation propellers and 50 percent for counter-rotating propellers.

The Assault Transport of the future will be capable of operating in combat areas' where there are damaged or unprepared runways and will have a high degree of survivability. Propulsion system and structural design advances will provide the capability for 500-mile operational ranges with payloads up to 40,000 pounds. Advanced avionics (coupled with advanced landing gear systems) will allow all weather operation into and out of the damaged or unprepared fields without ground-based navigational aids.

The subsonic Long-Haul Airlifter for the military illustrated in Figure 9 appears to be a conventional aircraft; however, advanced propulsion, aerodynamics, and structures technology provide capabilities not available today. The advanced aircraft would carry large loads (up to 200,000 pounds) over long distances $(6,000$ nautical miles) without refueling. Its design will allow operation into battle areas with a high capability for survival. It will be aerodynamically clean and have an efficient propulsion system that will allow higher cruise speeds than available with current military transport aircraft.

Thus, it will have significantly increases productivity and operational flexibility.

\section{Commuter Aircraft}

Low cost and high efficiency are design drivers in the competitive, growing market of Commuter Aircraft. A representative future Commuter Aircraft is shown in Figure 10. The technology developments essential to the improvements postulated for this class of aircraft relate to the propulsion system (turboprops) and to natural laminar flow fuselage design. Also important are the development of technologies related to automated manufacturing of composite structures at low cost; advanced flight control for ride quality and operational efficiency; deicing for all-weather operation; and configuration arrangement for improved overall aerodynamic efficiency. Compared 
efficiency; deicing for all-weather operation; and configuration arrangement for improved overall aerodynamic efficiency. Compared with current designs, these advances will permit aircraft structural weight reductions of 10 to 15 percent, aerodynamic drag reduction of about 10 percent, and reductions in fuel consumption in the range of 20 to 30 percent.

There are two engine concepts available to Commuter Aircraft. These are the turbine engine and the intermittent combustion engine. Both concepts have multifuel capability, including the ability to burn turbine-engine fuel. The turbine engine has always been attractive because of its low weight compared with intermittent combustion engines. Specific fuel consumption comparable to that of the intermittent combustion engine will be possible through the use of projected advanced materials such as ceramics in hot-section components and for exhaust heat regeneration. Of the intermittent combustion concepts the most promising appears to be a high-speed, stratified-charge rotary engine. The rotary engine is conceptually a turbocharged, multirotor, stratified-charge engine having thermally insulated combustion chamber faces as well as exhaust gas passages to reduce waste heat losses.

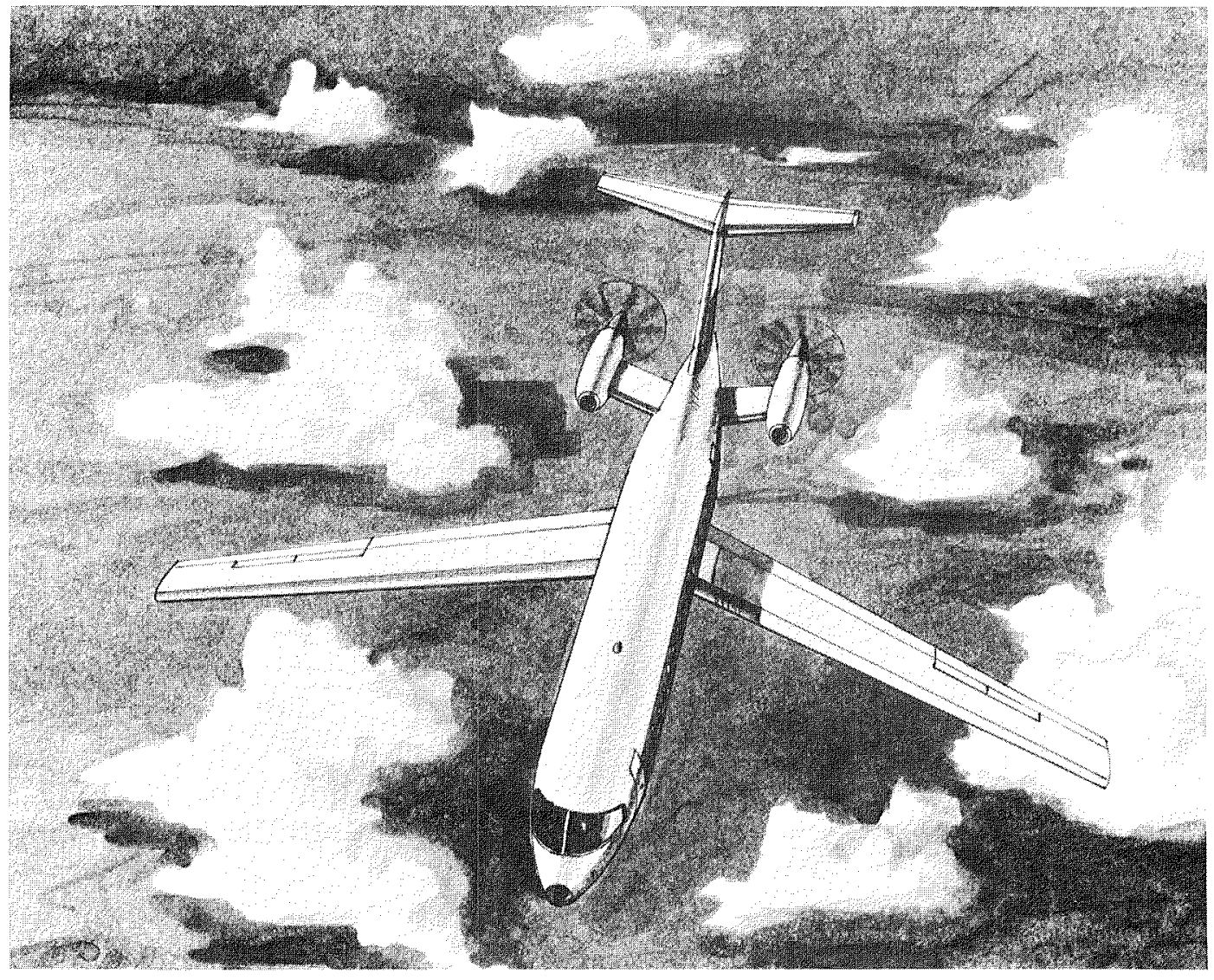

FIGURE 10 Commuter Aircraft. 


\section{Supersonic Transport}

The Supersonic Transport (SST) has a current equivalent in the Concorde, a four-engine afterburning turbojet. The Concorde has a gross weight of about 400,000 pounds and cruises across the Atlantic at about twice the speed of sound (approximately $1,500 \mathrm{mph}$ ) with 100 passengers.

With the application of possible technologies, an advanced SST could achieve up to three times the productivity of a similarly sized subsonic airplane while burning slightly less than twice as much fuel. It is estimated that the next generation of SSTs could cruise at speeds up to Mach 2.5, over ranges approaching 5,500 nautical miles. A Tokyo-San Francisco flight would require only four hours. An artist's rendering of advanced Supersonic Transports is shown in Figure 11. A twin fuselage configuration is illustrated as a possible concept, in addition to a single fuselage design.

The technologies identified as essential for a future SST include: lightweight, temperature-resistant airframe materials (new aluminum alloys, thermoplastic composites, and metal matrix titanium sandwiches); hot-section cooling and improved efficiency for engine components; and variable-cycle engines (such as the turbine-bypass cycle) with efficient airflow management. Another technology that becomes important for SSTs as the Mach number is increased above 2.5 is the need for fuel tank sealants capable of withstanding sustained high temperatures.

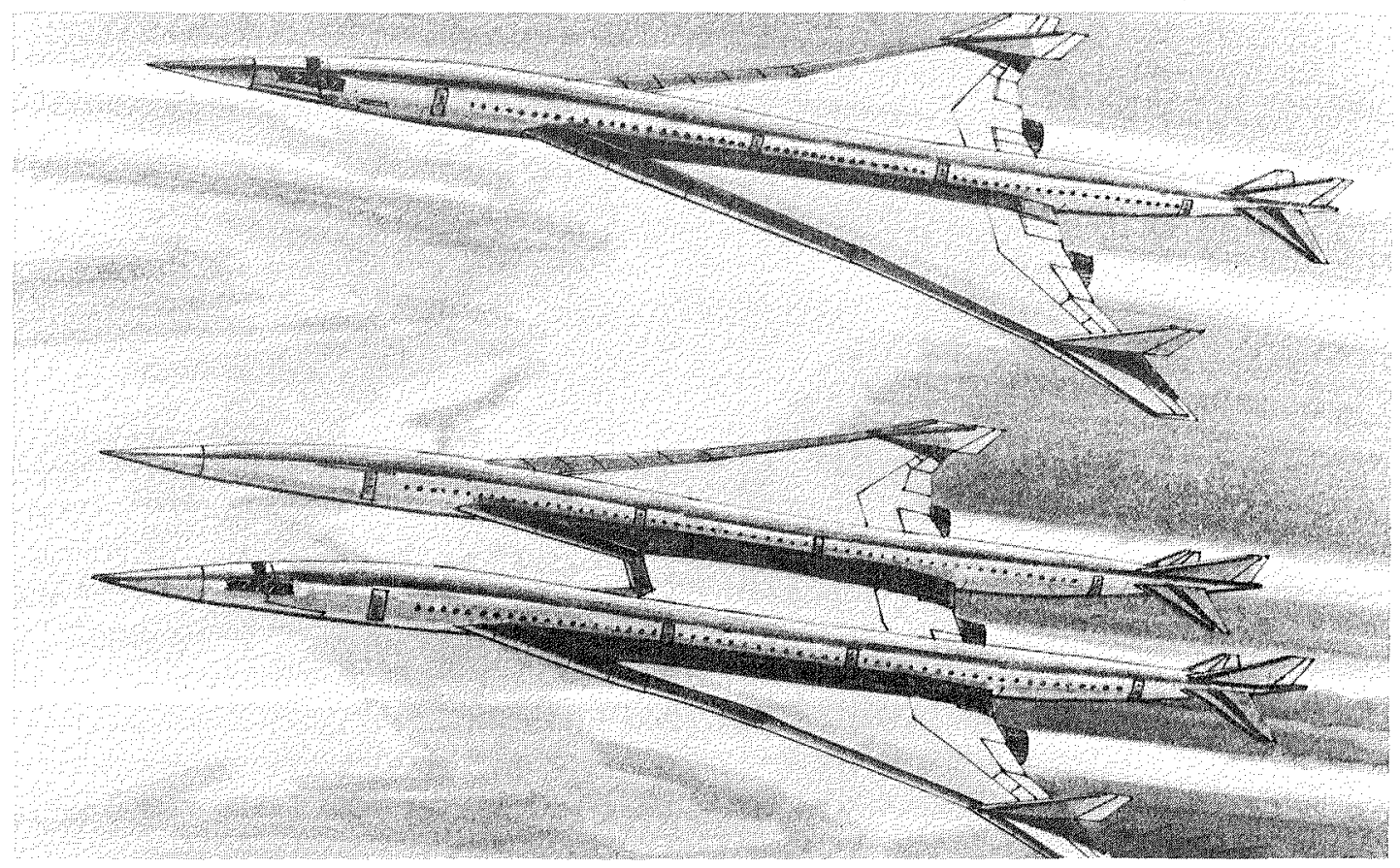

FIGURE 11 Supersonic Transports . 
The full realization of this level of performance for a future SST depends, to a degree, on technologies that have been classified as enhancing and supporting. Some of these technologies relate to design for laminar flow control, efficient structural design utilizing new materials, advanced flight path management systems, and automated control for high efficiency through the SST's operating envelope. Also important are conformance to airport and community noise restrictions and sonic boom minimization.

As has been noted, propulsion is a pacing technology for future advanced vehicle concepts. For the SST, the key is provision of fuel efficient operation at both supersonic and subsonic cruise while meeting low noise requirements. This will require a variable cycle engine such as the variable stream-control engine, double-bypass engine, or the turbine-bypass engine, all of which were examined in a NASA-sponsored Supersonic Cruise Research Program, terminated in 1981. Other more advanced propulsion concepts include the supersonic through-flow fan engine which eliminates the need for a large heavy inlet to reduce inlet air to subsonic speed at the fan face.

\section{Rotorcraft}

Rotorcraft cover a broad range of vertical lift aircraft, as illustrated in Figure 12, Next Generation Helicopters--year 2000, and Figure 13, Advanced High-Speed Rotorcraft. Such aircraft are of interest to both civil and military users. In general, higher performance and reductions in noise and vibration are key future design features. For the next generation of rotorcraft, new technology will provide vehicles with high productivity, larger payload-to-weight ratios, better ride, and lower noise than current rotorcraft. The new rotorcraft will have all-weather flight and precision hover capability with low pilot workload.

Rotorcraft of the future will have speed, range, payload, and endurance beyond those of conventional rotorcraft. As illustrated in Figure 13, the unique features of advanced high-speed rotorcraft (i.e., tilt, stopped, folding, and stowed rotors) will enable these vehicles to operate in forward flight similar to conventional subsonic cruise aircraft and still retain the ability to hover and vertically takeoff and 1 and.

Future engines for rotorcraft are essentially the same as for commuter aircraft. Thus, turbine and intermittent combustion engines need to be considered. Because high speed is one of the most desirable characteristics of the advanced rotorcraft, all concepts involve the use of propulsion systems thrusting horizontally rather than pitching the rotorcraft to achieve forward thrust. In some concepts, this is". accomplished by decoupling the rotor drive during cruise, using a convertible engine. 


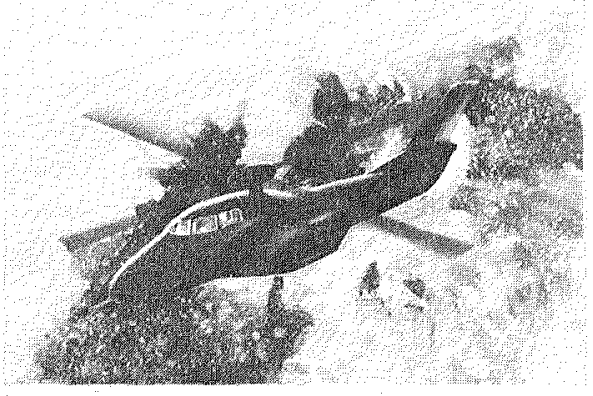

SWELE HOTOM MELICOPTEA

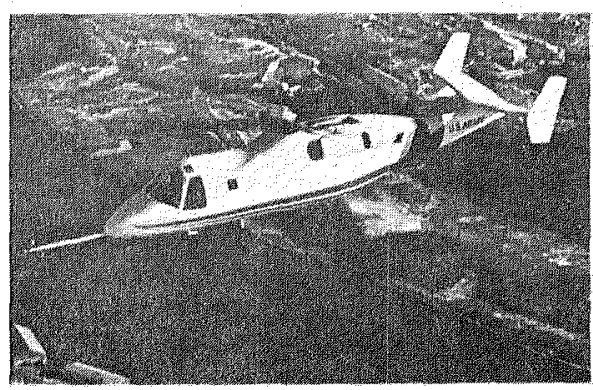

ABC IADUANCWE-BLAOE COHCEPT)

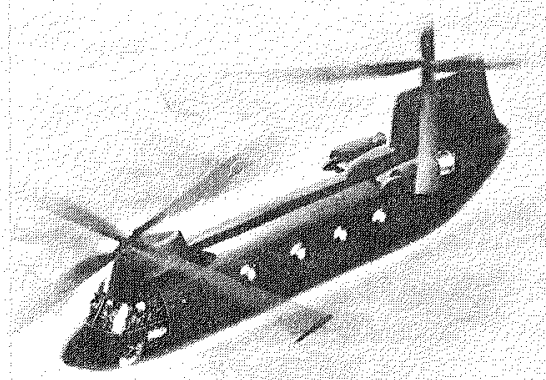

TANDEM-ROTOR HELCOPTER

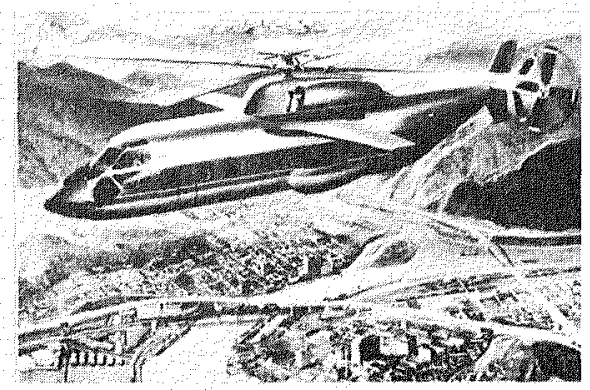

CONVENTIONAL COMPOUND

FIGURE 12 Next-Generation Helicopters, year 2000 .

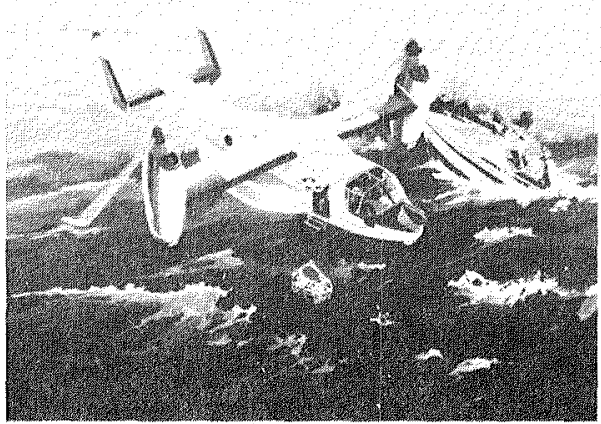

TILTROTOR

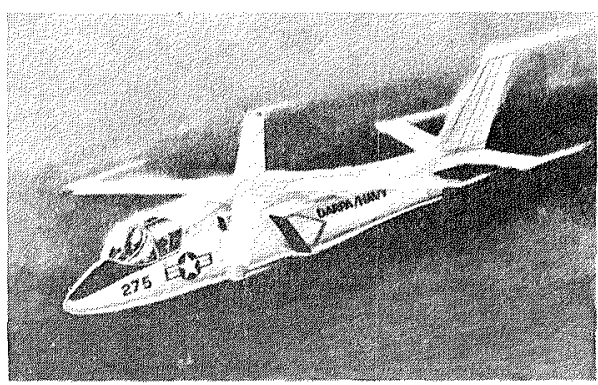

x. WInt

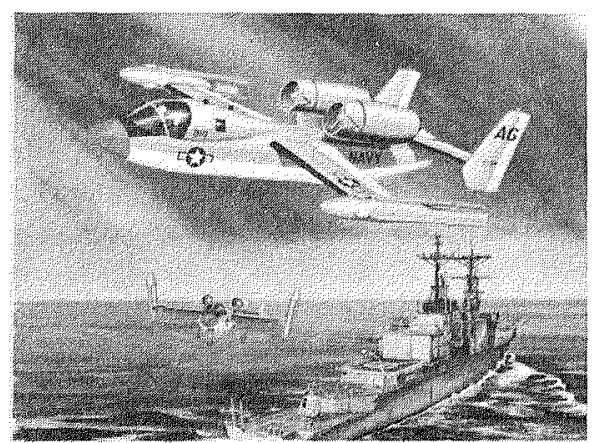

FOLDING TILTROTOR

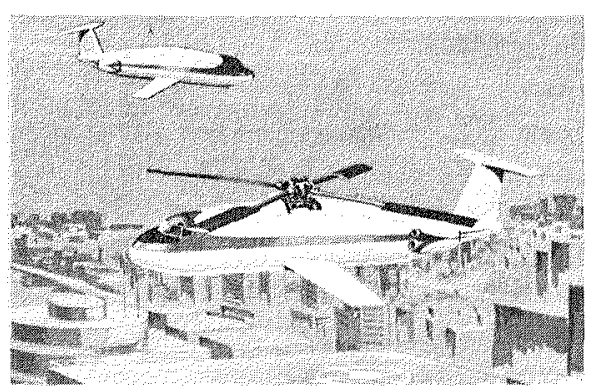

SIUGLE STOWED ROTOH

FIGURE 13 Advanced High-Speed Rotorcraft. 
Extremely High Altitude Aircraft

Unmanned aircraft (Figure 14, Extremely High Altitude Aircraft-Solar Powered, and Figure 15, Extremely High Altitude Aicraft-Microwave Powered) that can fly at very high altitudes for long durations (one week or more) will be possible with projected aeronautical technology advances. This will provide a new, unique aircraft capability for military and civil use. Development of such aircraft will depend in large measure on development of revolutionary propulsion concepts, such as solar and microwave power and ultralight structures. Although the concepts shown are heavier-than-air aircraft, lighterthan-air concepts are also possible. These aircraft could provide reconnaissance and intelligence data, collect atmospheric samples, support search and rescue activities, and function in some cases as alternatives to satellites.

\section{Transatmospheric Aircraft}

Figure 16, Transatmospheric Aircraft, and Figure 17, Next Generation Shuttle, depict representative Transatmospheric Aircraft. These vehicles could build on the Hypersonic Aircraft technology described earlier aided by rocket propulsion to achieve orbital speeds. Possible characteristics include on-demand launch, high cross-range, flexible earth return, good cruise and maneuverability during the atmospheric phase of operation, and airplane-like operational turnaround for launch after a landing. These capabilities will be realized through the application of advanced technology in the areas of aerodynamics, propulsion, materials and structures, flight control, and integrated avionics that had been demonstrated on Hypersonic Aircraft. Propulsion again is a key. At speeds in excess of the Hypersonic Aircraft (Mach 12), combustor air temperature could exceed oxygen/hydrogen combustion temperatures. Aircraft heat loads will be less than that of a Mach 12 aircraft during a one-hour cruise.

\section{RELATED ACTIVITIES--PROGRAM DEVELOPMENT}

Subsequent to the Vehicle Application Panel's study but prior to the publication of this report, the President's Office of Science and Technology Policy (OSTP) published the results of a special study entitled National Aeronautical R\&D Goals. The OSTP study took into consideration ASEB's Aerotech 2000 study and preliminary findings from this vehicle applications study. The vehicle classes and related technology developments that OSTP recommended be pursued as a matter of national policy are:

- Subsonics Goal: Build Trans-Century Renewal

-- Envisions technology for an entirely new generation of fuel-efficient, affordable U.S. aircraft operating in a modernized National Airspace System.

-- Captures immense civil aircraft market opportunities by technologically superseding foreign competitive challenges. 


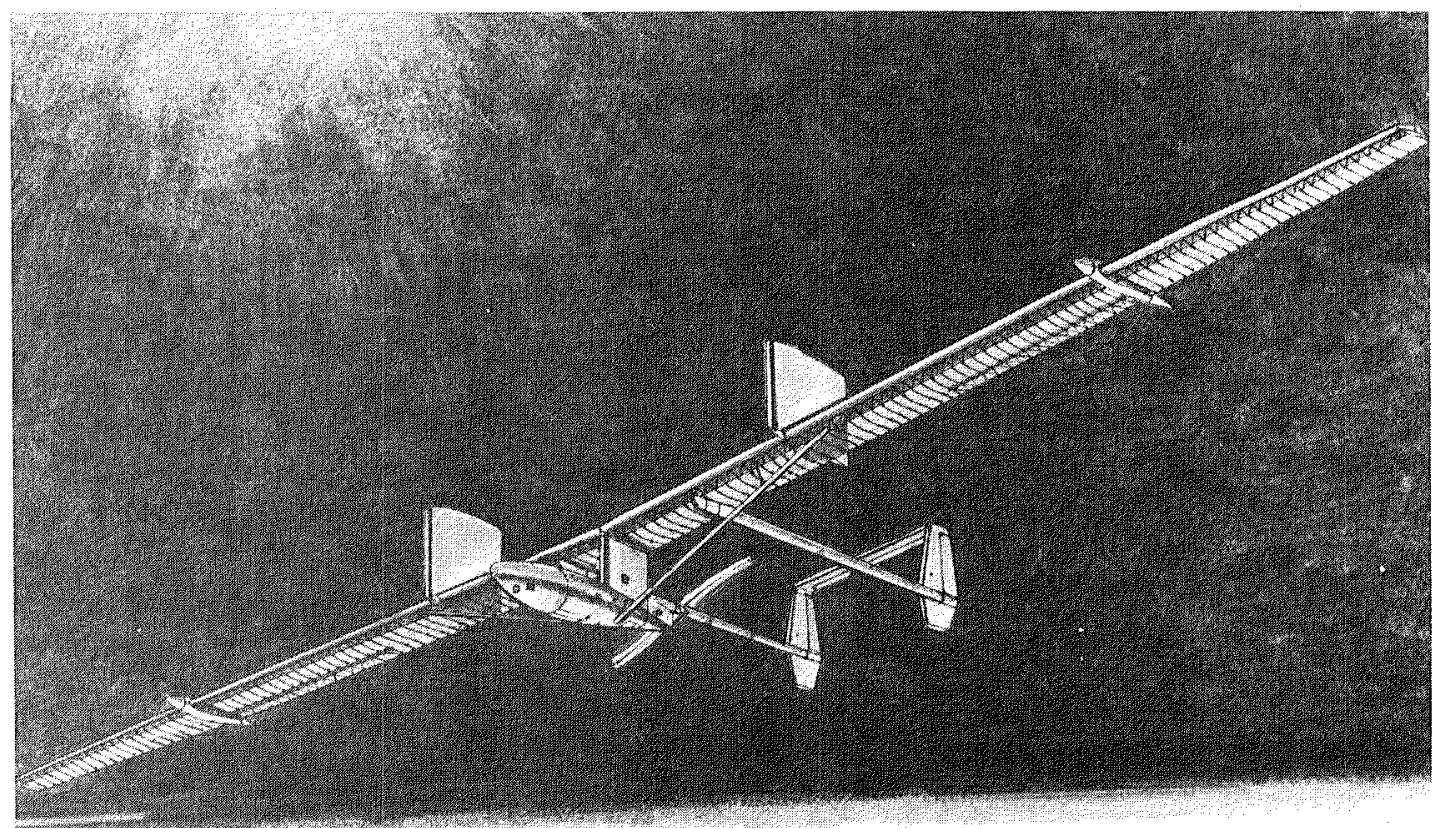

FIGURE 14 Extremely High Altitude Aircraft, Solar Powered.

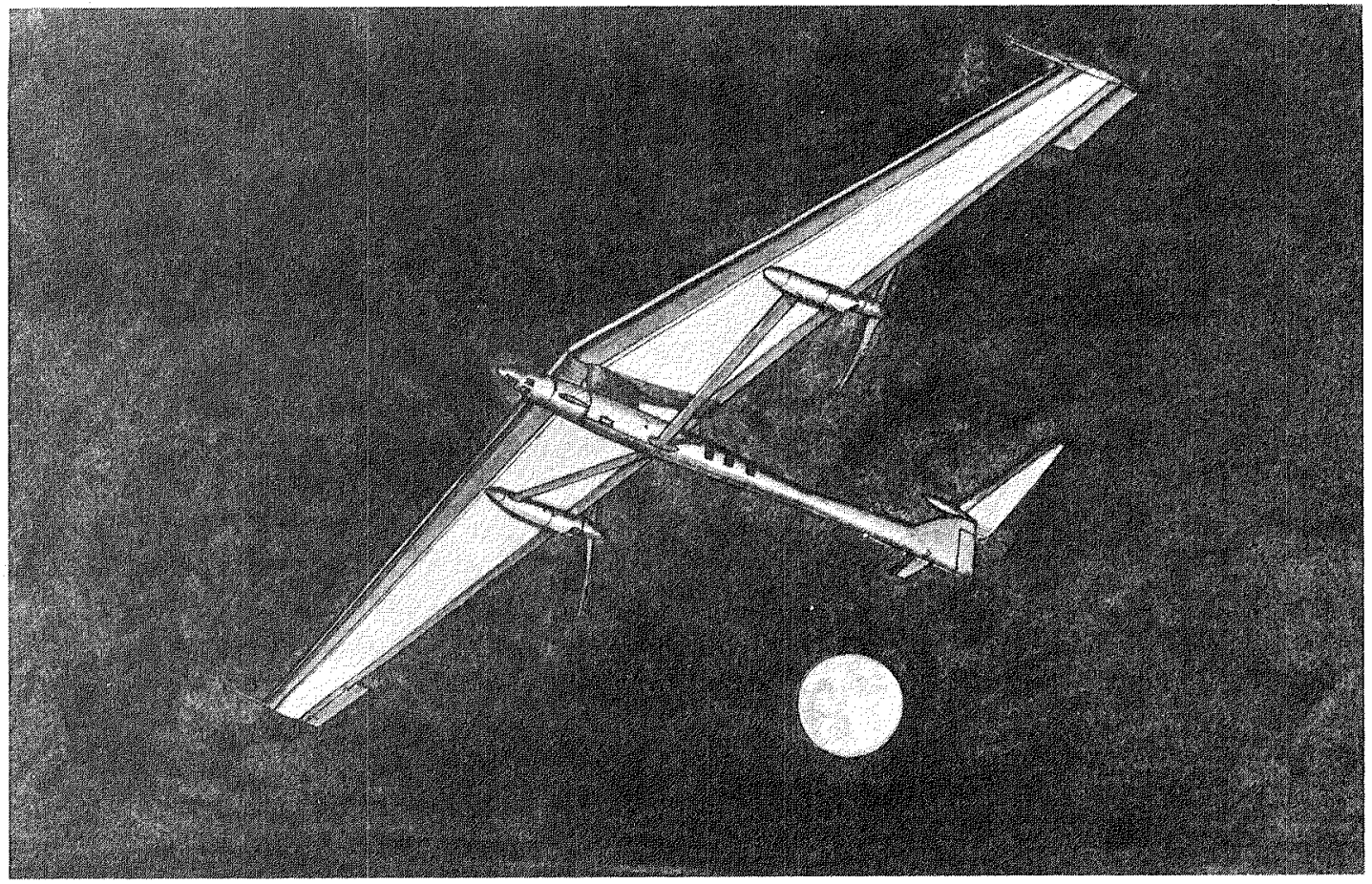

FIGURE 15 Extremely High Altitude Aixcraft, Microwave Powered. 


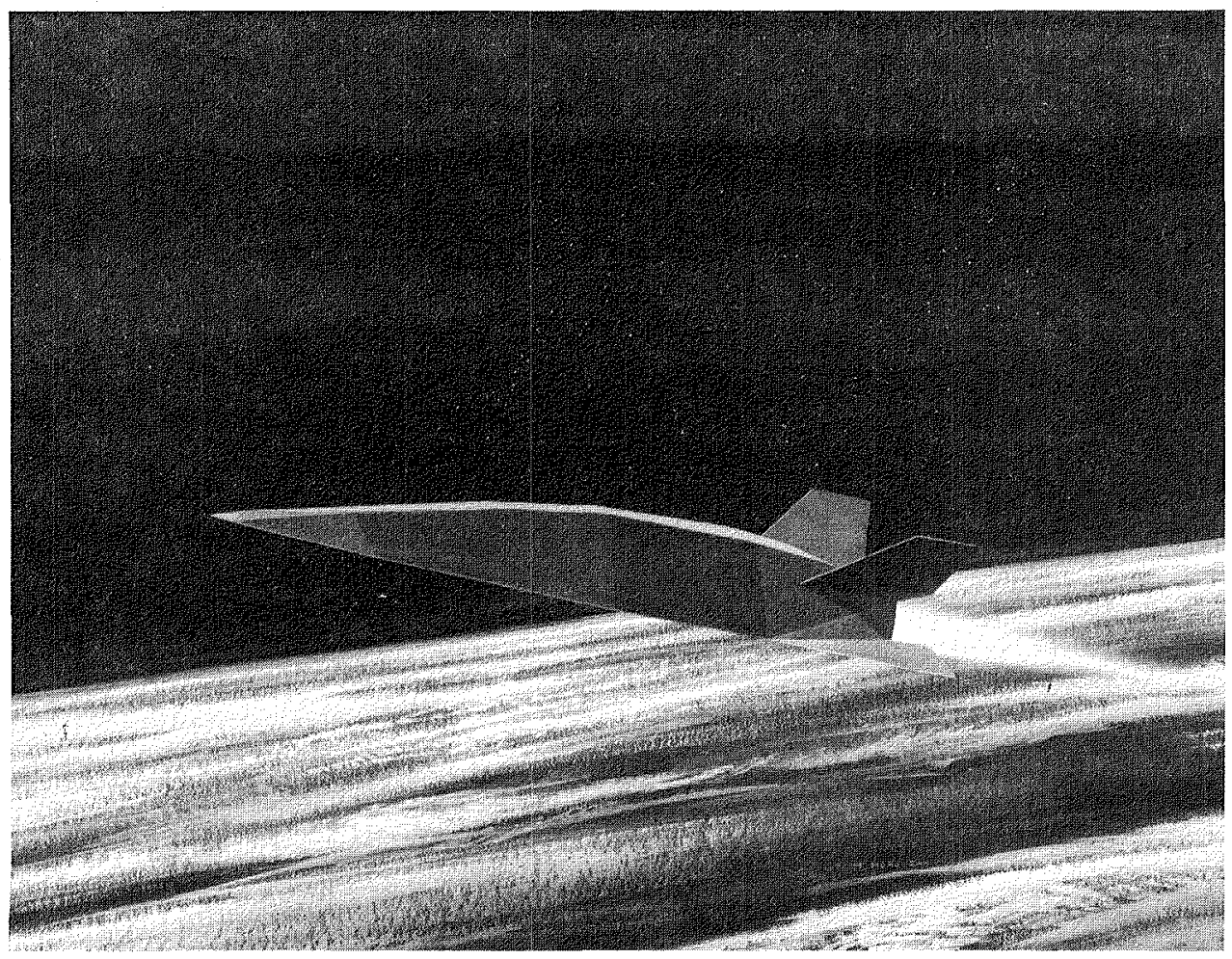

\section{FIGURE 16 Transatmospheric Aircraft.}

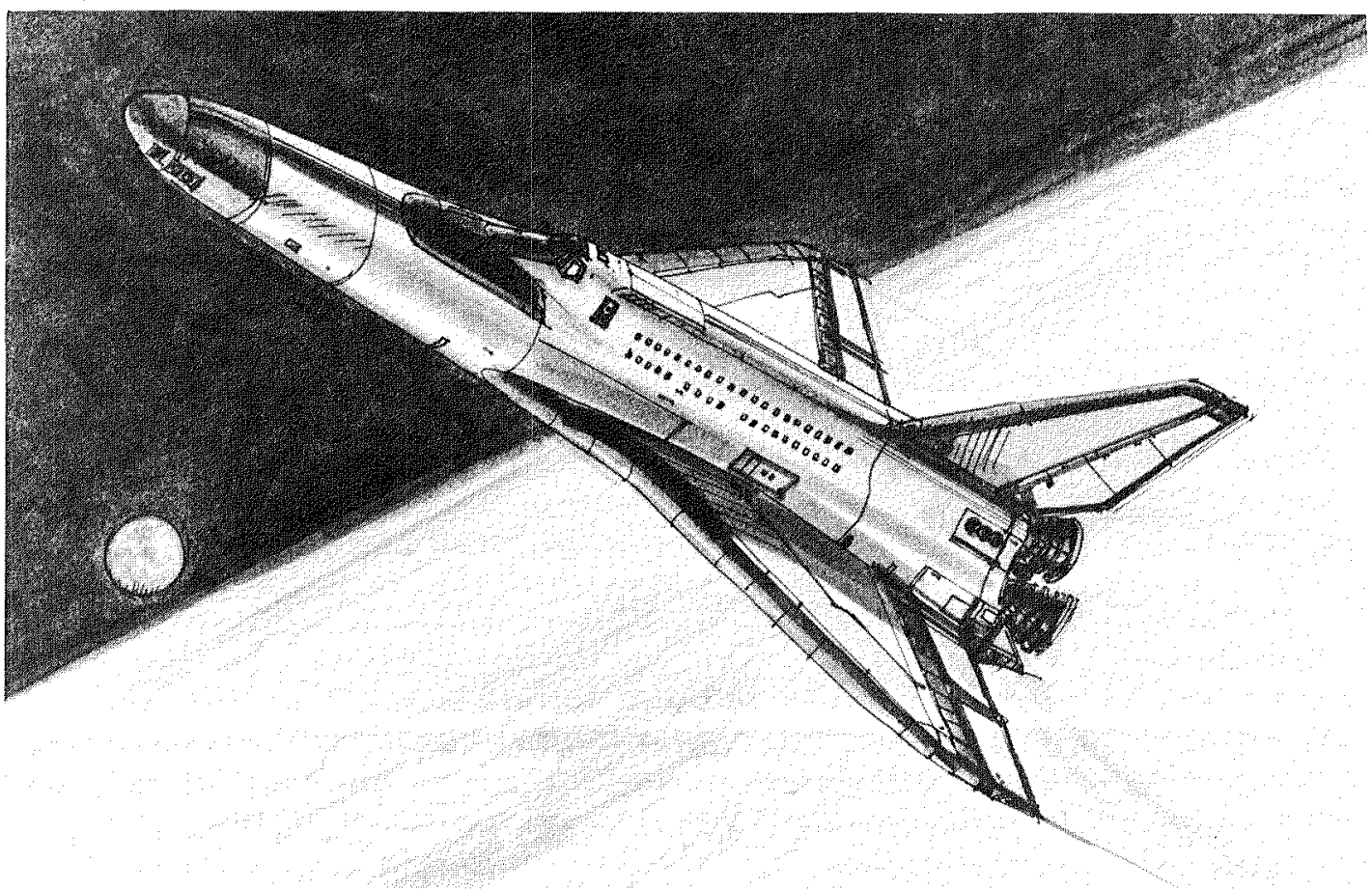

FIGURE 17 Next Generation Shuttle. 
-- Supports development of advanced military aircraft capabilities.

-- Requires acceleration of key technology advances for a 1995 readiness target.

-- Applications well into the next century.

- Supersonics Goal: Attain Long-Distance Efficiency

-- Develops pacing technologies for sustained supersonıc cruise capability.

-- Enables linking of farthest reaches of Pacific Rim in four to five hours. Recognizes growing U.S. strategic and economic interests with partnership potential.

-- Provides military with enhancements in basing flexibility, long-distance responsiveness, and survivability.

-- Applications through much of the next century.

- Transatmospheric Goal: Secure Future Options

-- Pursues research toward capability to cruise routinely and maneuver into and out of the atmosphere with takeoff and landing from conventional runways.

-- Builds on progressive subsonic, supersonic, and hypersonic advancements in aeronautics technology as well as Space Shuttle experience.

-- Influences long-range options for both aeronautics and space.

-- Significant to military and civil twenty-first century leadership.

This report of the ASEB Vehicle Applications Panel provides a preliminary identification of the technology developments deemed worthy of consideration for the selected aircraft classes. However, further effort is needed to identify realistic objectives and plans, including costs and schedules for specific technology development programs .

It is recognized that the maturation of the relevant technologies will be a function of civil and military needs and economics and that the development of specific plans will account for these factors as well as the actual state of technology development.

Before such plans can be developed, it is necessary for civil and military users to identify and assess reasonable future requirements and for the aviation industry to conduct assessments of design feasibility, risks, costs, and markets. It is recognized, as we11, that a sound technology data base is required before such analyses can be carried out with a reasonable degree of confidence.

Through an iterative process, work needs to be undertaken to identify and ensure reasonable progress in developing a technology data base, and a nearly concurrent effort needs to be planned and implemented to define the more extensive and costly technology development effort required to enable firm commitments to be made to proceed with aircraft specification, design, and development. 
This section of the report contains descriptive information for each of the aircraft classes examined by the Vehicle Applications Panel. The descriptions represent the views of the panel members on the selected aircraft types and include comments on desirable and possible characteristics, technology needs (both essential as well as enhancing and supporting), and technology development program implications. For each class of vehicle, desirable and possible characteristics are presented to illustrate the new or advanced capabilities that could be realized if the projected aeronautical technology developments believed to be possible are realized.

\section{MILITARY AIRCRAFT}

\section{Subsonic Strike Aircraft}

\section{Desirable and Possible Characteristics}

Contemporary strike aircraft such as the F-15, F-16, F/A-18, A-6, and A-7 employ countermeasures and combat agility to improve combat survivability. The A-10 relies primarily on hardness and passive protection. None of these aircraft, however, are designed to avoid detection as a primary means of helping to assure combat survivability.

Vehicle survivability in combat can be examined through a hierarchy of design factors that can be characterized as follows:

- Detection avoidance--if the vehicle cannot be detected, survivability is virtually assured.

- Nontargetability--given detection, the next objective is to apply countermeasures denying the threat the ability to target weapons, thus helping survivability through integrated applications of low observables and countermeasures.

- Hit avoidance--if threat weapons are targeted, the vehicle should possess means of avoiding the weapon through threat warning in combination with in-flight agility and weapon-defeating countermeasures. 
- Survival of a hit--passive hardening of the vehicle (expensive in terms of weight and performance penalties) provides 1 imited protection and is the least effective means of survivability enhancement.

New combat vehicle designs should be tested by this hierarchy and attempts made to achieve the highest practical survivability level. In strategic systems, survivability is heavily weighted toward emphasis on detection avoidance through reduced observability, flight profile selection, and other appropriate means. However, as the mission scenario shifts to the tactical arena, detection avoidance can no longer be relied on as the exclusive survivability enhancement tool.

Projections of technology developments indicate that by the year 2000 it would be possible to achieve high tactical strike survivability by reducing an enemy's ability to target lethal weapons on the aircraft. The desirable and possible characteristics of such an aircraft are:

- An ability to cruise and operate efficiently at high subsonic speeds (Mach $0.9+$ ) at high or low altitude.

- An ability to rapidly make short duration flight path changes of sufficient magnitude to avoid ground-to-air or air-to-air defense systems.

- Sustained maneuver capability consistent with maneuvers for target approach, weapon delivery, and egress from the target area.

- Short takeoff and landing to permit operation from damaged runways and/or carrier ships.

- Range on internal fuel significantly better than today's strike aircraft, i.e., an unrefueled range sufficient to support deployment worldwide without refueling or to perform deep strike missions.

Technology Needs

Essential Technology

Low Observability Configuration shaping and component integration to achieve signature reductions of several orders of magnitude over today's operational tactical aircraft will be required and achievable.

Materials and Structures Metal matrix or advanced organic composite materials can be developed for the airframe in which structural elements will be configured to take advantage of their characteristics as radar absorbers and diffusers and to achieve the smooth surface contours needed for reduced observability and improved performance efficiency.

Controls Controls can be developed that will lead to the elimination of surface areas and discontinuities associated with classical aero- 
dynamic control surfaces. The propulsion system is envisioned as the primary control effector to achieve this capability.

Two principal issues must be addressed in using the propulsion system for primary flight stabilization and control. First, control system gains and authorities must be programmed as a function of position of the aircraft in its flight envelope to achieve desired maneuverability and flying qualities. Second, propulsion system reliability must be improved to provide control system catastrophic failure rates approaching 1 in 1 billion flight hours. These levels of performance probably dictate both redundancy (multiple engines) and major advances in engine component and control system reliability associated with digital fly-by-wire (DFWB) systems.

Propulsion The propulsion system can be a principal contributor to radar, infrared, and visual signatures. Integration of the propulsion system is critical for a Subsonic Strike Aircraft. The following areas require special attention: inlet configurations to minimize nose-on radar signatures; propulsion system nozzle development to provide needed propulsion functions consistent with minimization of radar and infrared signatures; efficient engine operation for extended periods of cruise and loiter flight as well as accommodation of high-speed terrain-following flight profiles and terrain avoidance at low altitude; and minimization of thrust augmentation through conventional afterburning because of the adverse effect of afterburning on both observability and combat radius of action. The technology advanced are possible.

Enhancing/Supporting Technology

Aerodynamics Aerodynamic and structural efficiency will be improved by use of advanced supercritical airfoils that delay drag divergence and achieve extensive passive laminar flow for drag reduction. Payload and/or fuel will be carried either externally or in conformal appendages that reduce detection signature and/or improve aerodynamic performance.

Human Factors In spite of current and projected progress in the area of man-machine integration, it is expected that mission demands for the Subsonic Strike Aircraft will dictate a two-person crew with duties divided between piloting and systems management functions. However, to ensure efficiency of this arrangement, a great deal of attention will be given to improving the communications and operating interfaces between the two crew members, onboard equipments, and the aircraft.

Program Implications

A well-conceived technology development program plan will have to be developed that recognizes the need for focused effort in the essential technology areas and maintains progress in the enhancing/supporting 
technology areas. The initial step in developing this integrated plan or road map appears to be an analytical assessment of improvements required in the various technology areas to achieve operational objectives. This would provide insight into how to structure and sequence the technology development effort.

The technology efforts must, of course, be complemented by threat and scenario studies that provide periodic updates and reassessments of program objectives.

$\underline{\text { Summary }}$

A major design feature of this class of aircraft will be reduced observability from radar and other detection techniques to improve combat survivability. If detected, high maneuverability will be important. These characteristics will be realized through technology developments in materials, configuration shaping (including integration of the airframe and propulsion system), and engine cycle design.

Advanced technology that could be available in the year 2000 could provide an aircraft with a combat radius exceeding 1,000 nautical miles and a capability for long-range deployment without in-flight refueling. Advanced controls, integrating both aerodynamic and propulsion system control effectors, could contribute to vehicle signature reduction and associated survivability by providing increased flexibility to tailor and shape the external configuration. A summary assessment of the technologies that are essential and enhancing/supporting to the design and development of advanced Subsonic Strike Aircraft is shown in Figure 18 .

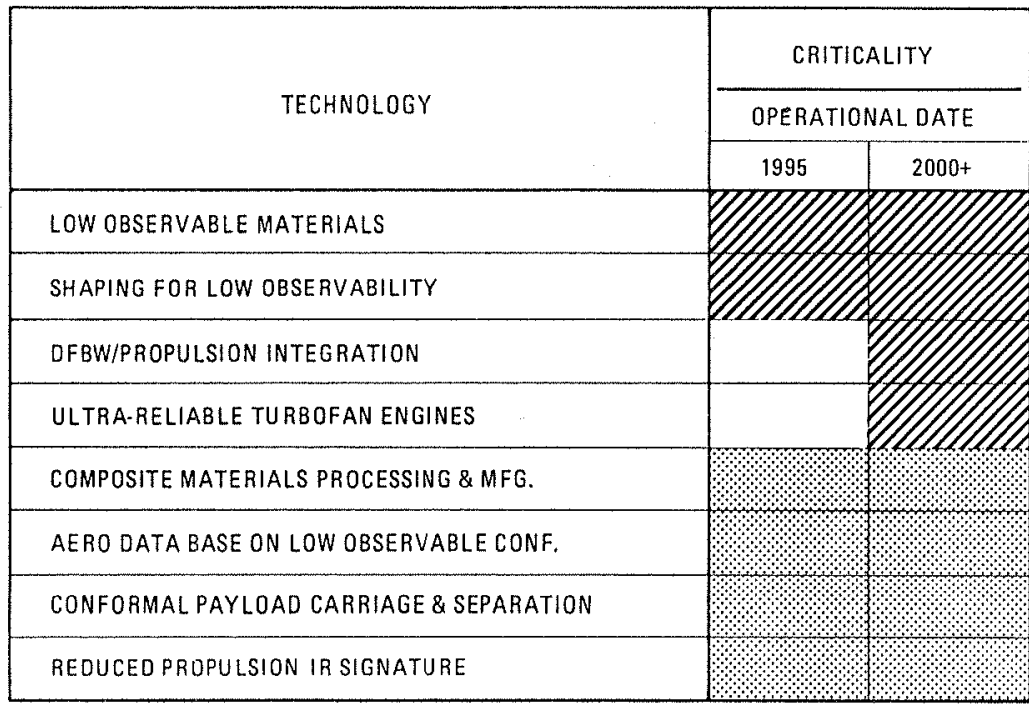

ESSENTIAL

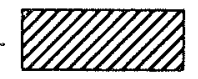

ENHANCING/SUPPORTING

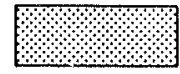

FIGURE 18 Technology matrix, Subsonic Strike Aircraft. 
The engine for this vehicle will stress low exhaust temperature (nonaugmented), minimum smoke, a conformal inlet, and a vectorable nozzle. For the nonaugmented engine, the main combustor outlet temperature will need to approach stoichiometric values. Also, very high reliability is essential if the propulsion system is used as a primary control device.

The propulsion system for the advanced Subsonic Strike Aircraft could be a variable-cycle engine incorporating features essential for other military vehicles. The technology matrix displayed in Figure 19 covers related critical and enhancing/supporting technology work associated with this and other pertinent propulsion systems for the Subsonic Strike Aircraft. Ohter enhancing/supporting technologies for the propulsion system are summarized in Table 4. The basic characteristics of the projected advanced Subsonic Strike Aircraft are presented in Table 5 .

\section{Supersonic Short Takeoff-Vertical Landing Aircraft}

Desirable and Possible Characteristics

A tactical aircraft with the capability to operate from short or damaged runways and from small aircraft carriers or other ships will provide great military operational flexibility. Threat projections suggest a need for supersonic performance for fighter-interceptor operations and improved combat maneuverability for survival in strike missions. Supersonic flight performance, in fact, will result in thrust levels compatible with Short Takeoff-Vertical Landing (STOVL) capability. This suggests the possibility of minimal weight penalty to add STOVL capability. Technology advances required would include thrust management and aerodynamic and propulsion system control integration that would have little weight and cost impact.

By the year 2000, the technology could be in hand to design STOVL aircraft with speeds in the range of Mach 2.0 to 2.5 that would have combat maneuver capability at low supersonic speeds and the ability to use thrust vectoring for maneuver enhancement throughout the flight envelope. This aircraft could be envisioned to be a marriage of the sustained in-flight supersonic performance of today's F-16 and F/A-18 aircraft with the basing capability, maneuverability, and operational flexibility of the AV-8B Vertical Takeoff and Landing (VTOL) aircraft.

The design range and mission of a supersonic STOVL design obviously depends on deployment, utilization, and operational considerations. If missions are Navy-oriented with emphasis on quick reaction from a dispersed air-capable ship, range needs to be compatible with interception of anticipated inbound threats. However, aircraft-weapon system design is also a function of the weapon's capability. It is possible in the case of a system incorporating a long-range highperformance missile that the supersonic STOVL fighter would be the "first stage" of the missile. 


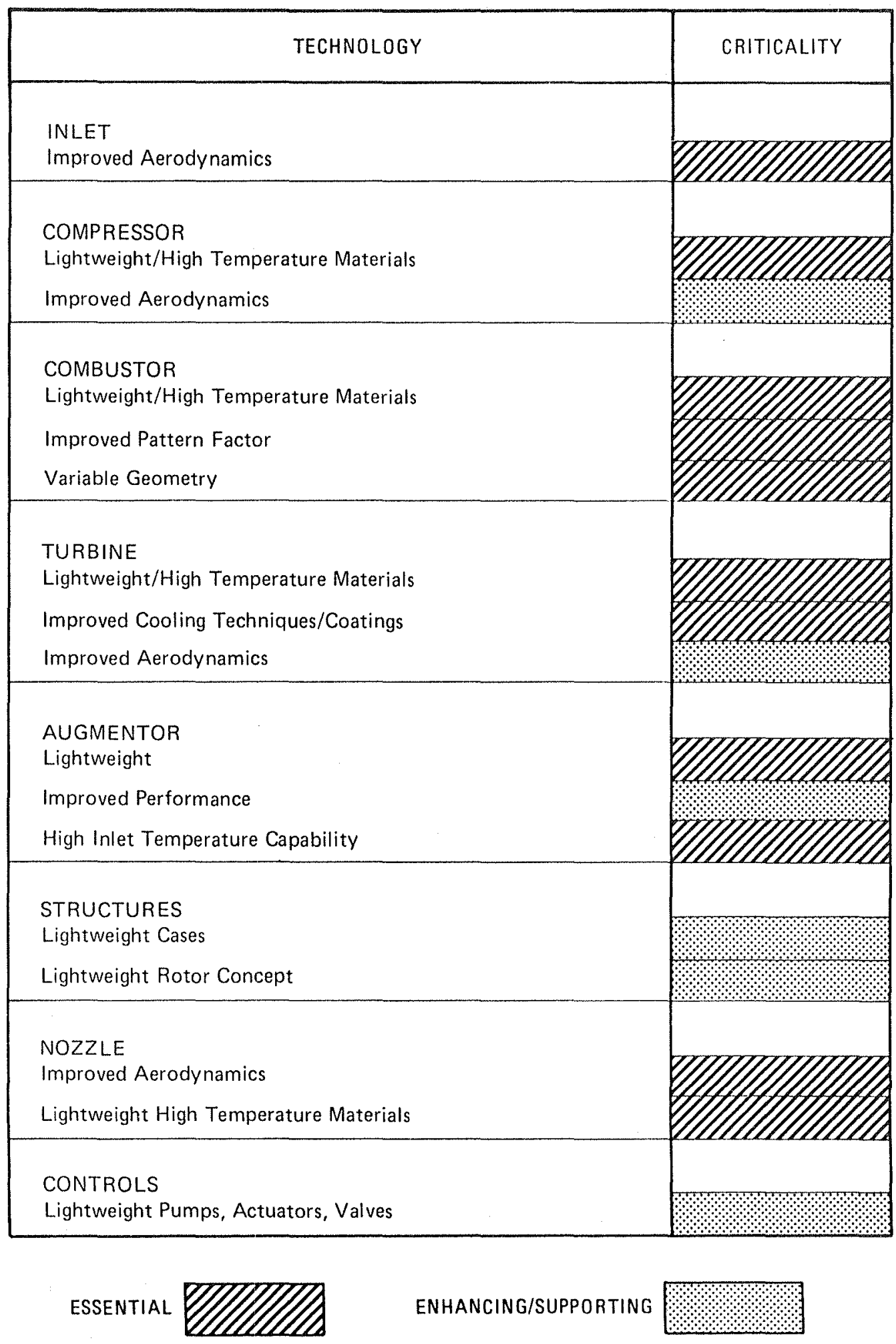

FIGURE 19 Technology matrix, Advanced Fighter propulsion systems. 
TABLE 4 Enhancing/Supporting Propulsion

Technology Needs for Subsonic Strike Aircraft

- High turbine inlet temperature

- Regenerator

- Clean combustor

- Vectorable nozzle

- Variable geometry

- Advanced materials

TABLE 5 Basic Characteristics of the Subsonic Strike Aircraft

Factor

Mid 1990s

$2000+$

Weight empty (1bs)

Zero fuel weight (lbs)

Internal fuel weight (lbs)

Mission gross weights (1bs)

4,000 lbs payload

12,000 lbs payload

Engine

Controls

High lift device

Wing loading at takeoff (psf)

Wing area/wetted area

Overall length ( $f t$ )

Span ( $f t$ )

Height ( $f t$ )

Projected wing area (sq $f t$ )

Wing/airfoil technology
20,000

21,500

15,500

41,000

50,000

F404 derivative

DFBW aerodynamic

"effectors"

Conventional

mechanical

90-110

0.22

56

43

13

906

Supercritical
18,500

20,000

14,000

38,000

47,000

JFE variant

DFBW full authority

SAS and control

Propulsion "effectors"

Circulation/boundary

layer control

70-90

$0.3-0.35$

54

43

11

875

Supercritical natural laminar flow 
Technology Needs

Essential Technology

Aero-propulsion Integration The essential technologies include propulsion and its integration into the aircraft. Development of efficient thrust management and vectoring systems compatible with supersonic operations, short takeoff, and vertical landings will be required. Inlet and nozzle design will differ significantly for various flight regimes and will require integrated aerodynamic and propulsion system control harmony. The aerodynamic configuration in climb-out and cruise must be efficient. Both the engine itself and the control devices will require significant technology development.

Turbojet engines for supersonic fighters are projected to have thrust-to-weight ratios in excess of 15 by the year 2000 . With such engines, supersonic aircraft could have thrust-to-weight ratios of 1.4 or greater, thus, inherently providing sufficient thrust for STOVL capability. By thrust vectoring that results in thrust forces acting through the center-of-gravity, STOVL capability can be achieved with minimal performance penalties. Essential are integrated propulsion and controls, including both both longitudinal and lateral axes thrust vectoring; reaction controls; and efficient inlet-engine operation throughout flight envelopes extremes.

Advanced STOVL engines will use composite materials to reduce weight while minimizing manufacturing cost. Carbon-carbon composites will find application in high temperature regions like the nozzles. The turbine will likely use ceramics, single crystal metals, and advanced thermal barrier coatings.

Enhancing/Supporting Technology

Enhancing/supporting technologies include: advanced aerodynamics, airframe and engine control integration, and advanced airframe materials and structures. Propulsion-airframe integration would be used to generate beneficial induced lift for short takeoff. Supersonic flight performance would depend on a configuration that "cleans up" after takeoff to minimize wave and interference drag. These requirements will require careful innovative design. Another area where careful design is required is maintenance of acceptable ground footprint temperatures and exhaust velocities during takeoff and landing so that basing is not restricted.

Because light airframe weight is a paramount STOVL requirement, extensive use of graphite and epoxy composites is anticipated. Polyimide and bismaleimide composites for local hot spots will find application around engine exhaust nozzles and thrust deflectors. Metal matrix and/or laminated metallics may be employed in areas subject to severe, acoustically induced vibrations. Advanced 
processing and manufacturing techniques will be needed to produce these materials.

Digital fly-by-wire technology will be used to achieve control harmony, response, and acceptable flying qualities for STOVL aircraft throughout their flight regimes and will include maneuvering enhancement. Such integration is particularly critical in the transition and conversion phases of STOVL flight.

Combat survivability of the STOVL tactical aircraft will depend on performance, agility, and countermeasures. The ability to vector thrust will contribute to survivability in terms of hit avoidance. Other design factors that will contribute to survivability are integration of the missile/weapons and aircraft and reduced observability through treatment of the propulsion system, and reduced airplane profiles.

\section{STOVL Propulsion Systems}

Propulsion is of critical importance to STOVL aircraft. The technical disciplines associated with propulsion warrant special attention. A supersonic STOVL propulsion system needs to have the following:

- High thrust per unit of engine weight, low frontal area, low volume, and high airflow rate.

- Low specific fuel consumption for subsonic loiter and cruise and for supersonic cruise.

- Flight control at zero or low speeds, including control of the thrust vector, and a tolerance to large compressor bleed flow.

- Short duration high power capability for takeoff, landing, and maneuvering.

- Thrust augmentation--burning, ejectors, or fans.

- Cool footprints and low hot-gas reingestion requiring low jet velocities and temperatures in low speed operations near landing surfaces.

- Low observables--low jet temperatures and velocities.

Several propulsion concepts are candidates for supersonic STOVL aircraft. Each has advantages and drawbacks. Leading contenders are systems with remote augmented lift systems, vectored thrust, ejectors, and tandem fans.

Remote Augmented Lift Systems (RALS) These systems bleed and duct air from ahead of the fan and augment the fan thrust by additional burning. There are two principal types of RALS: the Fan-Air Burning System and the Compressor-Air Burning System, each with a number of variations. For the Fan-Air Burning System there can be:

- A single top inlet and two swiveling side fan-air nozzles.

- Twin side inlets and a single bottom vectoring fan-air nozzle. 
- Separate fan and core flows for vertical and cruise operation.

- Separate fan and core flows for vertical operation and confluent flows for cruise operation.

- Ventral or swiveling non-afterburning core flow nozzles for vertical operation.

- Ejector cooling of burned fan air.

For the Compressor-Air Burning System, there can be:

- Compressor bleed and burn at remote nozzles.

- Compressor bleed to power remote turbo-compressor units.

- Above with main compressor-air burning or with turbo compressor burning.

- Use of turbo compressor for both vertical and horizontal thrust.

The technology developments required for RALS need to address, ' among other matters, inlets, nozzles, burners, fans and compressors, turbines, ducts and valves, and materials.

Inlets The inlet must be (1) short to accommodate the forward location of the engine while maintaining good pilot visibility and must yield good pressure recovery with low drag throughout the aircraft's operational range, (2) have good high angle-of-attack tolerance, and (3) be located such that there is low reingestion.

Nozzles The nozzles need to provide $0^{\circ}$ to $110^{\circ}$ thrust deflection and accommodate the throat area changes associated with afterburning and the expansion area changes associated with low and supersonic speeds. The nozzle-airframe must be integrated and the system lightweight with a high-temperature tolerance.

Burners Compact, efficient, and controllable burners are required. The burner must be stable over a wide range of operating conditions.

Fans and Compressors These need to have high stage loading, high airflow per unit of frontal area, and high efficiency with good stall margins. These characteristics will reduce the number of stages and blades and improve distortion tolerance.

Turbines For efficient high thrust, the turbine must operate at high temperatures. This will be accomplished by improved materials, cooling, and better combustion patterns.

Ducts and Valves The ducting system for a RALS propulsion system may need to turn the flow up to $360^{\circ}$. The ducting must have low losses, frontal area and volume with low back pressure, and flow distortions. The ducting control valves must be coordinated with each other to maintain desired flow characteristics.

Materials Composite materials technology advances for light weight and high-temperature and pressure tolerance are a generic requirement for all classes of engines. 
In summary, for RALS, technology advances in materials, internal aerodynamics, and engine cycles will yield engine thrust-to-weight ratios of 12 to 15 by the year 2000. Variable cycle engines will provide lower specific fuel consumption at both subsonic and supersonic speeds. High stage loadings and more refined and efficient aerodynamic designs will yield a lower parts count. Also important will be advanced manufacturing techniques, including integrated blade and disk stage designs that will allow lower production costs.

Vectored Thrust Systems These systems have separate fan- and core-flow swiveling nozzles with the possibility of burning exhaust air in the fan for supersonic flight. The variations in this system are principally in the number of nozzles: two aft-swiveling, two forward-swiveling; one aft-vectoring, two forward-swiveling; or a single mixed-flow nozzle and collander or swirl type burner.

The technology advances identified for RALS apply to the Vectored Thrust System except that the burners, short and curved, may involve a rectangular-to-circular transition, and require ignition at high altitude and low flight speed.

Ejector Systems These systems augment the fan-air thrust with a downward-directed ejector at low speeds and by burning and aftdirecting of the jet at high speeds. The type of ejector, the engine cycles, and the airframe/ejector integration will vary from those of the RALS and vectored thrust engines as noted here:

- Ejector types

-- Modest primary-air pressure ratio (subsonic secondary flow), i.e., steady primary, rotating primary, and pulsed primary.

-- High primary pressure ratio, i.e., supersonic secondary and two-stage compression.

-- Blown or unblown diffusers.

-- Acoustically enhanced mixing.

- Cycle types

-- Ejector primary-air heating, i.e., burning, all core flow, and mixed fan and core flow.

-- Core jet cooling, i.e., mixed fan and core flow, all core flow to ejector, and core jet cooling ejector.

-- Turbine bypass engine with turbo compressor to provide ejector primary air.

- Airframe ejector integration

-- Longitudinal front ejector for pitching moment.

-- Varlable deflection angle, spanwise wing trailing edge ejector for augmented $1 \mathrm{ift}$.

-- Trailing edge ejector for boundary layer acceleration for the aircraft.

The propulsion system component characteristics and technology advances projected for the RALS also apply to the ejector system. Ejector augmentation ratios of about 1.6 are desirable and possible. 
To obtain the compactness required for supersonic flight, the ejectors must be foldable.

Tandem Fan Systems The tandem fan is characterized by axial spacing of fan stages on a common shaft. It has a variable-cycle engine with fan stages operating in a parallel-flow, high-bypass-ratio mode for zero and subsonic speeds and in a series-flow, moderate-bypass-ratio mode at supersonic speeds.

Tandem Fan Generally, the system has a top inlet for the aft fan and core, and a ventral nozzle for the front fan air. The parallel-toseries flow transfer valve is of the venetian blind type.

Hybrid Tandem Fan In this arrangement, the aft fan inlet is coannular with the front fan. The parallel-to-series transfer valve is of the annular inverter type. The front fan air is collected in an annular duct and ducted to swiveling nozzles. This system is adaptable for use at subsonic cruise and loiter conditions in the parallel mode.

Spaced Low Spool Fan In the limit for the above systems, the complete low spool fan may be placed forward of the core compressor. This increases design flexibility by permitting adjustment of the forward fan thrust vector.

Variable Core Supercharging One of the effects of parallel operation is to reduce the thrust of the engine core. This thrust loss could be made up in part by a variable-pressure-ratio core, supercharging stage.

The component characteristics and technology advances required for the RALS pertain also to the tandem fan system; however, the pressure recovery and distortion characteristics through the aft inlet and the parallel-to-series transfer valve are important tandem fan system considerations.

\section{Program Implications}

Several propulsion concepts are potential candidates for application to a supersonic STOVL aircraft. Each system has its own set of advantages and disadvantages. Flight demonstration of more than one system is probably not affordable and, hopefully, is unnecessary. A combination of ground-based propulsion system demonstrations at large scale, supported and augmented by appropriate propulsion rig tests, configuration tests, and flight simulation, should serve to resolve many technological uncertainties and build the technology base for the various candidates. However, flight tests would be desirable and may prove to be necessary to validate the ground-based work due to the inability to simulate adequately the operating environment of these complex systems and the cost of correcting design errors, if made. 
To keep costs acceptable, it may be necessary for the propulsion system used for STOVL to have many of its engine parts common with other advanced engine developments for future fighter aircraft. A three- to four-year technology program should be undertaken to help resolve the direction of such future engine technology developments. The program would continue studies and assessments of candidate systems; test critical components to establish performance parameters; undertake large-scale, ground-based propulsion system tests to validate model and rig tests including compatibility of components and control dynamics involving subscale research on engine components, engine control development, modeling of controls, and simulation; piloted simulation of the combined propulsion and aircraft system; and flight tests of a technology development and demonstrator aircraft to validate analytical work and ground-based tests.

Summary

An advanced STOVL, a fighter-interceptor airplane, will be able to operate from short or damaged runways or from appropriate Navy ships. Maximum speed in the range of Mach 2.0 to 2.5 will be possible. Enhanced maneuvering capability will be available through the use of thrust vectoring combined with aerodynamic controls. Thrust management and vectoring will be used for takeoff and landing, but the system must be efficient and compatible with supersonic operations. Advanced avionics will provide appropriate mixing of controls throughout the flight envelope of the aircraft. A lightweight airframe, a high thrust-to-weight propulsive system, and a fully integrated control system will be especially important.

The technology matrix for the Supersonic STOVL aircraft, Figure 20, presents the broad essential and the enhancing/supporting technology

\begin{tabular}{|c|c|}
\hline TECHNOLOGY & CRITICALITY \\
\hline THRUST MANAGEMENT \& VECTORING SYSTEMS & \\
\hline INTEGRATED CONCEPTS \& OPERATIONS & \\
\hline ENGINE MATERIALS & \\
\hline AIRFRAME-PROPULSION INTEGRATION & \\
\hline DIGITAL FLY-BY-WIRE CONTROLS & \\
\hline MISSILE AND WEAPONS INTEGRATION & \\
\hline MATERIALS PROCESSING AND MANUFACTURING & \\
\hline
\end{tabular}

ESSENTIAL

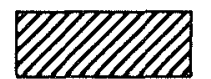

ENHANCING/SUPPORTING

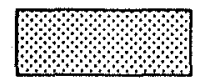

FIGURE 20 Technology matrix, Supersonic STOVL. 
areas. The propulsion system, its integration with the airframe, and the integration of the aircraft and engine controls is critical to the design and development of Supersonic STOVL aircraft.

Many fighters today have engine-thrust-to-aircraft-gross-weight ratios greater than 1.0 yet cannot achieve STOVL performance. It is not only a question of thrust loading, but also of having the thrust vectors at the right place(s) on the vehicle. Thus, thrust-directing devices are an essential feature of STOVL aircraft, and such things as vectorable nozzles, remote augmentation (i.e., burning, fans, and ejectors), and reaction control systems are necessary ingredients. Figure 21 summarizes propulsion-system-related technology needs. Projected improvements in major design parameters by the year 2000 , providing adequate application of resources (i.e., funding, manpower, and facilities), are noted in Table 6.

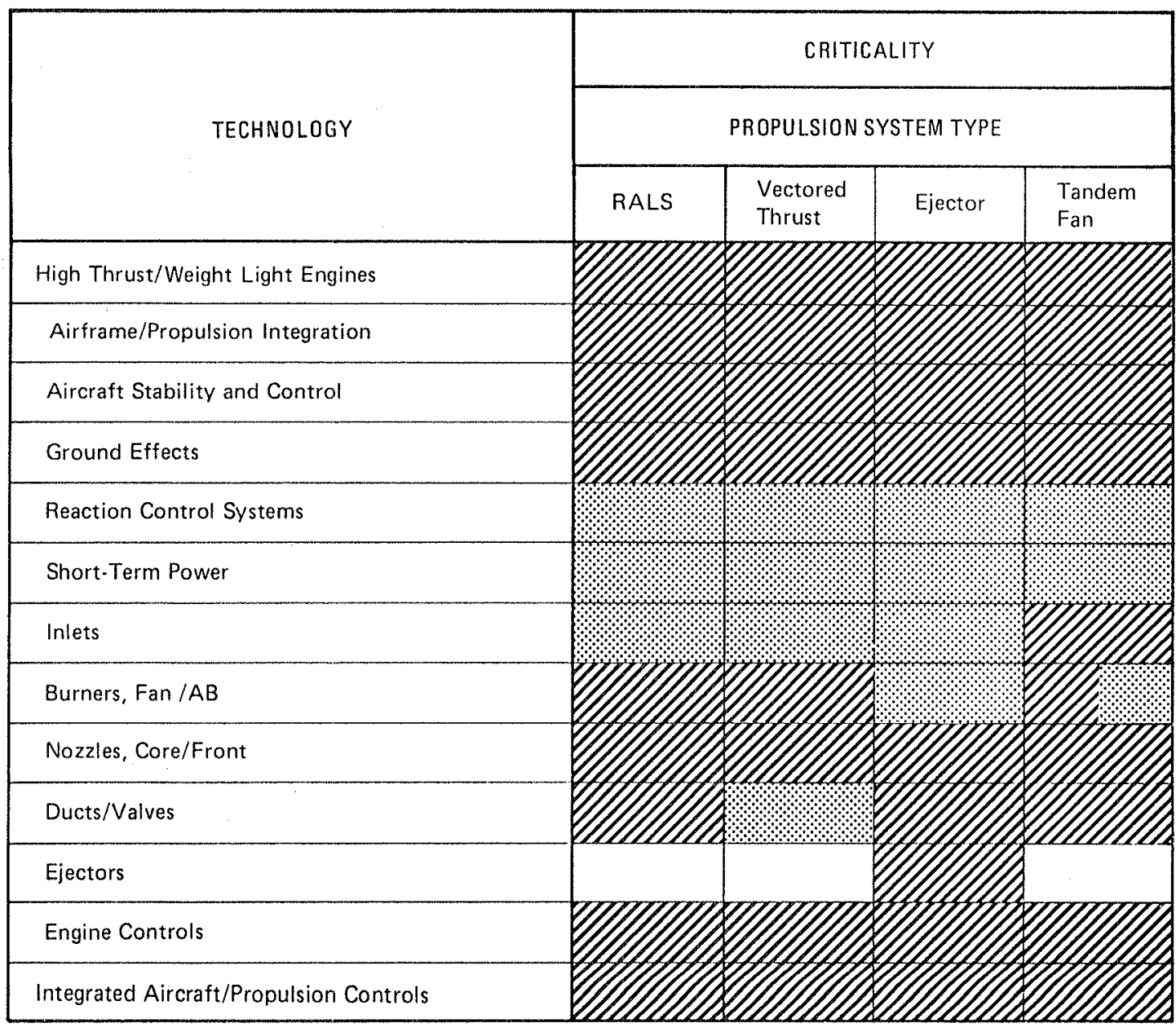

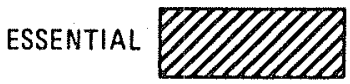

ENHANCING/SUPPORTING

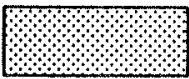

FIGURE 21 Technology matrix, Supersonic STOVL propulsion. 
TABLE 6 Performance Projections for STOVL

\begin{tabular}{|ll|}
\hline & $\begin{array}{l}\text { Projected } \\
\text { Improvement } \\
\text { (Year 2000) }\end{array}$ \\
\hline Aechnology Factor & $20 \%$ \\
Specific fuel consumption & $10 \%$ \\
Engine weight & $33 \%$ \\
Structural weight & $22 \%$ \\
\hline
\end{tabular}

Advanced Fighter

Desirable and Possible Characteristics

The next round of advanced U.S. tactical fighters will build on technologies available in the late 1980s. This 1980 s technology base will permit the design and development of tactical fighter aircraft with sustained supersonic cruise and maneuver capability at Mach 2 to 2.5 .

A projected advanced Mach 3.5 fighter, based on year 2000 technology, could have greatly enhanced performance capabilities. This class of vehicle will be possible through advances in propulsion, structures, aerodynamics, and integrated flight/propulsion control sys tems .

Operational altitudes could exceed 70,000 feet. At cruise speeds (Mach 3.5), it should be possible to exceed 2 gs in maneuvers. To avoid threats the aircraft could zoom climb to over 100,000 feet.

At lower speeds and altitudes (for example, Mach 2 and 40,000 feet), maneuvers of 4 to 5 gs should be possible. With the operating efficiencies expected, it should be feasible to fly three times farther on a given amount of fuel at Mach 3.5 than current fighters operating at Mach 2. It should be possible for an Advanced Fighter to have a radius of action of about 1,000 miles with payloads of about 2,000 pounds. The related takeoff weight might be on the order of 100,000 pounds.

Other desirable and possible characteristics include:

- Relatively long-duration subsonic flight.

- Subsonic loiter-dash capability.

- High maneuverability compared with today's fighters.

- Low detection signature. 
Technology Needs

Essential Technology

The technologies essential to the design and development of these Advanced Fighter aircraft relate to the areas of propulsion, materials, and aerodynamics. However, if these aircraft are to be effective, it will be necessary to develop compatible hypersonic air-to-air and air-to-surface weapons. These weapons will have extended range and maneuver capability over today's designs through the use of ramjet propulsion and efficient aerodynamics.

Propulsion The propulsion system--inlets, compressor, combustor, turbine, and exit nozzle--will be operated at high temperatures. The engine might use a compound turbine ramjet engine cycle. The combustor exit temperatures will be on the order of $3,600^{\circ} \mathrm{F}$. Turbine inlet temperatures would be in excess of $3,000^{\circ} \mathrm{F}$. Sea level engine pressure ratios would be 12 to 15 for Mach 3 designs, compared with 8 for current supersonic propulsion systems. Sea level, static, thrust-toweight ratios will be greater than 25 percent above current derivative engines for fighters. With unique design features, such as highthrottle ratio (greater than 1.15) or fuel-rich burning, improvements over current fighter engines could be expected, i.e., engine thrustto-weight at 6 to 1 for afterburner power and 2 to 1 at dry power at Mach 2. Specific fuel consumption could be less than 1.8 pounds per hour per pound of thrust in dry power.

High pressure recovery and mixed compression inlets will be employed. These inlets will have low drag and stable operation in high-Mach maneuvers through application of advanced technology for control of inlet shock and integration of the propulsion/airplane flight control system. High-area-ratio nozzles (with thrust-vector reverse) incorporating fully independent throat and exit area controls will be available. The combined control system will provide rapid response throughout the aircraft flight envelope.

An advanced afterburning turbojet with a high throttle ratio (combustor temperature at Mach 3.5 to combustor temperature at takeoff) and a high maximum cumbustor temperature will provide a 250 percent increase in dry power specific thrust at Mach 3.5 relative to current propulsion systems. This will allow reduced augmentation operation and significantly reduce fuel consumption. The use of innovative structural concepts and lightweight, high-strength materials will result in significantly reduced engine specific weights relative to current engines.

The propulsive system could be a low-bypass-ratio turbojet, with or without variable-cycle features, or a turboramjet. Combustor exit temperatures will approach $3,600^{\circ} \mathrm{F}$ or higher. Overall engine pressure ratios of 9 to 16 (compared with present values of 8 ) should be attainable and could be accomplished in one spool. High, unaugmented, specific thrust should be available for efficient cruise with the 
afterburner used only for acceleration and high maneuverability. The turbine bypass feature, indicated to be a benefit on engines for the supersonic transport, will probably prove beneficial for the advanced fighter also.

The compressor and turbine will have advanced aerodynamics and lightweight construction to improve efficiencies. The combustor will be designed to provide a high temperature rise and high heat release rates. A five- to seven-stage compressor will be driven by a single-stage, high-pressure turbine. Turbine cooling levels will be reduced through the use of improved turbine blade materials, ceramic coatings, and advanced cooling techniques.

To achieve high levels of performance, exhaust nozzles will have high exit-to-throat area ratios and nozzle pressure ratios approaching 90. The ratio of gross-to-net thrust at Mach 3.5 will be on the order of 3 to 1 for dry power operation. Efficient inlet and nozzle performance is essential.

Figure 19 presents the propulsion system technologies considered essential to the realization of a Mach 3.5 advanced fighter. Also noted are areas of enhancing/supporting technology.

Materials To make significant improvements in engine performance and engine weight, low density structural materials that operate at high temperatures will have to be developed. High melting point materials such as refractory metals (e.g., niobium and tantalum), intermetallics (e.g., titanium aluminum, nickel aluminum, cobalt aluminum, and niobium aluminum) and ceramics (e.g., silicon carbide, silicon nitride, alumina, and zirconium oxide) are potential candidates. Flame resistant titanium and nickel compounds will be used in compressors operating at inlet temperatures of $900^{\circ} \mathrm{F}$ and exit temperatures of $1,600^{\circ} \mathrm{F}$. Advanced nonmetallic materials, such as COMPGLAS, will be used as combustor liners to reduce weight and cooling air requirements.

Turbine materials being developed will allow increases in combustor exit temperature and substantially reduce the cooling air requirements. Single crystal superalloys, refractory metals, and transitional aluminides will be developed further for turbine blades and disks, as will nonmetallics for blade outer air seals.

Carbon-carbon composites will be used in nonrotating structures, such as turbine exhaust cases, augmentor liners and cases, and exhaust nozzle flaps and seals, to reduce cooling requirements and weight.

As has been noted, significant performance gains can be attained at Mach 3.5 with materials and turbine cooling technology that allow very high combustor temperature operation with the levels of turbine cooling used on current $2,000^{\circ} \mathrm{F}$ engines.

Figure 22, Turbojets for the Advanced Fighter, shows the gains in dry power specific thrust (thrust/airflow) that are projected to be 


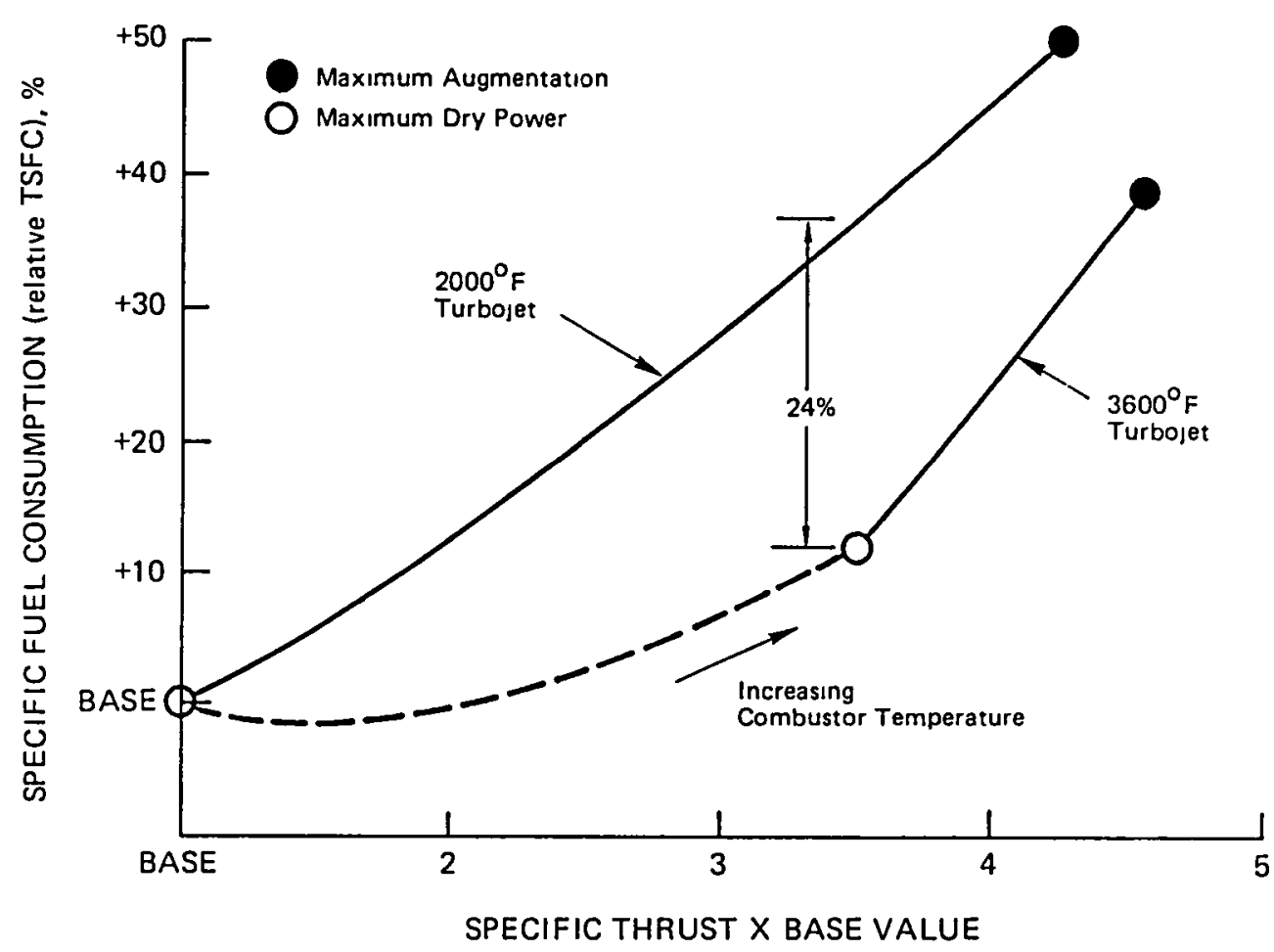

Source: NASA Lewis Research Center.

FIGURE 22 Turbojets for the Advanced Fighter.

achieved by increasing turbine temperature. A $2,700^{\circ} \mathrm{F}$ turbojet will produce double the maximum dry power thrust of a $2,000^{\circ} \mathrm{F}$ turbojet with no increase in specific fuel consumption. A $3,600^{\circ} \mathrm{F}$ turbojet will produce 3.5 times the thrust of a $2,000^{\circ} \mathrm{F}$ engine while only increasing the specific fuel consumption by 12 percent.

Further gains in Mach 3.5 performance will be achieved through the development of materials that will allow compressor discharge temperature to be increased from the current level of $1,250^{\circ} \mathrm{F}$.

Aircraft external surface temperatures of up to $1,000^{\circ} \mathrm{F}$ (slightly higher than the SR-71 aircraft) will be possible. Critical areas will be wing and tail leading edges, inlets, and nozzles. Advanced metallics (powder-metal and ingot alloys) with advanced composites (including metal matrix composites) will be available for efficient, durable, affordable structures.

High-temperature, lightweight, high strength-to-density ratio material will be used for most of the primary support structures. Most probably this will be thin-skin titanium or a similar hightemperature alloy. In some areas thin insulation blankets may be used. 
For the relatively short mission times of Advanced Fighters ( 30 minutes at Mach 3 with a range of about $1,000 \mathrm{miles}$ ), it will be possible to use the fuel as a heat sink.

Aerodynamics Supersonic maneuvering will be possible through aerodynamic improvements. A lift-to-drag ratio for high-speed cruise of about 8 (at Mach 3) and possibly 10 (at Mach 2) will be possible. The achievement of sustained maneuver factors in excess of 2 gs at Mach 3.5 at 70,000 feet will be due to improved drag-polar shapes compared with current designs. This will result from nonlinear supersonic wing design, efficient leading- and trailing-edge devices, and/or variable camber. Lift coefficients of more than 2 will be available for landing.

Low-observability architecture (a low level of detectability to radar, infrared, visual, and acoustic sensors) in order to launch weapons before detection will be an integral part of the design. To enhance supersonic cruise and maneuvering, the aircraft will probably have relatively high wing loading and possibly some form of thrust vectoring, although at present this technique generally is not an efficient means of maneuver enhancement above speeds in the range of Mach 0.6 to 0.8 .

The aircraft will be highly maneuverable, capable of controllable maneuvers beyond maximum lift. Envisioned is control at angles of attack of $50^{\circ}$ to $90^{\circ}$. Combat maneuvering for survivability is important, as is the ability to launch weapons. This ability to maneuver with "reckless abandon" will help in evading missiles and in bringing weapons to bear on targets. Important armaments include short-range (i.e., less than 10 miles) laser weapons, advanced guns with integrated fire-control/flight-control systems, and supersonic/ hypersonic missiles. It is postulated that there will be a capability to identify, track, fire, assess damage, and reattack multiple (up to 20) targets at both long and short range.

Self-optimizing flight control systems will enhance operational flexibility. Using nonconventional flight controls, it will be possible to optimize the trimmed lift-to-drag ratio, maximize the lift coefficient, and handling qualities over the full flight envelope. An ability to reconfigure the aircraft automatically in the event of system failure will provide fail-safe flight.

\section{Enhancing/Supporting Technology}

In addition to the technology developments that are possible (in propulsion, high temperature materials, structural design, and aerodynamics) for a future Mach 3.5 fighter, the following improvements will enhance the Advanced Fighter:

- Thrust vectoring/thrust reversing nozzle systems.

- Variable geometry lifting surfaces that adjust wing shape, sweep, and area as a function of speed and altitude. 
- Advanced functional crew station design, flight suits, and protection and escape systems.

- Systems and onboard equipment that minimize dependence on ground equipment; demonstrate high reliability under nuclear, biological, or chemical attacks; and have high performance, versatile auxiliary power and environmental control.

- High heating value fuels.

- Temperature tolerant, low drag, and transparent canopies.

- Advanced displays and avionics including long-range sensors (4-pi steradians coverage).

- Integrated fire and flight controls.

In addition, the following matters are pertinent to enhancing Advanced Fighter capability.

The Advanced Fighter payload (about 2,000 pounds) is projected to include long-range advanced hypersonic air-to-air or air-to-ground missiles. A crew of one or two will be carried who, through the use of data from onboard computers and sensors, will be presented with total situation awareness information (threats, targets, and a battle management plan). The crew will be advised of the best course of action at any given time through the advanced display system. This system could include helmet-mounted displays and voice or other audible signals.

The application of technology advances will provide cost effective and affordable systems. A 10 percent reduction in life-cycle cost associated with higher performance could save $\$ 2$ billion in operational program costs, which would more than pay for the research and technology development effort projected. A reduction of at least 50 percent in maintenance hours per flight hour, relative to today's fighters, is feasible. Fault tolerant/reliable/reconfigurable subsystems at all levels (i.e., propulsion, flight control, weapons, and avionics) will serve to enhance reliability, availability, and operational performance.

\section{Program Implications and Summary}

The needed technology development program should include:

- A high pressure ratio, lightweight, single spool, compressor program. The successful design, fabrication, and testing of such a component are key to developing the technology base and demonstrating the advantages of such an arrangement.

- A demonstration of diffuser and combustor operation at high combustor exit temperatures. Determination of ignition and blowout characteristics as well as system pressure loss and pattern factor characteristics at high levels of compressor discharge bleed is needed.

- Proof-of-concept performance and durability testing of related turbines.

- Design of exhaust systems in parallel with material development. Demonstration of advanced high-temperature, lightweight composites 
for exhaust system components are assessed to be important. Thrust vectoring, reversing, and nozzle performance at both high and low nozzle pressure ratios is a severe challenge. Ensuring the ability to integrate both the aircraft's air induction system and aft end aerodynamics is also a challenge for these aircraft designs.

- Flight demonstration of the technology for high performance propulsion concepts at full-scale to prove the technology and concepts.

- Demonstration of high-temperature structural design concepts for a variety of materials (i.e., thermoplastics, metal matrix, and powder metals) for airframes and integral wing and fuel tank designs will be required.

- Development and flight of a technology development/demonstrator aircraft (possibly at about half scale) to validate aerodynamics, stability and control, and airframe-propulsion integration. Corollary weapons technology development and demonstration programs, including weapons carriage/separation, will be critical parts of such a program.

Figure 23 displays the technology matrix for Advanced Fighter Aircraft. If the technologies addressed are developed, it is projected that Advanced Fighters designed and developed in the year $2000+$ would have the levels of improvement noted in Table 7 .

\section{Hypersonic Vehicles}

It is possible to develop the technology necessary for the design of manned and unmanned Hypersonic Vehicles that could operate in the sensible atmosphere at Mach 5 to as high as Mach 12 by the year 2000 . For such aircraft, new propulsion concepts, new thermal management system technology, advanced high-temperature materials, flight control systems, and liquid cryogenic fuel technology would be required. Applications of these classes of aircraft would range from military weapons to long-range civilian transports, and the first stage of advanced aerospace vehicles that would go into orbit. The design Mach numbers of these vehicles can be determined through operational analyses considering the state of development of relevant technology. The design may take unexpected turns as new research data allow enhanced performance.

The major keys to enhanced performance are propulsion, materials, and structures technologies. Many types of propulsion systems have been proposed, including dual-cycle engines (turbojet/ramjet), composite engines (turboramjets, airturborockets), high Mach-number engines (scramjets), and even more exotic cycles (hydrogen expanders and liquid air cycles). Each of these concepts has its own set of advantages and disadvantages, limitations, and applications. Each engine type will require large-scale, extensive experimental research to validate performance based on analyses and simple experimental work. However, if propulsion technology for hypersonic speeds in general can be advanced in critical areas, the opportunities for successful will be enhanced. For example: long-life, high-temperature 


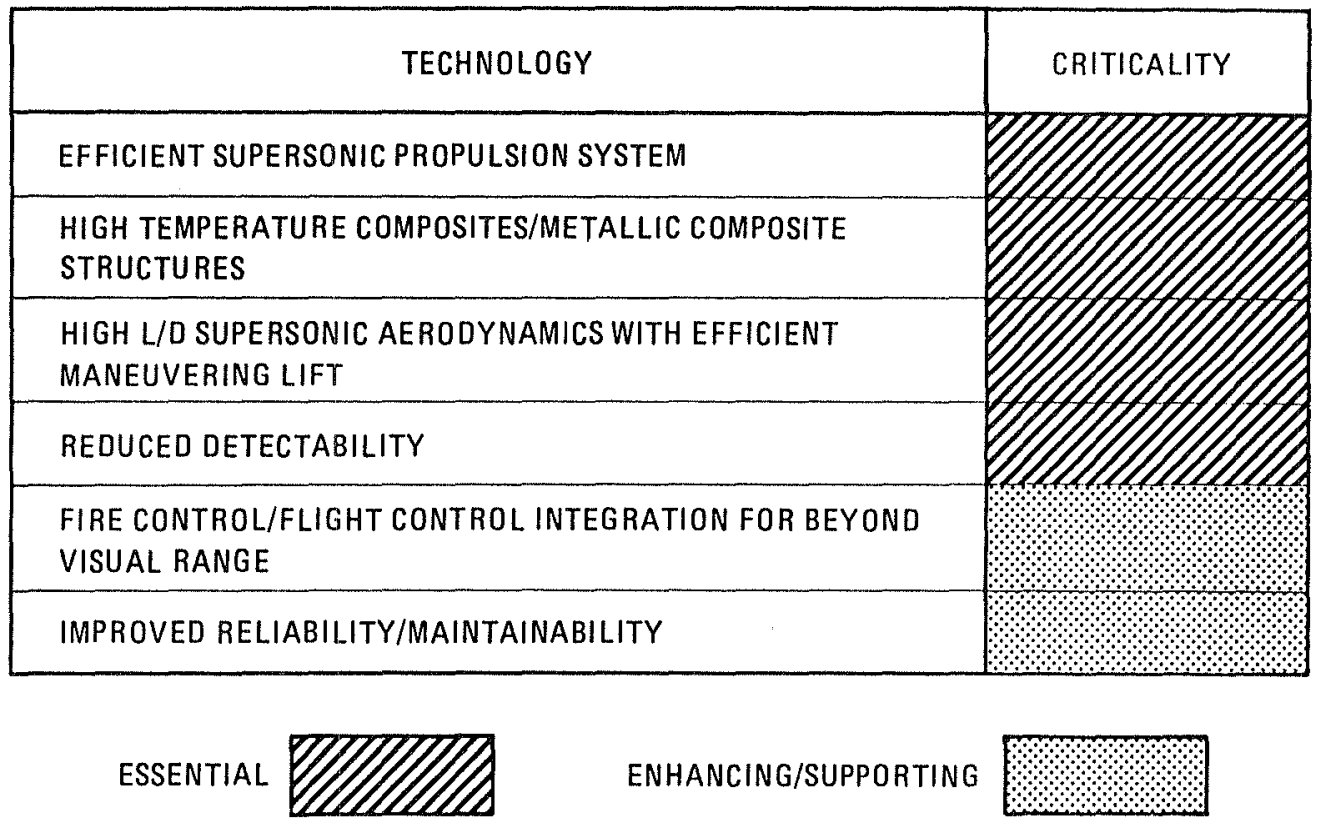

FIGURE 23 Technology matrix, Advanced Fighter Aircraft.

TABLE 7 Performance Projections for Advanced Fighter

\begin{tabular}{ll}
\hline Technology Factor & $\begin{array}{l}\text { Projected } \\
\text { Improvement } \\
\text { (Year 2000) }\end{array}$ \\
\hline Fuel consumption at Mach 3.5+ & $-50 \%$ \\
Dry power thrust-to-weight at Mach 2 & $+300 \%$ \\
Structural weight & $-30 \%$ \\
Supersonic maximum lift & $+50 \%$ to $100 \%$ \\
Maintenance manhours per flight hour & $-50 \%$
\end{tabular}


materials; regenerative cooling for engines, inlets, and nozzles; liquid cryogenic fuel system for long life aircraft; inlet boundary layer control; and integration of propulsion cycles to allow continuous propulsion system operation through subsonic, transonic, supersonic, and hypersonic speeds.

Future viable Hypersonic Vehicles will depend critically on precursor research and technology development in materials. New metal matrix composites and rapid solidification materials are candidates for high-temperature and long-life aircraft applications. Advances in silicon carbides, carbon-carbon, and other materials will require special attention, but no apparent barriers exist.

Integration of the propulsion system and the airframe is critical for hypersonic aircraft. In fact, in all probability, it will not be possible to design the airframe and the propulsion system separately. The propulsion system, due to its size, will be a dominate factor in the aerodynamics of the aircraft system.

\section{Desirable and Possible Characteristics}

Hypersonic Airbreathing Missile

One future vehicle that could have significant advantages over today's rocket-powered missiles is the Hypersonic Airbreathing Missile (Figure 24). This vehicle will utilize a supersonic combustion ramjet (scramjet) burning high-density hydrocarbon fuel. It would be rocket boosted to supersonic speeds, where a scramjet sustainer cruise engine would take over for the flight to the target. This would provide a much greater range than current rocket-powered missiles with the same launch weight because of greater system efficiency.

A missile of this type, because of its relatively short flight duration, could be cooled passively using high-temperature materials in hot areas and insulating materials for less temperature-tolerant (aerodynamically heated) structures. Because long life is not required for missile applications, carbon-carbon composite materials for the scramjet inlet, burner, and nozzle would be appropriate. The primary airframe, fuel tank, and related elements would be insulated and less temperature-tolerant structures.

\section{Military Penetrator Aircraft}

A Military Penetrator Aircraft concept, one of many possible concepts for reconnaissance or bombing is illustrated in Figure 25 . It could fly over enemy defense threats at Mach 5 and altitudes up to 100,000 feet. It could have intercontinental range and be about the size of contemporary reconnaissance aircraft. 


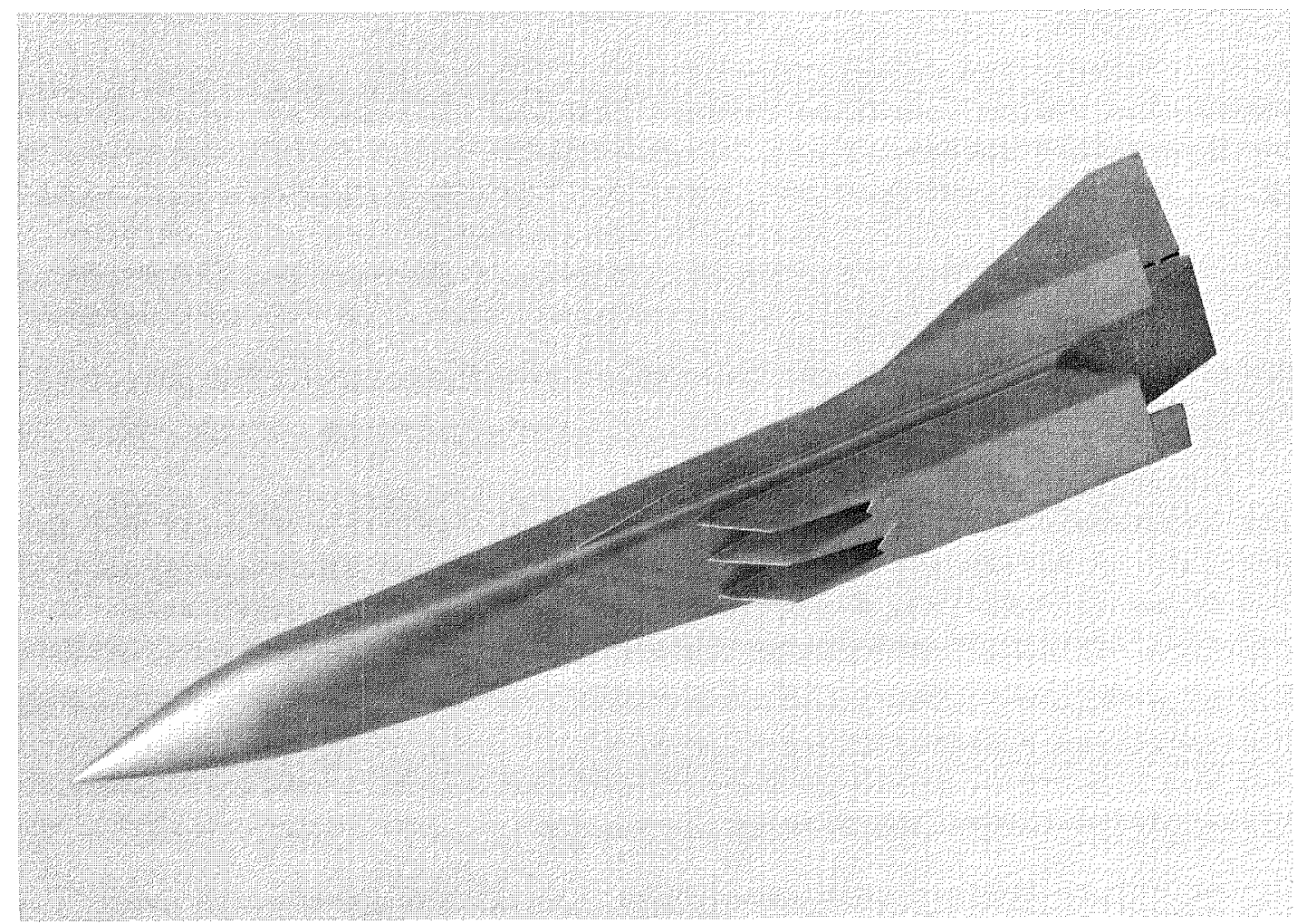

FIGURE 24 Hypersonic Airbreathing Missile.

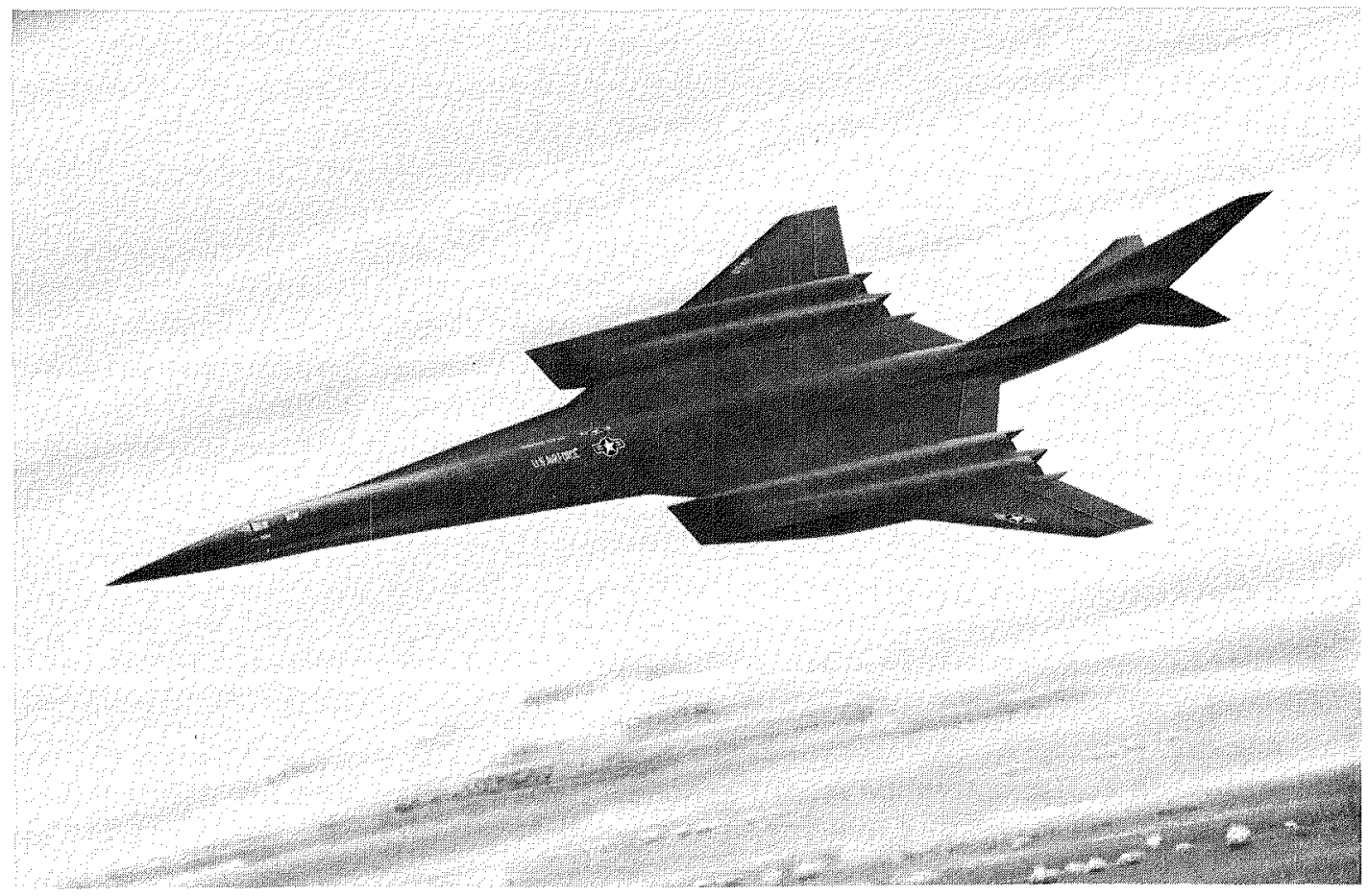

FIGURE 25 Military Penetrator Aircraft. 
These penetrators would utilize methane-fueled, dual cycle, propulsion systems, which could employ dual-flow inlets and nozzles to service turbojets and separate ramjets. This is just one of several propulsion cycles that would be appropriate. The airframes could be constructed primarily of titanium-based materials with nickel-based superalloys applied in the hotter areas of the propulsion systems. The engine and nozzle systems would be regeneratively cooled with liquid methane fuel. Power for the vehicle systems would be generated with turbines through which methane gas is expanded.

Hypersonic Accelerator Vehicle

Another hypersonic concept, an airbreathing Hypersonic Accelerator Vehicle (Figure 26) could be attractive as a higher-speed version of the Military Penetrator Aircraft or a first-stage booster for space vehicles. This class of hypersonic vehicle would provide aircraft-like flexibility in space operations. It would have horizontal takeoff and landing capability, allow dispersal to bases in all parts of the world, and have the potential for a relatively broad range of orbits. For such an application, the propulsion system could be a lightweight high thrust-to-weight ratio accelerator engine. This engine might be a turboramjet-rocket or some other type of combined cycle concept. The goal would be to provide low weight and high thrust over a wide range of speeds and operation for a reasonable number of missions rather than for a limited number of hours.

For high speed aerodynamic cruise, handling the total vehicle heat load is a challenge, thermal management a critical technology. The temperatures are similar to the booster vehicle, but the exposure times to high temperature are longer. The propulsion system would probably require regenerative cooling in the hot sections and hightemperature materials in the inlet, burner, and nozzle. A vehicle of this type could either use liquid methane or liquid hydrogen fuel, depending on a number of design trades. These trades would involve vehicle volume, fuel heat capacity, and fuel energy content. As a booster vehicle, the staging operation would have to be given special attention to ensure safe vehicle-booster separation.

Hypersonic Transport Aircraft

The Hypersonic Transport Aircraft (Figure 27) would cruise long distances at very high speed, substantially reducing travel time on intercontinental flights. For example, a Mach 6 transport aircraft could fly from San Francisco to Tokyo in approximately 2.5 hours as compared with about 13 hours presently required to make the trip nonstop in a Subsonic Transport. This aircraft could make three one-way trips to the Subsonic Aircraft's one, allowing about two hours turnaround time at each stop. Although an aircraft with this kind of performance and certificated for commercial passenger service would be expensive to develop, its productivity could be quite high since it could $\log$ about three times as many passenger-miles in a day as a Subsonic Transport. 


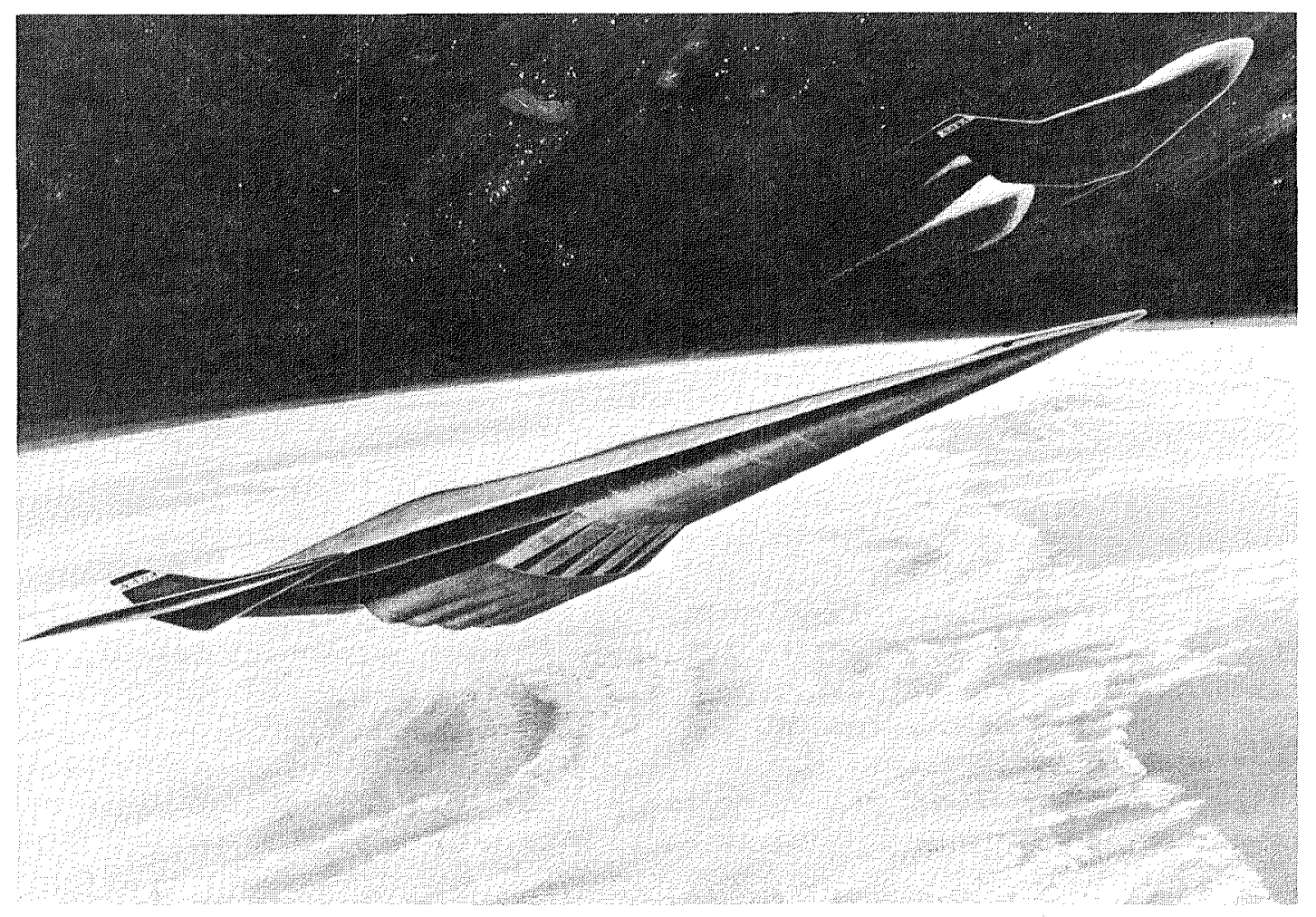

FIGURE 26 Hypersonic Accelerator Vehicle.

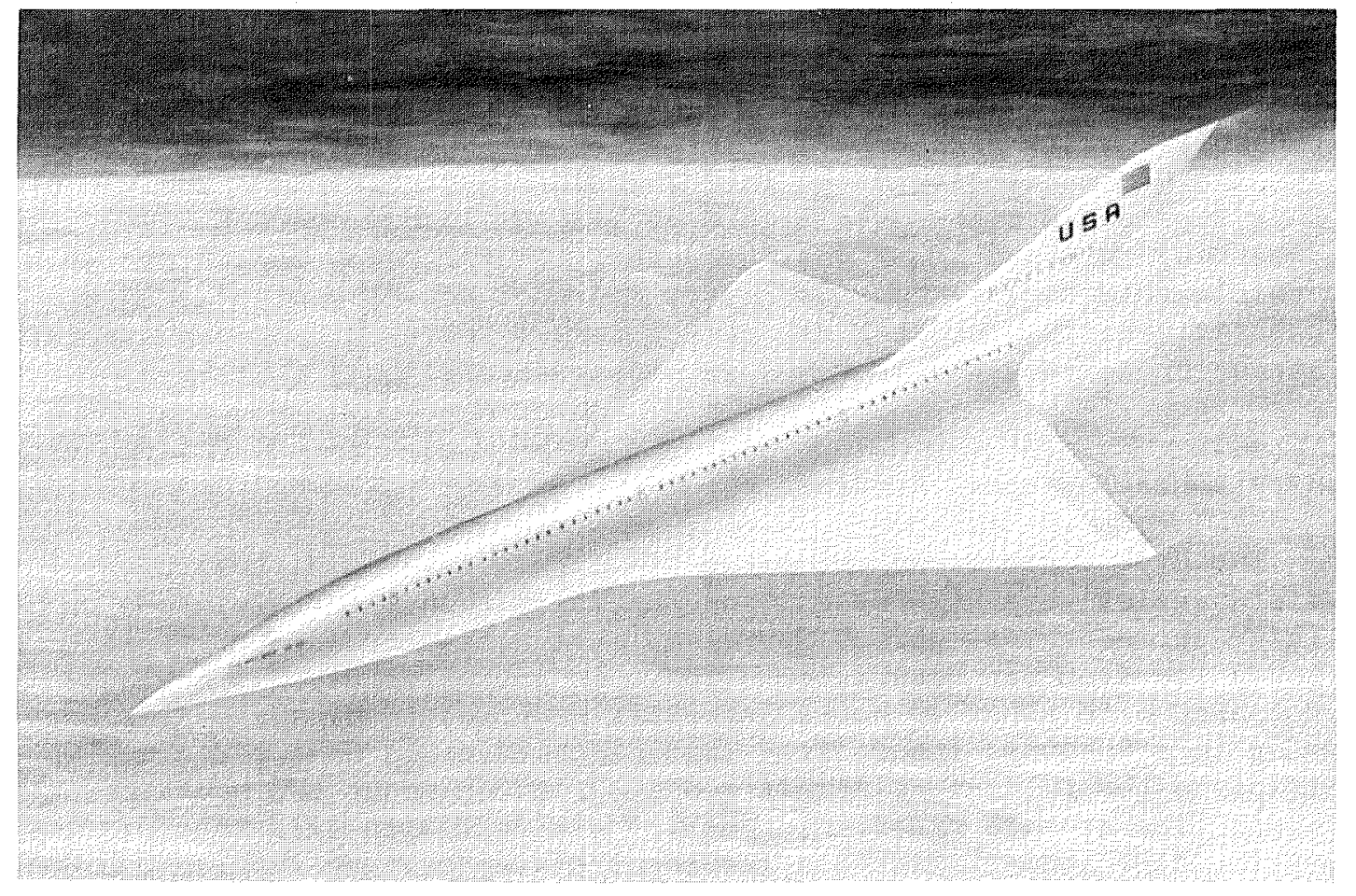

FIGURE 27 Hypersonic Transport Aircraft. 
Because of its high cruise speed, the aircraft will be at high temperatures for extended periods of time. The Hypersonic Transport Aircraft would require careful design to insulate fuel and payload and to reduce cryogenic (liquid) fuel boil-off. The cryogenic fuel itself could be used as a heat sink. The propulsion system would be a lightweight airturbo ramjet engine for efficient cruise at Mach 5 to 6 . The system would require a dual-flow inlet and nozzle arrangement with variable geometry. A thermal management system would be essential for safe operation of this aircraft.

The commercial Hypersonic Transport Aircraft may well follow military development of such aircraft. The economic desirability and viability of such aircraft needs to be verified before development is undertaken. However, the vehicle is technically possible with the advances in hypersonic technology deemed attainable through the application of resources.

\section{Technology Needs}

Essential Technology

For Hypersonic Aircraft, essential technologies relate to propulsion systems, materials (and structures), aerodynamics, vehicle controls, and fuel logistics. Aerodynamics as well as engine efficiency are also major concerns. Three decades of research have verified general performance potential. The data base is sufficient to allow commitment to preliminary design and component development if the results of mission need and economic analyses support such a commitment.

Propulsion Before the envisioned Hypersonic Vehicles could be started with confidence, significant technology deficiencies must be resolved. Propulsion is the major deficiency. The relationship, in terms of specific impulse, among hydrocarbon- and hydrogen-fueled engine concepts is shown in Figure 28. The advantage that airbreathing engines have over rockets, in specific impulse, is shown as a function of Mach number. At supersonic speeds, the hydrogen-fueled, subsonic combustion ramjet is more efficient in producing thrust than the turbojet, but the design is adversely affected by the very large volume required for fuel. The supersonic combustion ramjet (scramjet) becomes useful from Mach 4 to perhaps as high as Mach 12. The use of hydrogen fuel more than doubles the specific impulse and this fuel would be required for cooling at speeds above Mach 7. Some combined cycles (turboramjet and turboramjet-rocket) and some of the more exotic cycles ( 1 iquid air cycle and supercharged ejector ramjet) are not shown. These concepts lie within the hydrocarbon/hydrogen fuel ramjet/scramjet region.

Propulsion systems, materials, and Mach number relationships, as shown in Figure 29, reflect the increased-temperature environment (requiring increased cooling and higher temperature materials) in which propulsion systems must function as flight speed is increased. 


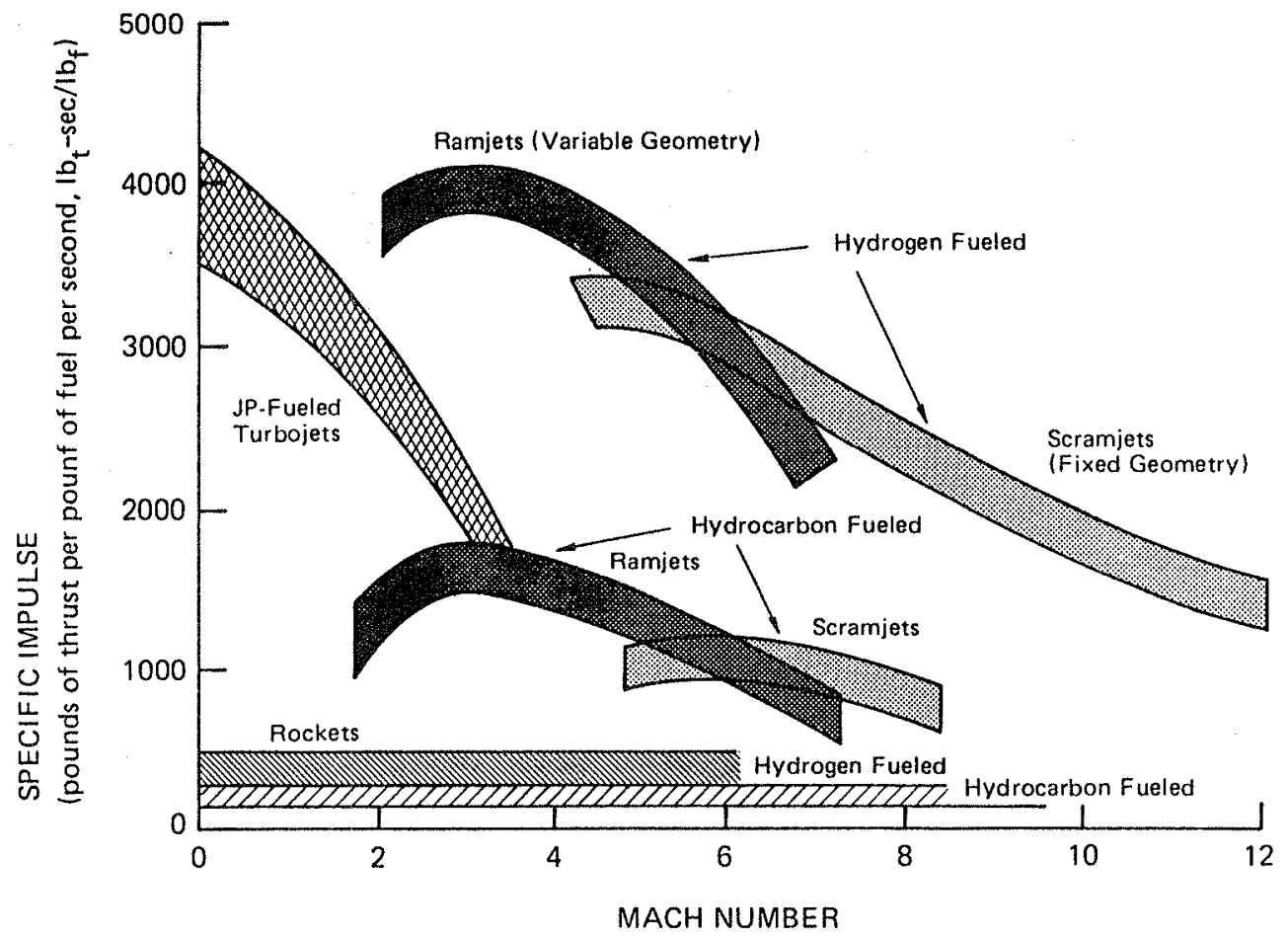

Source: Astronautics and Aeronautics, Dec. 1976, 14(12): 20-37.

FIGURE 28 Propulsion system fuel efficiency.

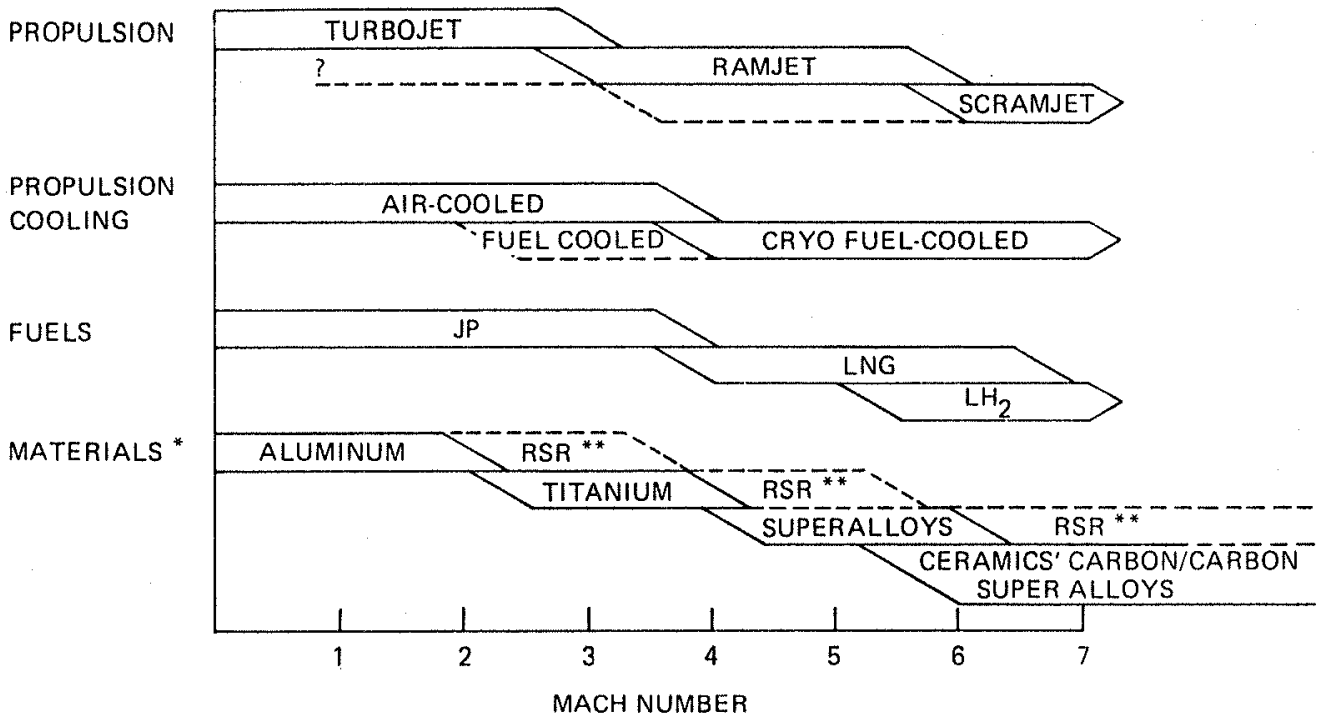

*Materials selection depends very much on dynamic pressure, time, and durability requirements. $* *$ RSR--Rapid solidification rate material

FIGURE 29 Propulsion system, materials, and Mach number relationships. 
The critical areas for research related to Hypersonic Airbreathing Missiles are in scramjet combustion, engine design, and in the management of the high thermal environment that the missiles will experience.

The Military Penetrator requires advances in dual turbojet/ramjet propulsion including associated variable geometry inlets and nozzles. The regenerative cooling system for the burner and nozzle, which will use cryogenic methane fuel as the coolant, requires research and technology development on lightweight heat exchangers.

The Hypersonic Accelerator will require a lightweight propulsion system and probably call for combined-cycle engine systems, such as turboramjet-rockets, that have high thrust over the wide range of Mach numbers needed for high staging speeds. For these applications, a combined-cycle engine could be used in conjunction with a scramjet to attain very high staging speeds. This development would demand technology advances in variable geometry inlets, burners, and nozzles that were regeneratively cooled.

A major program to prepare technology for comercial application is required for the Hypersonic Transport. Liquified natural gas (LNG) and liquified petroleum gas (LPG) fuels are commercially developed for ground use. This technology needs to be transferred to aircraft. The basic technologies used to develop the Mach 6 and Mach 12 aircraft are applicable but need to be applied to commercial aircraft operations.

Materials For cases where Hypersonic Vehicles use high-density hydrocarbon fuel, there would be no significant heat sink capacity in the fuel. The airframe must be designed as either a heat sink using high specific heat materials (beryllium) or as an insulated structure, or a combination of both. The propulsion system could use coated carbon-carbon composite materials in the hot sections.

The Military Penetrator Aircraft and the Hypersonic Transport could be built largely of titanium. The propulsion system is expected to require the use of ceramics with high temperature titanium for the hottest areas. Refractory metals with durable coatings or superalloys are always fallback positions.

Aerodynamic Shape When fuel density drops from $481 \mathrm{~b} / \mathrm{ft}^{3}$ for JP-4, to $28 \mathrm{lb} / \mathrm{ft}^{3}$ for cryogenic methane, to $4.6 \mathrm{lb} / \mathrm{ft}^{3}$ for cryogenic hydrogen, the fuel volume becomes so large that a complete blending of the propulsion and aerodynamic systems is required. This is critical for Hypersonic Vehicles since aerodynamic as well as volumetric efficiency must be incorporated in the design, a significant challenge. Both analytical and experimental data are needed. For Hypersonic Transport Aircraft, the design must incorporate high lift-to-drag ratios and good takeoff and landing characteristics. The development of analytical procedures for the design of efficient integrated airframe and propulsion systems through the full flight envelope is of 
importance as will be the development of hypersonic gas dynamic facilities to experimentally verify analyses.

Flight control These aircraft, operating over a broad range of speed and altitude, will require integration of aerodynamic and propulsion system controls over a range of changing aerodynamic and engine cycle characteristics. Automated systems using specialized sensors and tailored data management systems will be needed. Data handling and presentation will be of special importance to the crew for decision making and automated operation.

Fuel Logistics/Supply Hypersonic Vehicles will require large quantities of cryogenic propellants. Fuel manufacturing, storage and distribution, and related technology development for cryogenic propellants and special fuels will be critical to the operation of these high performance aircraft. In-situ manufacture of cryogenic propellants has potential given the research and development progress being made on magnetic refrigerators at Los Alamos Labortory.

\section{Enhancing/Supporting Technology}

There are a number of areas where the technology needs improvement to support the achievement of design goals. Areas of interest in the propulsion area include supersonic flow-through compression, designs for low cost production, high aerodynamic efficiency, and materials/ structures that serve to enhance efficiency and hold costs down. Brief comments on propulsion and aerodynamic technology have been made. Following are other comments pertinent to materials/structures, costs, and some other factors that will be of concern to designers.

Materials/Structures Materials for Hypersonic Vehicles can be a greater challenge than materials for reentry vehicles because of the extended time of operation at high temperatures and the resulting large heat loads associated with hypersonic cruise. Materials to accommodate cruise speeds up to Mach 16 at acceptable weights are available. However, improvements are needed in material composition and production and in structural fabrication to reduce weight, increase durability and reliability, and reduce the costs of procurement and fabrication.

Application of heat-pipe technology could eliminate the need for heavy high-temperature materials for leading edges, control surfaces, and engine components. Multilayer ceramic composites, carbon-carbon, and metal matrix composites offer potential payoffs in durability and reliability.

Thermally protected, cool primary structures can be as much as two to four times lighter than hot metallic structures using available materials. Multilayer ceramic materials and advanced carbon-carbon 
composites are possible approaches to low weight and viable hot primary structures. Their inherent high temperature capability with lower weight, to a degree, decouples thermal analysis uncertainties from weight penalties.

Research on materials to permit full application of passive countermeasures in military operations would be of value. Such research could include: regeneratively cooled engine structures, liquid metal heat-pipe leading edges and engine structures, and nonmetallic structural thermal protection systems.

Costs Cost is a major deterrent to the development and operation of advanced systems of this class. To a degree, costs can be controlled through careful selection of specifications and designs and the exercise of prudent acquisition processes. In addition, manufacturing processes need attention if costs are to be contained for limited production items. Cost control also means operationally efficient systems (including launch) that require little maintenance and repair.

Other Computer-assisted piloting should make two-man crews possible with the exception of unique military missions that could require more than two crew members. This technology is essentially in hand but application requires the identification of the mission unique requirements and the evaluation of criteria and analytical techniques.

For military applications, a significant supporting technology item is the parallel development of weapons systems compatible with hypersonic flight. Weapons that can be carried on Subsonic or Supersonic Aircraft are not necessarily suitable for Hypersonic Aircraft.

\section{Program Implications}

Hypersonic vehicle concepts will require considerable aerodynamic technology development related to vehicle configurations for both onand off-design conditions and include inlets, nozzles, and propulsion system integration if the vehicles are to be feasible.

All four of the hypersonic vehicle concepts projected have supporting technology needs. Areas such as flight control, propulsion system control, cooling system control (including fail safe systems for manned vehicles), and low-cost fabrication techniques for high-temperature structures will need attention. These supporting technologies should await developments in the essential technology areas. However, selective items such as bearings, lubricants, and seals will need timely attention so that successful design and development of inlets, engines, and nozzles are not precluded. Thus, a careful survey of supporting technology needs should be conducted and implemented as the essential technology areas are being worked. 
A phased program would permit early program judgments to be made on items for acceleration, termination, or redirection. Thus, when the time comes to commit to large-scale work, system design can be based on sound demonstrated technology. As part of this process, it would be prudent to use lower-risk, precursor-vehicle research prior to development of a full-capability hypersonic research aircraft should such a research aircraft program be indicated. A possible precursor/ full-system technology development program is shown in Table 8 .

A related large-scale development of importance is an airport-based manufacturing, storage, and handling facility for cryogenic fuels. This effort could include such program elements as are shown in Table 9 .

TABLE 8 Hypersonic Technology Activity

$\begin{array}{ll}\text { Precursor Research } & \begin{array}{l}\text { Hypersonic Aeronautical } \\ \text { Research System }\end{array}\end{array}$

Subscale in wind tunnel or in Mach 3+ (SR 71) aircraft

Research missile with scramjet engine. Full-scale operational missile, subscale aeronautical system engine module, to Mach $12+$
Multicycle engine in hypersonic aeronautical research aircraft, to Mach 6

Hypersonic aeronautical research aircraft with scramjet engine to Mach $12+$

TABLE 9 Cryogenic Fuel Program Elements

\begin{tabular}{|cc|}
\hline Precursor Research & $\begin{array}{l}\text { Hypersonic Aeronautical } \\
\text { Research System }\end{array}$ \\
\hline $\begin{array}{c}\text { Subscale airport-based cryo- } \\
\text { genic fuel production, } \\
\text { handling, and storage } \\
\text { facility }\end{array}$ & $\begin{array}{l}\text { Full-scale airport-based } \\
\text { cryogenic fuel production, } \\
\text { handling, and storage } \\
\text { facility }\end{array}$ \\
\hline
\end{tabular}


Further implementation of the program will require these kinds of supporting effort:

- Controls: Development of manned simulators to assist in the design and demonstration of computer-assisted piloting. The long-range goals should be directed at mechanisms for interfacing the human operator with future computer-based systems for management and control of hypersonic aircraft.

- Fuel logistics/supply: Definition of and design requirements for movable fuel production systems using a nuclear power source with fast-fill tankage capability.

- High-temperature compressor: Development of compressor technology for up to Mach 6 capability using active cooling, ceramic composites, or coated carbon-carbon materials.

- High-temperature materials: Development of high-temperature materials technology for active cooling to allow scramjet operation at Mach 12 and above.

- Low cost: Development of concepts for on-demand, low-cost operational modes with the associated technology for military systems need to be developed. Design and manufacturing of Hypersonic Aircraft has to be tailored to typical aircraft low production rates. Highly integrated controls and avionics demand software development and maintenance and are a key technology.

\section{$\underline{\text { Summary }}$}

Hypersonic Vehicles, both manned and unmanned, operating in the sensible atmosphere will be able to operate at speeds up to Mach 12. For such vehicles, new propulsion technologies; new aerodynamics, structures, and control techniques; and cryogenic fuel handling will be required. Figure 30 presents essential and enhancing/supporting technologies for aircraft of this class.

These aircraft would make use of multicycle propulsion systems for high efficiency throughout their flight envelopes, and new materials and structures to allow high heat loads and low weight for both the airframe and engine. Cruise speeds of Mach 6 to 8 would be realized with ranges of hundreds of miles for the interceptors to thousands of miles for the other aircraft. The propulsion concepts include airturbo ramjets and hydrogen expansion cyrojets for the lower hypersonic speeds. For very high speeds, supersonic combustion ramjets (scramjets) would be utilized.

Integration of the airframe and propulsion system are important for low total vehicle drag and proper conditioning of the intake air for efficient propulsion system operation, as well as for the handing of the hot exhaust gases.

The essential and enhancing technologies for Hypersonic Vehicles propulsion are delineated in Figure 31. 


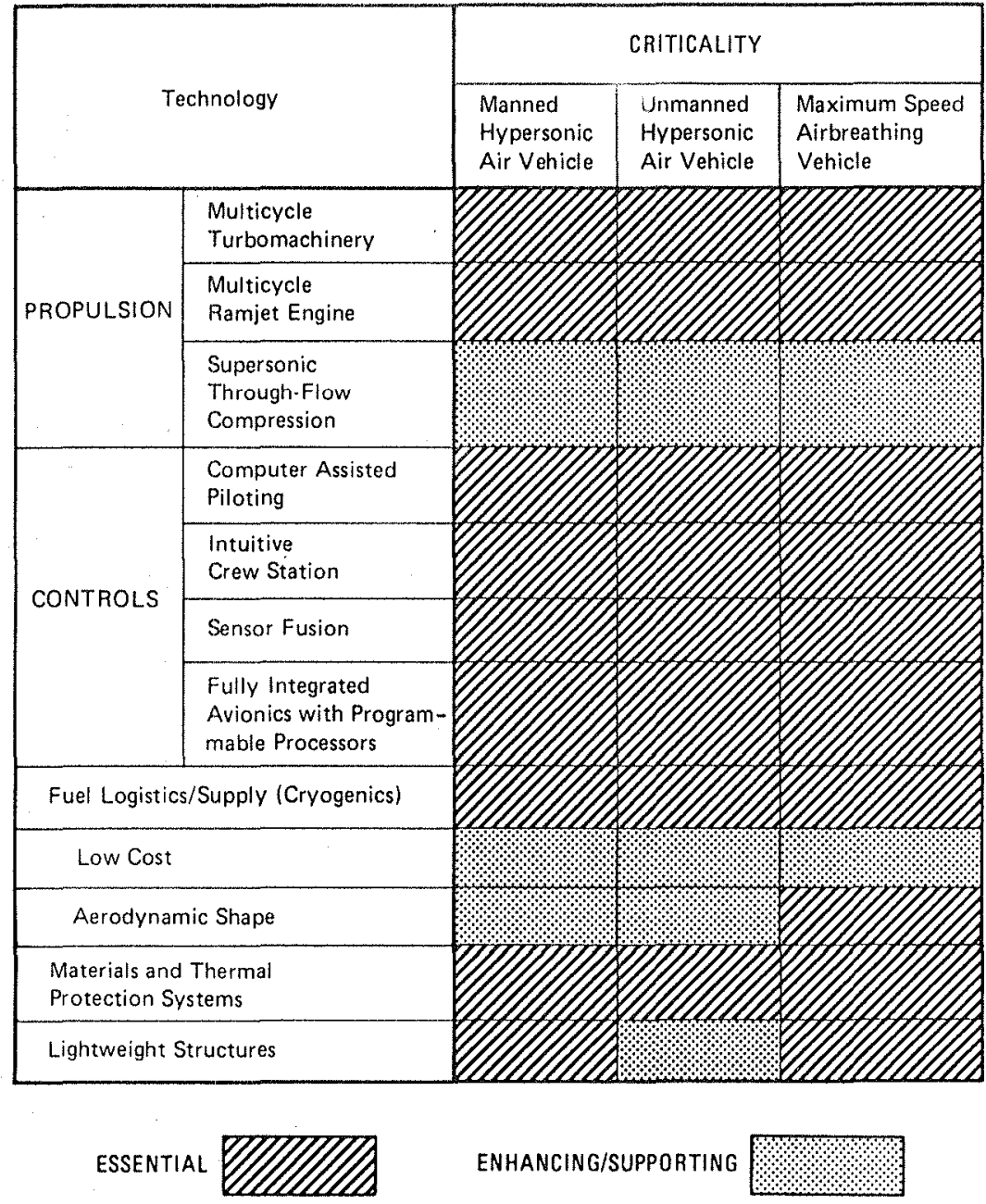

FIGURE 30 Technology matrix, Hypersonic Vehicles.

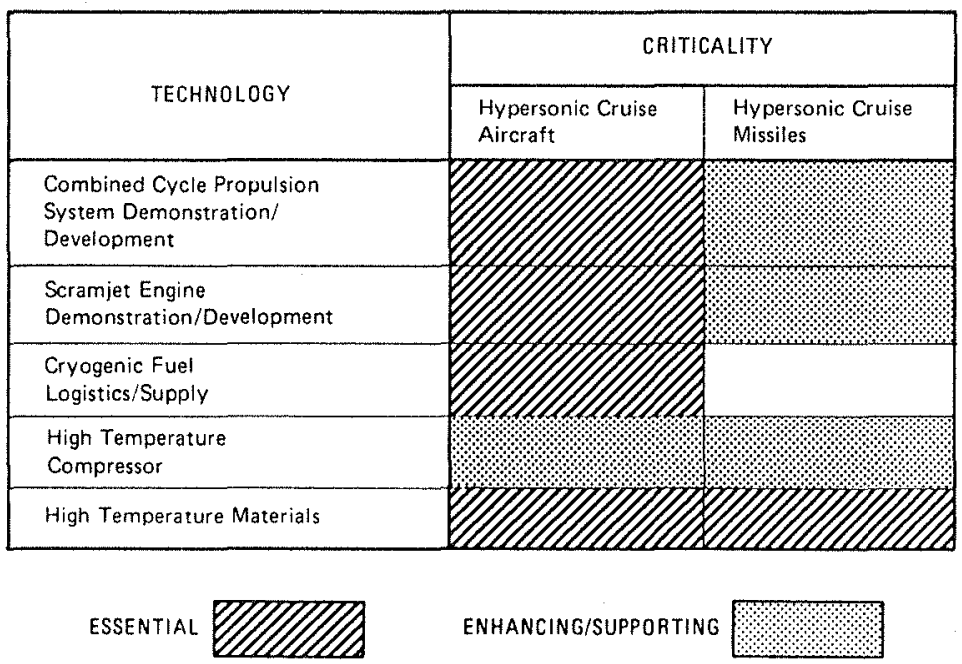

FIGURE 31 Technology matrix, Hypersonic Vehicle propulsion systems. 


\section{TRANSPORT AIRCRAFT}

\section{Subsonic Transport}

Desirable and Possible Characteristics

Short-/Medium- and Long-Range Commercial Transports and military transports such as Long-Haul Airlifters, Assault and Short-Haul Transports, short takeoff and landing (STOL), and short takeoff including vertical landing (STOVL) transports are included in this aircraft category.

Short-/Medium- and Long-Range Commercial Transports that are very efficient, productive, and community friendly can be available in the twenty-first century. They will benefit the commercial passenger by providing outstanding travel value; the community by producing low levels of acoustic emissions and pollutants; and the airlines by generating attractive return on investment through operational efficiency.

A new 130-180 passenger Short-/Medium-Range Transport would cruise between speeds of Mach 0.7 and 0.8 and have a range of 1,400 to 3,000 nautical miles.

A new Long-Range Commercial Transport could have a design range of about 6,000 nautical miles and cruise at Mach 0.8 to 0.9 with 300 to 600 passengers at altitudes approaching 50,000 feet, well above the shorter range high-density traffic.

Long-Haul Military Airlifters will be possible with payloads upwards of 200,000 pounds and ranges of 6,000 nautical miles or more, thereby reducing dependency on in-flight refueling or foreign bases for refueling. Global range capability is possible, but may be of limited interest because of facility and/or associated economic limitations (e.g., airfields and runway lengths and widths).

Assault Transports will be capable of STOL or STOVL operations into combat areas with relative runway independence and improved survivability capability in a hostile environment while carrying payloads up to 40,000 pounds over 500 nautical miles without refueling at the delivery site.

For the military, new Short-Haul Transports will provide the capability to deliver 5,000 pound payloads out to 400 nautical miles on a high priority basis.

With adequate resources, the technology could be in hand by the year 2000 to design each of these vehicles to perform civil or military missions efficiently and effectively. 
Technology Needs

Essential Technology

The essential technologies involve propulsion, aerodynamics, structures and materials, and the synergistic integration of these into appropriate vehicle concepts and configurations.

Propulsion Fuel efficiency is paramount for commercial Subsonic Transport Alrcraft. Significant improvements in fuel efficiency at the short/medium ranges are obtainable with advanced turbofan and propfan engines. The advanced propfan engine offers a 40 to 50 percent reduction in fuel consumption over today's short-haul aircraft engines.

However, development of certain technologies is essential to capitalize on the benefits of the propfan. This includes propellers that operate efficiently with high disk loadings and high horsepower, efficient propeller drive systems (whether geared or gearless), efficient propulsion airframe integration, and propeller systems with acceptable acoustics and associated cabin vibration levels. Understanding and controlling propeller-airframe acoustics and structural interactions for both single and counter-rotation propfans are important. Improved materials, lubricants, and lubrication techniques are needed to ensure reliable, efficient gear systems for both turbofan and turboprop propulsion systems.

Development of efficient propulsion concepts is also essential to both the Long-Range Commercial Transport and the Long-Haul Military Airlifter. Advanced turbofan engines may be competitive with propfans, particularly if increased bypass and pressure ratios can be obtained and effectively integrated with the airframe. Materials with higher strength and higher operating temperature capability for combustors and turbines are fundamental for operation at the high pressure ratios and temperatures envisioned. Swept turbofan blades offer a significant improvement in component aerodynamic efficiency and translate into higher operating efficiency. Propfans also hold promise for large fuel savings. Lighter, more efficient engines will be required to meet the mission requirements of Military Assault Transports. For STOVL aircraft, higher thrust-to-weight-ratio propulsion systems and efficient airframe-propulsion system integration are essential to providing useful STOVL payload and range capability.

Aerodynamics Substantial improvements in aerodynamic efficiency are possible through wing design and vehicle drag reduction. Innovative concepts for wings, airfoil sections, tip vortex control devices, vehicle control, and mission adaptive variable geometry wings offer the opportunity for substantial reductions in induced drag. Laminar flow control and turbulence modification can reduce parasite drag. A better understanding of laminar flow instability, including the influence of the propulsion system installation and of turbulence control and modification, is required along with a much better 
definition of advanced structural control concepts for allowing the design of high-aspect-ratio (greater than 12), low-weight wings. It is necessary to improve high-lift system design technology, including powered lift concepts, to maintain a balance between high- and low-speed performance. Obtaining the efficiencies that advanced concepts offer without sacrificing low acquisition cost, particularly for smaller short- and medium-range aircraft, is indeed a challenge.

Cruise drag reduction is very important for long-range vehicles because of the longer flight time at cruise conditions. Aerodynamic configuration definition for military aircraft may be dominated primarily by the design requirements for STOL or STOVL operations, survivability, and high maneuverability at low-speeds. To decrease aircraft weight and increase maneuverability, reduced stability margins might be required, dictating the need for automated stability and control.

Materials and Structures Advanced materials and structural concepts offer the opportunity for significant airframe improvements on all transport classes through weight reduction and aerodynamic efficiency improvements and through relaxation of traditional design constraints. These advanced materials and structural concepts include new aluminumlithium alloys, thermoplastic and metal matrix composites, superplastic forming, diffusion-bonded titanium sandwich construction, and advanced joining concepts such as adhesive bonding. New aluminum-1ithium alloys offer weight reduction and stiffness improvements. Composites, a concept of growing promise due to the synergistic influence on aircraft design, have application barriers with regard to cost and testing for integrity. Superplastic forming and diffusion-bonded titanium sandwich construction is promising, particularly in combination with machined slots or holes for laminar flow control, but has manufacturing costs which must be overcome for large-scale application. Advanced joining concepts could reduce manufacturing cost, but obtaining quality assurance in production while maintaining competitive costs has to be addressed.

Acoustics In the twenty-first century, lower noise emissions will be required for community acceptance of commercial aircraft. Advanced propulsion technology and control of turbulence of the airflow over the airframe offer opportunities to reduce noise. Passenger acceptance of a new aircraft will require a vibration and acoustic environment within the passenger cabin equivalent to current turbofan-powered aircraft. The challenge is to achieve an acceptable cabin environment with advanced technology propfans or turbofans without significant loss of engine performance or aircraft efficiency as a result of added airframe weight for acoustic treatment.

Controls, Avionics, and Subsystems Highly integrated automatic flight control systems will be essential if the benefits of system/airframe integration are to be achieved, i.e., lower operational and 
maintenance costs. Involved are such matters as stability augmentation; load alleviation; control of takeoff, landing, rollout, and taxi; and flight and energy management.

Landing Gear Active, high-flotation landing gears will be required for the Military Airlifter and Assault and Short-Haul Transports that operate into and out of semi-improved, short, or unprepared fields.

Enhancing/Supporting Technology

Enhancing/supporting technologies are needed to fully realize improved productivity, reliability, maintainability, survivability, and reduced cost. Reduced bleed-air capability of advanced engines will require a means of supplying power for the aircraft pneumatic systems with less penalty than is tolerated today. Among the possible solutions are engines designed for bleed-air extraction at multiple locations, engine-driven auxiliary air compressors, electric-motordriven environmental supply systems, and hybrids of these systems.

Wider employment of electric power to drive or replace hydraulic and pneumatic services will require the development of concepts for increased generation capacity and higher integrity in the electrical load management and distribution systems, as well as lightweight, reliable electromechanical actuators. The technology for more efficient electric power systems employing such concepts as bi-directional resonant converters, utilizing improved magnetic materials and solid state electronics, is needed, together with multiple transmitter digital data buses, utilizing integrated graphite conductors and/or fiber optics. For military applications, system survivability is required.

The system for laminar-flow control must provide not only for suction but surface cleaning and ice protection in a cost-effective manner.

The continued broadening of jet fuel specifications may cause a problem for future propulsion system designs. Such jet fuels will require technology developments in engine and fuel system components. More accurate and reliable methods of measuring fuel quantity in the aircraft's tanks will also be needed. Further anti-misting fuel work is needed as a means of reducing the fire hazard in future aircraft.

Interior material standards will have to be upgraded to meet more stringent fire safety requirements. The goal is to develop materials that will provide passenger comfort with thermal resistance and low toxicity in the event of a fire. Damage-tolerant, lightweight materials and structure and lightweight armor will aid in achieving the required performance and survivability of military transports. The high-aspect ratio and unique structural concepts required for a low weight-fraction, Airlifter will necessitate the development of new aeroelastic analysis techniques for structural representation and modeling. These techniques will facilitate aeroelastic tailoring to 
eliminate flutter, control reversal, and possibly divergence through the use of nonisotropic composites.

Future airline operations will use advanced navigation systems that are fully integrated with automated air traffic control and global, cooperative airspace management systems.

Development of innovative and automated manufacturing is mandatory for cost-effective, large-scale use of the new materials and structural technologies to make full use of advanced composites, metal matrix, and the specially fabricated materials for laminar flow enhancement.

\section{Program Implications}

Advanced propulsion systems are a key to the realization of advanced subsonic transports, both civil and military. Significant improvement in propulsion efficiency should be pursued through development of engine cycle efficiency, higher bypass ratios, higher turbine temperatures, and appropriate materials. Related current emerging technologies need to be proven through large-scale engine component testing. For advanced propfan development, emphasis should be placed on ground, wind tunnel, and flight test demonstrations of both geared and nongeared propeller drive concepts.

Laminar flow control, turbulent drag reduction, and wing design concepts that reduce induced and compressibility drag are the leading technologies to pursue for improving aerodynamic efficiency. Considerable theoretical analyses and wind tunnel testing will be required to allow design of high-Mach-number configurations with acceptable stability, control and high lift characteristics, and low observability, if required. Configuration integration problems involving the propulsion system, structural design, and cost tradeoffs need to be considered in addition to aerodynamics.

Greater effort needs to be focused on computational fluid dynamic developments on fast Navier-Stokes codes applicable to high Reynolds number flows representative of full-scale flight. Augmentation of fundamental studies of flow stability and turbulence with emphasis on laminar flow control and turbulence modification is necessary. In-depth design studies and technology demonstrations of high-aspectratio, structurally-tailored, and/or actively-controlled wings must be conducted including full-scale flight demonstrations for wing laminarflow control and for reduction of fuselage drag due to turbulence.

A continuing effort on the development of structural materials and concepts including generic and technology development programs is vital. Ful1-scale design, fabrication, test, and in-service demonstrations to ensure reliability, viability, and cost effectiveness will be needed. Appropriate attention must be given to both metallic and nonmetallic matrices for lightweight structures with a view towards damage tolerance and radar absorbing properties for military 
applications. The search for aircraft interior materials that are fire-safe and provide a high level of passenger comfort will need to continued. Optimization methods and procedures for efficiently accommodating the aeroelastic characteristics (i.e., flutter, divergence, and reversal) of new materials in aircraft design must be developed.

Automated manufacturing techniques and equipment must be developed along with vehicle and component designs that allow automated manufacturing and test to reduce and control costs.

Developments for all-weather operations are required. This includes sensors for aircraft control and technology developments related to integration of satellite navigation aids; automatic air traffic control; and ground management including landing, rollout, and taxi. Advanced information distribution concepts such as flat panel and holographic displays, voice and touch controls, and data management systems that reduce crew workload and size need attention as do integrated displays, crew performance measurement systems, and artificial intelligence to assist in aircraft operational and support management.

An integrated control system could maintain the aircraft in a configuration and attitude for maximum performance and allow significant reduction in aircraft weight and operating cost. To accomplish this, sensors for accurately measuring structural, aerodynamic, and propulsion parameters will be needed. Development is also needed to provide affordable fault/damage reconfigurable systems and very reliable, verifiable software. Advanced airborne landing sensors, aids, and controls would also assist in improving aircraft efficiency and operational flexibility.

Efforts must continue on the development and testing of landing gear concepts for semi-improved and unprepared field operation for military aircraft.

Engines and aircraft fuel systems to accommodate a wider range of jet fuels (differing fuel properties) should be developed. The ultimate accomplishment would be development of a single fuel specification that would be compatible with all engines in the fleet--old and new. Also, fuel system gauging developments are needed. Fuel gauging concepts such as fiber optics and ultrasonics could improve measurement but need to be evaluated in the operating environment.

$\underline{\text { Summary }}$

Short-/medium-range civil Subsonic Transports, powered by advanced turboprops, will have high efficiency and low noise. They will provide a high level of ride comfort through automated flight controls and be capable of operating at speeds of Mach 0.7 to 0.8 .

An advanced Long-Range, Commercial Subsonic Transport is projected to be a more efficient and cruise at somewhat higher speeds than comparable current designs. It will provide greater range and/or 
payload capability and use less fuel than current comparable aircraft. This higher efficiency will be achieved by the application of new, low-weight materials and structures, lower overall drag due to more extensive laminar flow, and improved propulsive efficiency. These aircraft will have greater community acceptability because of low noise during takeoff and approach maneuvers.

The Long-Haul Military Airlifter will incorporate advanced propulsion, aerodynamics, and structures to provide range-payload-speed capabilities not available today. The advanced aircraft could carry large loads (up to 200,000 pounds) over long distances $(6,000$ nautical miles) without refueling. It will be aerodynamically clean and have an efficient propulsion system that would allow higher cruise speeds than available with current military transport aircraft, thus, significantly increasing productivity and operational flexibility.

The Assault Transport of the future will be capable of operating in combat areas where there are damaged or unprepared runways and will have a high degree of survivability. Propulsion system and structural design advances will provide the capability for 500-mile operational ranges with significant payloads (up to 40,000 pounds). Advanced avionics will allow al1-weather operation into and out of damaged or unprepared fields without ground-based navigational aids.

Future Short-Haul Military Transports will be capable of delivering special, high-value payloads on an urgent call basis. They could have STOL or STOVL capability, with high flotation for operation on unprepared fields, and would be designed to off-load and on-load payloads with a minimum of support equipment.

The technology matrix for Subsonic Transports (Figure 32) presents the assessed essential and enhancing/supporting technology areas. Technologically, the most demanding aircraft are the short- to medium-range commercial transport and the military Assault Transport. Major improvements in propulsion, aerodynamics, structures, and materials are critical to the design and development of the various Subsonic Transport concepts. The propulsion-system-related technology needs are summarized in Table 10. Improvements possible by the year 2000 , providing an adequate application of resources (i.e., funding, manpower, and facilities), are presented in Table 11.

\section{Commuter Aircraft}

Desirable and Possible Characteristics

For Commuter Aircraft, modular designs that provide a family of vehicles of various sizes could lead to lower cost.

There are many aircraft that fall into this category. They range from small airplanes such as the 15-passenger Beech B-C99 to mid-sized airplanes such as the 35-passenger SAAB-Fairchild 340 and DeHavilland Dash 8, to larger airplanes represented by 82-seat British Aerospace 


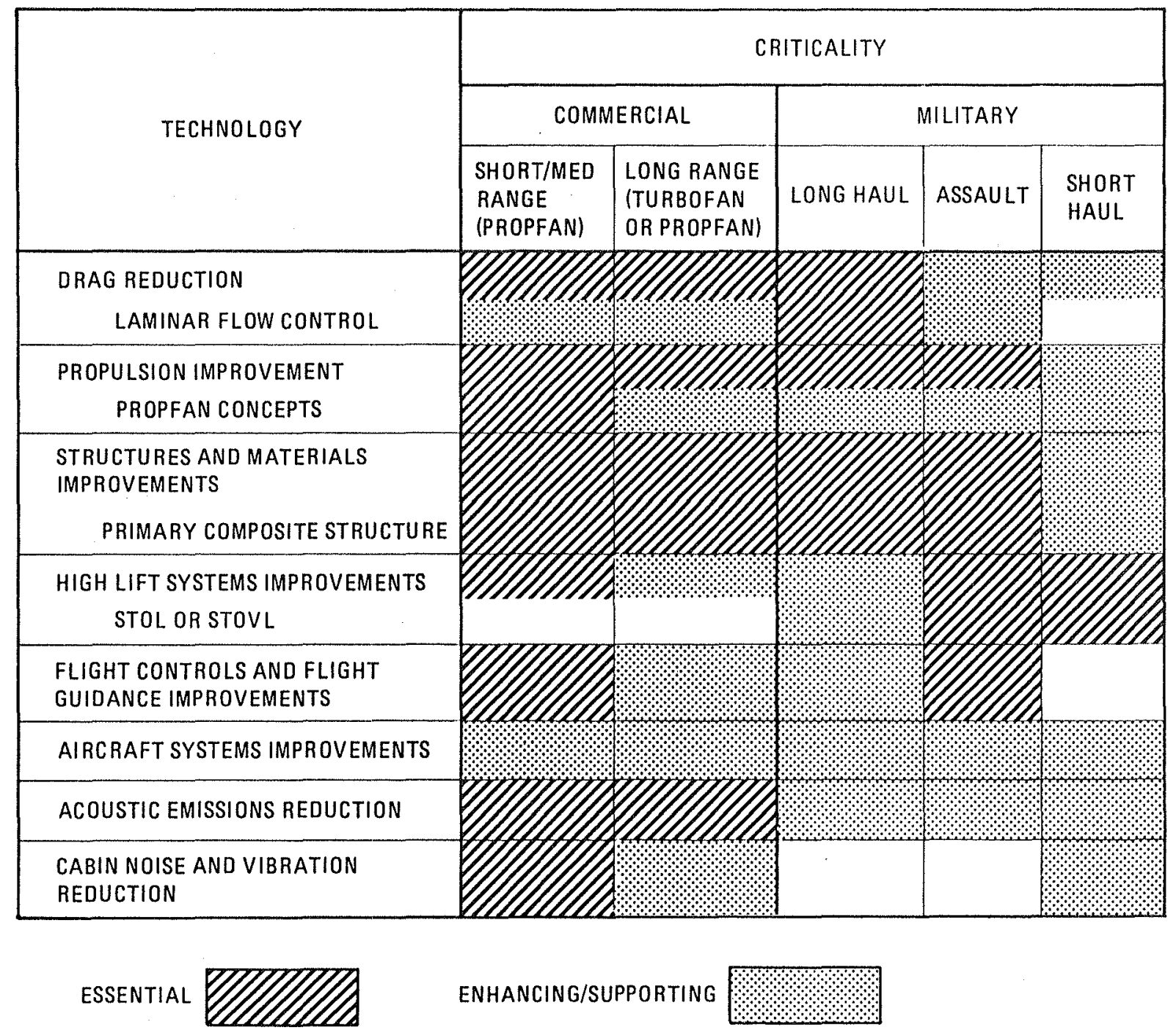

FIGURE 32 Technology matrix, Subsonic Transports. 
TABLE 10 Propulsion System Technology Needs

Essential Technologies Enhancing Technologies

- Low drag nacelle

- Swept fan blades

- Hot section materials

- Reduction gearing

- High efficiency compressor

- Statorless power turbine

- Turboprop/nacelle/inlet/ compressor interaction
- Propfan

- High speed turbine

- Closed loop clearance

- Damped high speed rotor

- Structural composites

TABLE 11 Performance Projections for Subsonic Transport Aircraft

Projected

Improvement

Technology Factor

(Year 2000)

Aerodynamic drag

Specific fuel consumption

Aircraft weight

Operation efficiency
$-15 \%$ to $-20 \%$

$-10 \%$ to $-35 \%$

$-15 \%$ to $-25 \%$

$+20 \%$ to $+30 \%$ 
BAC 146-100. The small to medium-sized vehicles generally employ turboprops, but some are piston engine powered. The turboprops cruise at approximately 270 knots at 15,000 feet and require $3,000-4,000$ feet of field length. The piston engined aircraft have somewhat lower performance. The turbofan-powered BAC 146 cruises at 420 knots at 26,000 feet and requires about 4,000 feet of field length. The stage lengths of these aircraft are under 1,000 miles.

By the year 2000, technology could be in hand to design a family of vehicles able to carry from 30 to 90 passengers at distances over 1,000 nautical miles at cruise speeds in excess of 300 knots (with initial climb rates in excess of 3,000 feet per minute). The balanced field lengths of less than 3,500 feet.

These vehicles would permit flexibility of operations for various route structures in the face of large variations in weather and traffic density.

Technology Needs

Essential Technology

The technologies that are essential for full realization of the potential of Commuter Aircraft would provide new approaches to powerplant design resulting in significant reductions in fuel consumption (operating costs), reductions in vehicle cost, and improved aerodynamic performance and further reductions in operating costs through extensive natural laminar flow on the aircraft.

Propulsion There are two types of propulsion systems available for the smaller Commuter Aircraft: the turboprop and the propellered intermittent combustion engine. With regard to small turbine engines, opportunities exist for evolving revolutionary engine technologies that overcome many of the fundamental, inherent limitations of small engines. First, ceramic or possibly advanced metal materials could allow turbine inlet temperatures to rise some $400^{\circ} \mathrm{F}$ to about $2,500^{\circ} \mathrm{F}$ without the need for active cooling. Second, regenerative engine cycles can reduce the high pressure ratios otherwise required, while yielding high thermodynamic efficiency. Advanced turbomachinery ceramic technology and regenerative cycle technology each offer 15- to 20-percent improvement in turbine engine efficiency and together could reduce mission fuel consumption 40 percent relative to state-of-the-art technology.

Intermittent combustion engines have much lower specific fuel consumption than turbine engines. Unfortunately, they have drawbacks. They provide poorer reliability, are three times heavier, are noisier, have higher vibration and require aviation gasoline which is in poor supply and disappearing from the market place. However, as with turbine engines, impressive opportunities exist for this type of 
engine as well. Ceramic or metal matrix materials offer higher levels of performance through increased operating temperatures with thermally insulated combustion chambers. A variant of the internal combustion piston engine, the lightweight rotary engines, could provide a smoothrunning engine with multifuel capability and dramatic performance improvements through stratified-charge combustion with fuel-injection and very high speed ignition, improved rotor sealing, advanced turbocharging, and "adiabatic" features.

Aerodynamics The attainment of laminar flow (naturally or in combination with some low-cost active system) on all lifting surfaces and on the fuselage is essential to significantly improved aerodynamic performance. The external configuration would be characterized by slightly swept wings with aspect ratios of up to 14 , multiple control elements on each lifting surface, and power plant location such as aft-mounted propellers to enhance efficiency and operational performance.

Enhancing/Supporting Technology

The enhancing/supporting technologies that would provide a superior vehicle are associated with propulsion systems, automated manufacturing of composite structures, advanced flight control systems, low drag configurations, and icing protection.

Propulsion The genesis of better powerplants is found in advances in basic research disciplines and component technology. Remarkable progress has been achieved during the history of aircraft powerplants, especially turbine engines. Looking toward the year 2000 and beyond, it is reasonable to foresee continued improvements stemming from better understanding of gas dynamics, heat transfer, and structural behavior. The same basic technology advances that will enhance the turbine engine will provide enhancement of intermittent-combustion engines.

One can anticipate, for example, the development of computational methods for three-dimensional viscous flow analysis that can be applied to fans, compressors, and turbines to characterize internal aerodynamic channel flow more accurately. This will be exploited to raise component efficiencies and reduce design and development effort. Similarly, improved heat-transfer computational tools (computational fluid mechanics) can be expected to result in lighter engines, better life estimates, and less engine development time and cost. Improved analytic capability can also enable rapid identification of new or novel propulsion concepts. Advances in the analysis of engine structural dynamics and instrumentation advances that would permit measurements of critical in-situ operational parameters (e.g., hot section temperatures and structural response) will also contribute to improved design. 
Generic component research involving traditional turbine engine components including propellers, fans, compressors, turbines, combustors, inlets and nozzles, shafts, gearboxes, and controls and will lead to improvements in propulsion system efficiency. Advances in mechanical component design will reduce gearbox weight and improve life and reliability fourfold. Coupled with advanced engine control techniques to reduce surge margin and to provide active rotating part clearance control and performance retention, these technology advances will reduce direct aircraft operating costs.

Centrifugal and axial compressor efficiencies will rise. Organic composites capable of withstanding temperatures of $800^{\circ} \mathrm{F}$ to $900^{\circ} \mathrm{F}$ may become practical for use in cold section static and rotating components. These would reduce engine weight. Better hot section metals and exotic cooling techniques, while definitely useful in large engines, are difficult to justify in small engine applications due to current fabrication complexity and high cost. Technology advances could reduce these barriers.

The enhancing technologies for the intermittent-combustion engine are basically those that will improve turbine engines. Application of improved computational fluid mechanics techniques will result in more accurate prediction of internal flows leading to improved design with reduced fuel consumption and a shorter development cycle. The use of composite materials for the cooler engine components will result in weight reductions and associated fuel savings. Improved lubricants will result in reduced maintenance and longer 1 ife. Advanced electronics will provide improved control systems and condition-monitoring systems. Finally, improvements in propeller technology postulated in the discussion of Subsonic Transports can provide the same benefits for Commuter Aircraft.

Structures The use of composite-fiber or composite-metal materials in primary aircraft structure, with allowance for modularity and automated production, is a challenge. The vehicle family concept will require a common fuselage cross section (with varying lengths) and a series of wings for takeoff gross weights of perhaps $25,000,50,000$, and 75,000 pounds. Innovative propulsion-airframe integration will be important. Sensors for onboard fault-testing may have to be identified and built into unconventional, hard-to-inspect structures.

Controls An advanced flight control system, automated, modular in design, and common to the family of aircraft, would incorporate onboard computers that maintain the best combination of vehicle speed, lift-to-drag ratio, and specific fuel consumption. Part of the wings' multisection control surfaces could be dedicated to enhancing ride quality. 
Aircraft management and control systems should be integrated into a two-pilot crew station using video displays common to the family of vehicles.

Aerodynamics The aerodynamic performance considerations include the integration of the propulsion system and airframe to enhance performance and stability and control characteristics while preserving the modular concept.

Finally, guidelines for the integration of deicing systems for commuter-class aircraft and an understanding of the effects of ice on laminar flow should be developed.

\section{Program Implications}

All of the essential and enhancing technologies can be developed individually, but ground-based test beds and flight tests with modified existing aircraft will be required to provide needed large-scale technology validation. In selected areas, it may be necessary to have new, possibly subscale, demonstrator aircraft to develop and fully evaluate the new technology and their synergistic effects for this class of aircraft.

The development of these technologies will allow the use of regenerative systems in turbine engines, stratified charge in advanced high-speed rotary engines, and high-temperature materials in both turbine and intermittant combustion engines. This requires an aggressive research and technology development program.

Small-scale tests in special, low-turbulence wind tunnels can help establish design guidelines for natural laminar-flow fuselages. The most promising concepts should be flight tested to assess scale and operational effects. Flight work may be necessary but may not have to involve complete configuration tests. Exploratory work can be accelerated through an effort that combines flow visualization and analytic modeling.

Optimization studies of the integration of the airframe, propulsion system, and controls should proceed from thorough analytic and simulation study to flight testing. The work of blending propeller and engine controls may need a flight vehicle with the same flexibility and dedicated role as earlier variable-stability research aircraft.

A program to identify means for maintaining quality control in the manufacture of composite structures and methods for nondestructive composite structures testing are needed. This will require joint NASA, industry, and FAA effort. In addition to nondestructive testing, there is a need to assess the integrity, fatigue 1 ife, and strength of composite structures, especially primary structures. This testing must be nondestructive, inexpensive, and simple to permit reliable use in the field. 
Summary

For Commuter Aircraft, low cost and high efficiency are special drivers in this competitive, growing market. Developments essential to the improvements projected for this class of aircraft are very efficient propulsion systems and natural laminar-flow fuselage design. The most promising turbine engine concept involves such unconventional design features as ceramic hot-section components and regenerative cycles. The most promising intermittent combustion concept is a high-speed, stratified-charge, multi-fuel rotary engine with thermally insulated rotors with an advanced turbocharger to reduce waste heat losses. Also important is the development of technology related to automated manufacturing of composite structures for low cost; advanced flight control for ride quality, operational efficiency, and al1-weather operation; deicing for all-weather operation; and configuration arrangement for improved overall aerodynamic efficiency. These advances will permit aircraft structural weight reductions of 10 to 15 percent, aerodynamic drag reduction of about 10 percent, and reductions in fuel consumption of about 50 percent compared with current aircraft.

The technology matrix for Commuter Aircraft (Figure 33) represents the essential and the enhancing/supporting technology areas. Figure 34 summarizes the propulsion-system-related technology needs. Improvements in major parameters projected for Commuter Aircraft by the year 2000 , assuming adequate technology development support, are noted in Table 12 .

\begin{tabular}{|l|l|} 
TECHNOLOGY \\
\hline RADICALLY NEW APPROACH TO POWERPLANT DESIGN \\
\hline FUSELAGE, NATU RAL LAM INAR FL OW \\
\hline ADUOMATED MANUFACTU RING TECHNOLOGY OF COMPOSITE STRUCTURES \\
\hline CONFIGURATION AERODYNAMITICALITY \\
\hline ICING RESEARCH
\end{tabular}

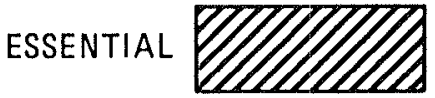

ENHANCING/SUPPORTING

FIGURE 33 Technology matrix, Commuter Aircraft. 


\begin{tabular}{|l|l|}
\hline \multicolumn{2}{|c|}{ TECHNOLOGY } \\
\hline Ceramic or Metal Matrix Composites/Uncooled Hot \\
Section Components (e.g. ceramics) \\
\hline Regenerator \\
\hline Improved Computational Methods \\
\hline System Instrumentation and Diagnostics \\
\hline Advanced Controls \\
\hline Bearings, Seals, \& Lubrication \\
\hline Advanced Centrifugal Compressor \\
\hline Advanced “Cold Section" Materials \\
\hline Propeller/Prop Fan \\
\hline Combustor/Combustion Chamber
\end{tabular}

ESSENTIAL

ENHANCING/SUPPORTING

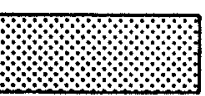

FIGURE 34 Technology matrix, Commuter Aircraft propulsion systems.

TABLE 12 Performance Projections for Commuter Aircraft

\begin{tabular}{|ll|}
\hline Technology Factor & $\begin{array}{l}\text { Projected } \\
\text { Improvement } \\
\text { (Year 2000) }\end{array}$ \\
\hline $\begin{array}{l}\text { Aerodynamic drag } \\
\text { Fuel consumption } \\
\text { Aircraft weight } \\
\text { Maintenance requirements }\end{array}$ & $-10 \%$ \\
\hline
\end{tabular}


Supersonic Transport

Desirable and Possible Characteristics

By the year 2000, technology can be available to permit the design of a commercially viable Supersonic Transport (SST); a vehicle that will be as acceptable and profitable as a comparably sized subsonic airplane. It will be able to operate within the existing air transportation system without any special dispensations carrying from 300 to 600 passengers in the Mach 2.2 to 3.2 range over distances of 3,000 to 5,500 nautical miles.

Today, the Concorde is the only Supersonic Transport in commercial operation, and it has logged over 80,000 hours at Mach 2. This 400,000 pound four-engined afterburning turbojet airplane carries 100 passengers 3,000+ miles across the Atlantic in a little over three hours. Studies in the United States indicate that future SSTs should have a greater payload and fly farther and faster than the Concorde. This requires possible and significant improvements in propulsion, aerodynamics, structures and materials, and manufacturing technology.

By the year 2000, the technology could be in hand to design a unique baseline configuration to permit development of a family of SSTs. These aircraft could be flying at speeds in the range of Mach 2.3 to 2.4 and as high as 3.2 . The several sizes are relatively easily adaptable to varying market requirements. They will have high commonality of major airplane components--the same fuselage, propulsion system, and outer-wing sections--but be modifiable to meet customers' passenger and range requirements. Optimization of the use of materials, structural design, and manufacturing processes (addressing component weight and cost) would further enhance the economics. Also, the future SST would benefit from the advanced avionics and other components being incorporated in Subsonic Transports to improve airplane control and engine operations and weight-saving associated with carbon brakes, use of radial tires, and new designs for seats, interiors, galleys, and lavatories. Short trip-times suggest fewer galleys for food service and a two-man crew. These actions have twice the payoff on an SST than they have on subsonic aircraft.

Selection of the design cruise Mach number would be determined by costs and operational considerations. For example, for speeds of Mach 2.3 to 2.4 , many of the subsystems and nonmetalics that have been developed for the latest subsonic airplanes could be used, saving costly development work. In addition, propulsion system requirements are less severe, variable geometry inlets are less complex, propulsionairframe integration is more easily managed, and some of the difficulties associated with fuel tank sealing are avoided. Technology for higher speed designs will require considerable attention. 
Technology Needs

Essential Technology

The essential technologies are related to propulsion and materials.

Propulsion Future engines for an SST will have to provide fuel efficient operation at both supersonic and subsonic cruise. They will be required to have low takeoff and landing noise. Propulsion concepts such as the pure turbojet, variable stream control, and double bypass engines do not meet all of the requirements for a successful SST. Cycle variability for both performance and noise without complexity is required.

Low engine frontal area is especially important for supersonic flight, as are high specific thrust and low specific fuel consumption. This infers nonafterburning engines with high turbine inlet temperatures. Advanced materials, especially in the hot section, are needed to permit high temperatures and light weight.

If the cruise speed is to be over Mach 2.5, complex variable geometry inlets become necessary. Advances in inlet technology in terms of aerodynamic design (airflow characteristics, boundary layer control, and efficiency) and mechanical design (low complexity and weight) will be required.

Because of the requirements for thrust reversers and noise abatement in addition to variable geometry inlets and engines, nozzles for these engines can a1so become complex and heavy. Low noise engine cycles and/or new noise abatement techniques, such as the inverse velocity profile and the thermal acoustic shield, are required.

Materials The particular materials selected for the SST will be dependent on the cruise Mach number selected. In addition, supersonic laminar flow could play a significant role in materials selection, providing significant reductions in heat transfer rates resulting in temperatures approximately $160^{\circ} \mathrm{F}$ cooler. At the present time, candidate materials include new aluminum alloys, titanium, and various types of composites in nonmetallic and metallic matrices. The manner in which these materials are fashioned is important. For example, sandwich materials are very attractive, especially for the wing lower surface, in that they provide insulation for in-wing fuel. Superplastic forming and diffusion bonding/weld brazing can significantly enhance structural efficiency and reduce weight, the number of parts, and costs.

Relatively little effort has been expended in the area of developing low-cost, lightweight, temperature-resistant materials. A pound of weight or fuel saved on an SST has twice the payoff as a pound saved on subsonic aircraft. The development of a high-temperature structures technology will have a high payoff. Some data are available on 
metal matrix composites, but little effort has been expended in thermoplastics. Development of the data base to make these approaches useful to the aircraft designer will require an effort similar in nature to the existing NASA nonmetallic composites program.

Following the U.S. SST program of the 1960s, a satisfactory fuel sealant good for aircraft cruise speeds up to Mach 2.4 was developed. Experience has shown that the sealing of an integral fuel tank of a high performance aircraft, cruising at speeds greater than Mach 2.5, is a difficult task. A successful fuel tank sealant for SSTs must be unaffected by aircraft fuels, adhere to materials of construction, resist thermal degradation, and accept structural deformation. In addition, sealant handling, application, and curing characteristics must be practical. Material repairability is also a prime concern.

Enhancing/Supporting Technology

Enhancing/supporting technologies that would provide a superior vehicle involve propulsion and aerodynamics.

Propulsion Evolutionary improvements in fans and compressors will result in systems with higher stage loading and fewer stages. These same improvements will also apply to turbines. Compressors and turbines will have adiabatic efficiencies of the order of 85 and 90 percent, respectively. In addition, advances in cooling and coatings will reduce the amount of cooling air required and, thus, improve engine performance. Combustor exit temperatures will be on the order of $3,000^{\circ} \mathrm{F}$. Also, active compressor and turbine blade tip clearance control will reduce leakage and improve engine performance. Electronic control systems will reduce control system complexity and cost. The vented nozzle concept has the potential for both improved nozzle performance and jet noise reduction. In the longer term, the supersonic through-flow fan can eliminate the heavy inlet required to diffuse the flow to subsonic conditions at the fan face and has the potential to improve engine performance by 10 percent and reduce engine weight by 30 to 40 percent.

Aerodynamics Laminar flow could increase the aircraft 1 ift-to-drag ratio at cruise from 10 to nearly 17 . This improvement alone would reduce the gross weight by almost half and double the seat-miles per gallon of fuel burned. Laminar flow, be it natural, actively induced, or a combination is being pursued in the subsonic area. Detailed data on effects of pressure gradient, surface waviness, sweep, crossflow, and construction techniques have been demonstrated in flight at subsonic speeds. The state of knowledge for supersonic laminar flow is in its infancy. Tunnels are ill equipped to develop this data base because of airflow disturbances (noise) and inadequate Reynolds number (model scale). Flight testing will be necessary. 
Results of previous flutter studies of supersonic configurations have raised questions as to the adequacy of existing analytical methods to predict supersonic flutter for arrow wings. The adequacy of unsteady aerodynamic theories, the level of detail required in finite element representations of the configuration, and the influence of other parameters that effect flutter are matters at issue.

Evaluations of supersonic cruise aircraft configurations are needed to better understand the contribution of the structural flexibility of these large aircraft on handling and ride qualities.

The ability to fabricate superplastic formed and diffusion bonded titanium sandwich panels of 3 by 3 feet to 3 by 5 feet has been demonstrated. Little information and no experience is available for processes and methods associated with larger panels of, say, 20 by 20 feet.

Revised operating procedures for Subsonic Transport Aircraft have shown considerable promise for minimizing noise around the airport community. Optimization and automation of SST operating procedures to reduce noise on and around airports is important.

\section{Program Implications}

An economically and environmentally acceptable Supersonic Transport will require a supersonic propulsion program aimed at providing better cycle definition and optimization; high stage loadings; improved internal flows; and improvements in metal alloys (single crystals), cooling capabilities, and material coatings. The turbine-bypass engine cycle is a step in the right direction. Just as important is work on hightemperature thermoplastic and metal matrix materials and development of the data base for low-cost, ultra-lightweight structures. Fuel tank sealants for operating speeds greater than Mach 2.5 is also required.

An aggressive and continuing effort to bring enhancing/supporting technologies to fruition will help assure economic success for the SST.

A series of flight experiments is necessary to develop the technology for the design of laminar-flow supersonic configurations. This could begin with a pallet experiment in the weapon bay of an F-106 or F-12 aircraft to determine the supersonic speed effects of pressure gradients and surface conditions on laminar flow.

A series of simulator studies should be conducted to determine the impact of structural flexibility on handing and ride quality. This should be paralleled by simulator and flight tests related to piloting and flight procedures for minimizing airport-community noise. The adequacy of analytical methods to predict full-scale flutter characteristics through wind-tunnel model testing needs to be established. 
Efforts to establish the proper integration of airplane oontrols with propulsion controls (inlet, engine, and exhaust nozzle) need to be pursued.

In the area of electronics and avionics, there is the need to develop dependable sensors and systems for measurement of air data and propulsion and structural parameters for flight envelope control and limiting. This will also require incorporation of affordable fault-tolerant systems including reliable software.

The development of manufacturing processes for very large superplastic forming and panel diffusion bonding are needed.

Finally, a series of flight experiments to study the impact of sonic boom levels of 1 pound per square foot (psf) or less having modified rise-times or multiple-peak signatures is necessary. An aircraft designed to create sonic booms with overpressure near 1 psf with modified rise-times may make supersonic flight over populated areas acceptable, thereby greatly increasing the utilization of an SST. There has been little increase in the understanding of sonic boom phenomena or its effects since the late 1960s, especially with respect to lower values of overpressure.

Summary

An advanced, commercially viable SST will achieve three times the productivity of a similarly sized subsonic airplane while burning less than twice as much fuel. It is estimated that future SSTs could cruise at speeds up to Mach 3.2 over ranges approaching 5,500 nautical miles, carrying as many as 600 passengers with a lift-to-drag ratio on the order of 17 at a gross weight less than 750,000 pounds. The development of the future SST requires improved propulsion systems for reduced fuel consumption, supersonic laminar flow to reduce cruise drag, reduced structural weight to improve payload-to-weight ratio, and reduced manufacturing costs to hold acquisition costs down. Also important are airport-community noise rule conformance and minimization of the sonic boom effect that will lessen ground overpressure and make supersonic overland flights acceptable.

By selection of wing-fuselage arrangements, a specific design concept can be tailored to accommodate different range and passenger route requirements. Trip times for SSTs with enhanced performance capabilities will be significantly less than for advanced Subsonic Transport Aircraft. Successful development and application of these technologies will allow future SSTs to be cost-competitive with future Subsonic Transports while providing much shorter trip times. For example, a Tokyo-San Francisco flight would require only four hours. 
The technology matrix shown in Figure 35 presents the broad essential and enhancing/supporting technology areas for the Supersonic Transport. The propulsion system and its integration with the airframe is critical to the design and development of an SST. Figure 36 summarizes the propulsion-system-related technology needs. Possible improvements by the year 2000 in major parameters, providing adequate resources are applied, are noted in Table 13. A comparison of lift-to-drag ratios (aerodynamic efficiency) and of passenger miles per gallon of fuel (a performance parameter) is presented in Table 14 for various supersonic designs including the existing Concorde aircraft.

\begin{tabular}{|l|} 
TECHNOLOGY \\
\hline MORE EFFICIENT PROPULSION SYSTEM \\
\hline LIGHTWEIGHT-LOW COST-TEMP. RESISTANT MATERIALS \\
\hline FUEL TANK SEALANT \\
\hline SUPERSONIC LAMINAR FLOW \\
\hline OPTIMIZATION OF LARGE-FLEXIBLE AIRCRAFT STRUCTURE \\
\hline FLIGHT ENVELOPE LIMITING \\
\hline MANUFACTURING PROCESSES, BONDING AND FORMING \\
\hline AIRPORT-COMMUNITY NOISE CONFORMANCE \\
\hline SONIC BOOM MINIMIZATION
\end{tabular}

ESSENTIAL

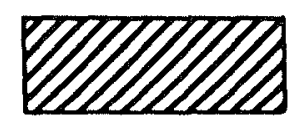

ENHANCING/SUPPORTING

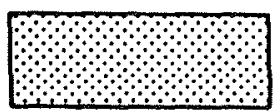

FIGURE 35 Technology matrix, commercial Supersonic Transport. 


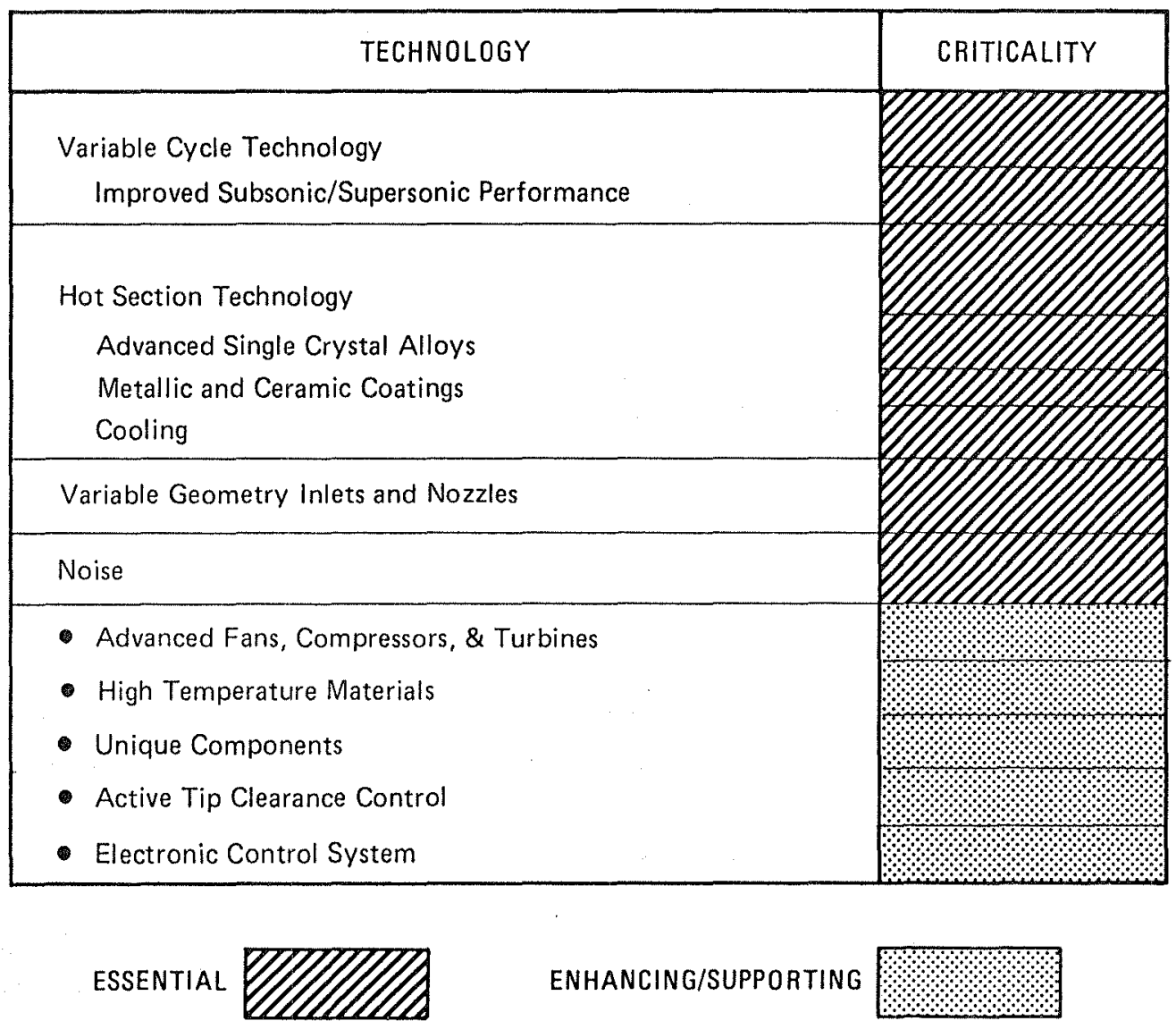

FIGURE 36 Technology matrix, Supersonic Transport propulsion systems.

TABLE 13 Performance Projections for Supersonic Transport

\begin{tabular}{|l|l|}
\hline Technology Factor & $\begin{array}{l}\text { Projected } \\
\text { Improvement } \\
\text { (Year 2000) }\end{array}$ \\
\hline Aerodynamic drag & $-30 \%$ to $-50 \%$ \\
Fuel consumption & $-5 \%$ to $-10 \%$ \\
Engine weight & $-15 \%$ to $-20 \%$ \\
Structura1 weight & $-15 \%$ \\
Landing gear weight & $-25 \%$ \\
Furnishings and equipment weight & $-15 \%$ \\
\hline
\end{tabular}


TABLE 14 Supersonic Cruise Aircraft Comparison

\begin{tabular}{|llllll|}
\hline & US SST & Concorde & $\begin{array}{l}\text { Research } \\
\text { Vehicle }\end{array}$ & Possible & Future \\
\hline $\begin{array}{c}\text { Year } \\
\text { Lift-to-drag } \\
\text { ratio }\end{array}$ & 1971 & 1976 & 1981 & 1984 & 2000 \\
$\begin{array}{c}\text { Passenger miles } \\
\text { per gallon } \\
\text { fuel }\end{array}$ & 8.5 & 7.3 & 9.3 & 10 & 17 \\
\hline
\end{tabular}

\section{ROTORCRAFT}

Desirable and Possible Characteristics

Current helicopters (Rotorcraft) have cruise speeds of 130 to 150 knots, empty to gross weight ratios of 0.5 to 0.6 , and payloads to 16 tons. They are restricted in speed by power levels, high vibration, and structural loads, and in range by lift-to-drag ratios of one-half or less than that of fixed wing aircraft. However, even with these restrictions, these machines are very useful because of their unique capability for vertical lift, hover and low-speed flight, and high maneuverability. They can operate from restricted sites and provide services other aircraft can not. This places great emphasis on reducing their noise signature for community acceptance in populated areas.

In this study, future Rotorcraft have been grouped as Next Generation Helicopters, Advanced High-Speed Rotorcraft, and Large Passenger Cargo Helicopters. Some general and desired characteristics apply to all of these categories: increased speed, greater lift, longer range, and fundamental improvements in reliability, vibration, noise, and safety as a means of increasing cost-effectiveness and user acceptance.

Next Generation Helicopters

Next Generation Helicopters are aircraft that could routinely operate at airspeeds of 180 to 225 knots by means of improved rotors, reduced drag, lighter structures, lower noise and vibration, and more efficient engines. Low vibration levels will provide a quiet, jet-smooth ride for passengers with improvement in reliability. From noise considerations, the machine will be acceptable to both the community and the crew and passengers. 
Extensive use of composite materials will reduce empty weight by 30 percent. Reduced fuel consumption because of the lighter weight structures and efficient rotors, low drag, and advanced engines will result in reduced aircraft size or increased useful loads for a given size. Operational dependability can be increased through reductions in downtime for maintenance, thereby increasing utilization. Remote site operations in extreme weather conditions, day and night, will be made possible by reliable flight control, guidance, and navigation systems. These systems will also increase safety of operation, provide precision hover, and reduce pilot workload.

Reduced drag and improved rotor performance at cruise are important prerequisites to the achievement of higher speed while holding engine power requirements at reasonable levels. Also important are increased maneuverability and control margins at high speeds. These will be possible through increased maximum rotor lift.

The compound helicopter, where auxiliary propulsion is provided through a horizontal thrusting engine and the rotor is unloaded by an auxiliary wing, has been studied and demonstrated. This type of machine offers one means of obtaining high cruise speeds for Rotorcraft. Unless impressive gains in rotor performance can be realized at high forward speeds, this may be the best means for attaining speeds as high as 200 to 300 knots.

A recent development in compound helicopters has been the coaxial (lift-offset) rotor system, demonstrated by the Advancing Blade Concept $(A B C)$ Compound demonstrator $\mathrm{XH}-59$.

Next Generation Helicopters offer opportunities for large passenger/ cargo vehicles. With technology development, these vehicles, by the year 2000 , will be able to handle payloads of 25 to 35 tons, or 150 to 225 passengers. Worldwide self-deployment and a 300-nautical-mile operating radius should be possible. Candidate configurations are the conventional shaft-driven, tandem rotor helicopter, the warm-cycle tip driven rotor, and tilting rotors. In addition, a multilift concept that involves the interconnection of two or more rotorcraft to share the load has potential for satisfying occasional very short distance, heavy-lift requirements.

\section{Advanced High Speed Rotorcraft}

For high-speed, longer-range missions, Advanced High Speed Rotorcraft will be provide lift for cruise by means other than a rotor propulsion system. The rotor may be tilted to provide cruise thrust with the lift provided by a wing; the rotor may be stopped and locked to form a stationary 1ifting surface (wing) with thrusting engines; or the rotor may be folded or folded and stowed with the vehicle relying on conventional wing and thrusting engines for high-speed flight. 
The desirable characteristics cited for the Next Generation Helicopter (i.e., low noise and vibration, good rotor performance, and reliability) apply here. Advanced High-Speed Rotorcraft, as do other aircraft, need reductions in structural component weight to increase payload-to-empty weight ratio for high performance.

Because rotorcraft tend to be complex, major emphasis must be directed to simplification and reliability. Each succeeding generation of rotorcraft has provided a threefold improvement in flight safety, and this trend must continue without significant cost penalties.

For the Advanced High-Speed Rotorcraft described here, speeds of 400 to 550 knots appear to be possible.

Tilt Rotor Vertical lift performance is primarily a function of the disk loading of the lifting system, which defines the power required to hover. The lift generated for a given horsepower is highest for rotors and becomes progessively lower for propellers, ducted fans, and turbofan/turbojet systems. From 1950 to 1970 , studies and tests of many types of high-speed configurations eliminated the higher diskloading concepts (propellers and fans) and led to a tilt rotor as the probable best compromise. Recent demonstration and testing of the Army/NASA XV-15 tilt-rotor research aircraft has proven the concept of the tilt rotor, a moderate disk-loading Rotorcraft. Other related concepts such as the stopped rotor and the folding tilt rotor require further research and development.

The first proposed production tilt-rotor Rotorcraft $(\mathrm{V}-22)$ will operate at speeds below 300 knots. The second-generation vehicle, in the 2000 era, should have speeds of 400 knots or better.

Folding Tilt Rotor Beyond the tilt rotor is the higher speed concept of the folding tilt rotor. Nearly identical in performance to the tilt rotor in hover and low-speed modes, it would feather the rotor after conversion to propeller-mode and fold the blades around the engine nacelle. Propulsive thrust is provided by a convertible engine, a combined shaft turbine, and a high-bypass-ratio fan engine that provides shaft power to drive the rotor and provides thrust for cruise flight.

Stopped Rotor The stopped-rotor Advanced High-Speed Rotorcraft is the $\mathrm{X}$-wing concept currently in research and technology development. The moderate disk-loading, four-bladed rotor functions as a helicopter rotor for hover and at low-speed. The rotor shaft is driven by a convertible fan engine and relies on circulation-control by blowing from both leading and trailing blade edges for lift and control. After acceleration to the conversion speed, the rotor is declutched, braked to a stop, and locked in position as an X-wing for high-speed flight. The convertible fan engine is the thrust engine. 
Single Stowed Rotor A fourth type of Advanced High-Speed Rotorcraft is the single stowed rotor configuration. The rotor is stopped in flight and stowed in a horizontal position at speeds above about 150 knots and a wing provides lift for cruise flight. The rotor propulsion system requirements are similar to those of the folding tilt rotor. Several promising concepts in this category have been investigated in wind-tunnel test programs.

Future military Rotrrcraft will be characterized as being highly maneuverable and having increased payload, speed, endurance, and range without significantly increasing the size of the aircraft. They will be designed to operate in close support of ground forces and engage in air-to-aur combat. Advanced weapon systems that are effective in adverse weather and low visibility will have to be integrated into the aircraft systems.

Technology Needs

Essential Technology

Figure 37 summarizes technology needs assessed to be important for Rotorcraft of the future. The essential technologies are those critical to providing the ability to design and develop the envisioned vehicle. The enhancing technologies are those that will significantly improve the designs, but are not crucial to their development.

Vibration Vibration has long been one of the barriers to a completely acceptable passenger environment in Rotorcraft. In the pursuit of high speed for helicopters, vibration is limiting. With rotors that operate in edgewise flight at or above 200 knots, vibratory forces grow precipitously and limit the speed achievable from both structural and human tolerance considerations. These limitations affect high-speed helicopters such as the $A B C$ and the speed achievable for conversion by convertible aircraft designs. Equally important are the reliability problems that arise because of vibration. A large portion of the unscheduled maintenance required on helicopters results from vibration.

External Noise Community acceptance of helicopter operations in urban areas is vital to the growth of helicopter transportation. Basic research and technology development in a number of areas to reduce external noise is required. An understanding of the sources of noise, its generation and transmission, is essential to permit the vehicle designer to accurately predict performance and external noise so that new Rotorcraft can be developed to meet future noise certification criteria. Today, performance is traded for noise reduction. Noise is also a problem for Advanced High-Speed Rotorcraft such as the X-wing and tilt rotor when in the helicopter mode for operation in terminal areas. 


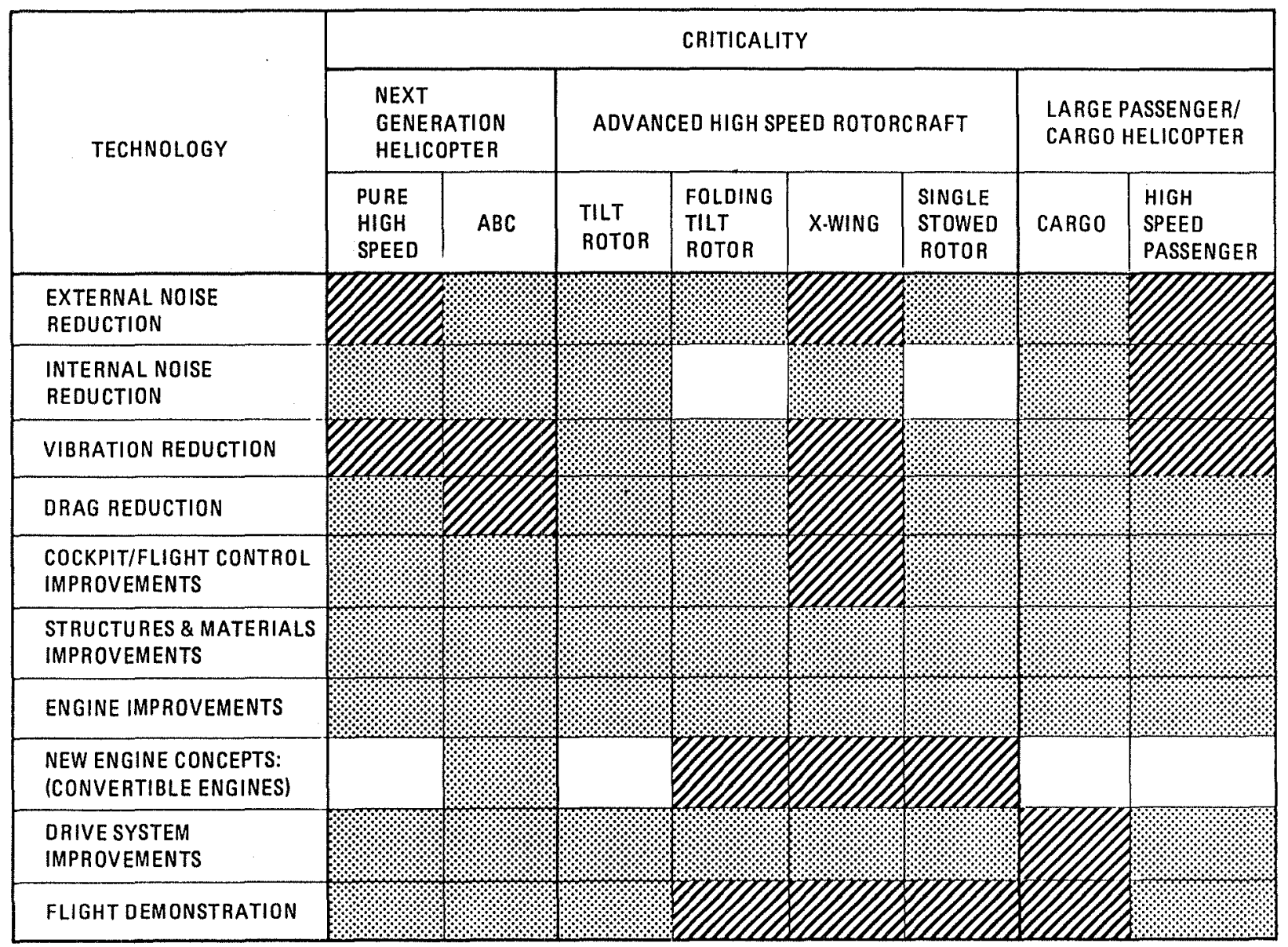

ESSENTIAL

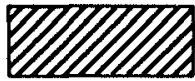

ENHANCING/SUPPORTING

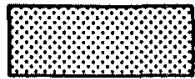

FIGURE 37 Technology matrix, Rotorcraft. 
Internal Noise To date, most interior noise reduction has been achieved through the application of acoustical treatment rather than noise reduction at the source (rotors, structures, and gearboxes). Although this approach can provide acceptable sound levels in small helicopters, the reduction of noise at the source becomes increasingly important as Rotorcraft get larger. In present practice, weight reductions achieved through new transmission technology have been offset due to the higher noise levels of the lighter transmissions. Substantial research is required to alleviate this problem.

Advanced Cockpits--Flight Controls For the X-wing, the development of a moment feedback flight control system for conversion operation and a higher harmonic control system to reduce vibration and noise in hover and flight through conversion is required.

For single-pilot nap-of-the-earth operations under night/all-weather conditions, the development of artificial intelligence concepts for integration into a highly automated advanced cockpit may be desirable. This will improve flight safety and mission effectiveness.

Propulsion Future engines for Rotorcraft will include advanced conventional turboshaft engines, turboshaft engines with such features as regeneration and/or ceramic hot-section components, and convertible engines to provide turboshaft power for vertical flight and turbofan thrust for high-speed forward flight. Advanced rotary and/or diesel intermittent combustion engines also should be available.

Al1 conventional engine components will show evolutionary improvements. Compressor and turbine efficiencies will be on the order of 85 percent and 90 percent, respectively. Turbine inlet temperatures will approach $3,000^{\circ} \mathrm{F}$. Nonmetallic materials will be in greater use. Components that are unconventional for Rotorcraft engines (e.g., regenerators, torque converters, and closable guide vanes) may begin to be used.

Figure 38 presents a summary of technology needs for Rotorcraft propulsion systems of the future. Three classes of Rotorcraft (Next Generation Helicopter, Advanced High-Speed Rotorcraft, Large Passenger/ Cargo Helicopter) will benefit from these kinds of advancements. None of the technologies are deemed to be essential for all of the Rotorcraft categories. Those considered essential for one or more of the vehicle classes are discussed here.

Convertible propulsion systems are essential for the single stowedrotor concept, the folding tilt rotor, and the $x$-wing. Convertible systems will eliminate the need for multiple engines by providing power for vertical flight as well as high-speed forward flight in one propulsion system. Another area essential to Advanced High-Speed Rotorcraft is the development of an integrated control system for the engine-geartrain-airframe. 


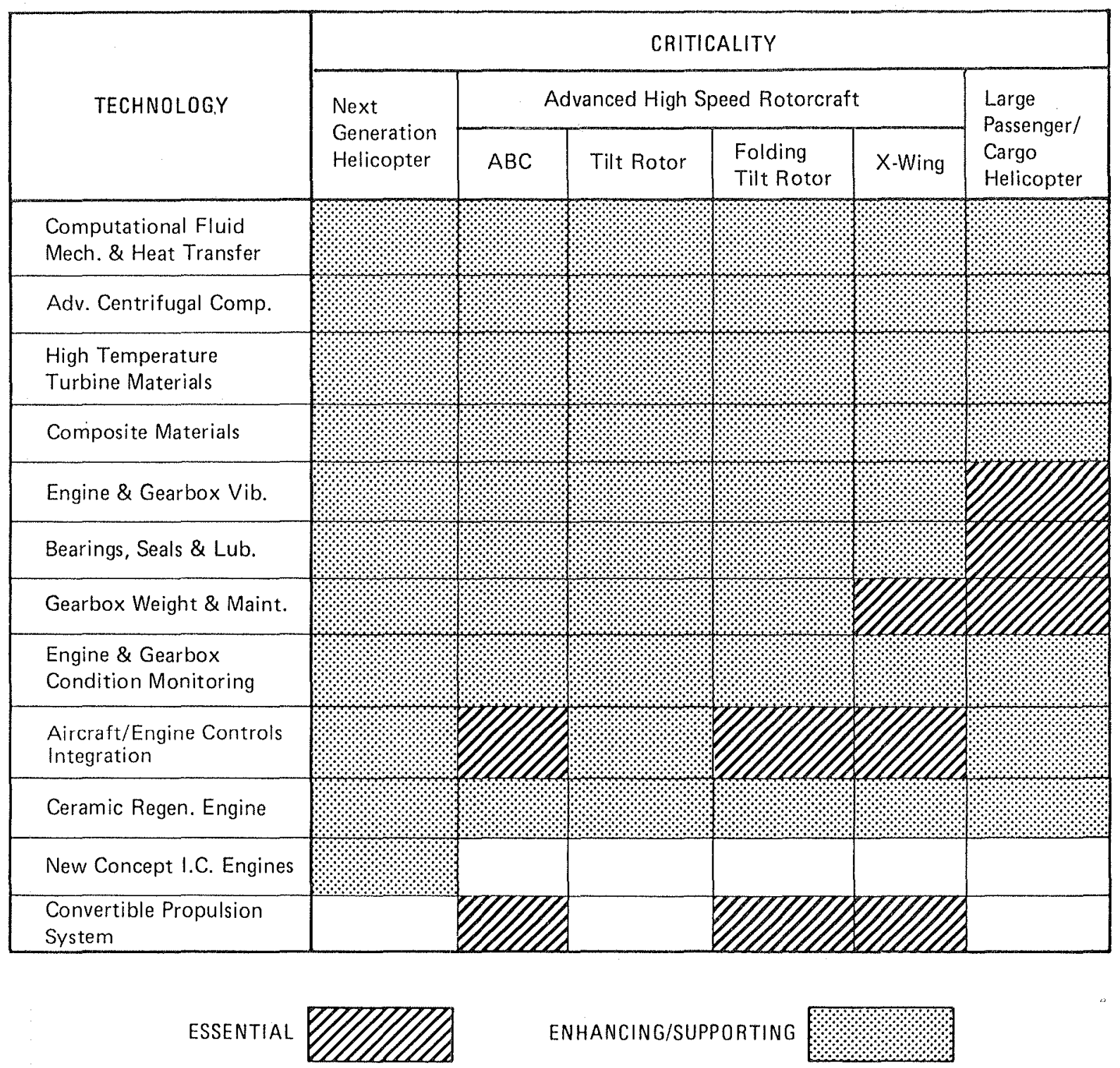

FIGURE 38 Technology matrix, Rotorcraft propulsion systems. 
For the Large Passenger/Cargo Helicopter, the essential technologies are those associated with gears, bearings, seals, and transmission lubrication. Improvements in these areas are required for increased reliability and reduced maintenance, weight, vibration, and noise.

For small Rotorcraft engines, the performance gains that will accrue from component research and technology activity will result in an improvement of about 15 percent in fuel burned compared with today's gas turbine engines.

Beyond the evolutionary process, there are opportunities for large gains with such engine systems as the regenerative/recuperative cycle, the variable capacity cycle, and the compound-cycle turbine diesel. The use of ceramic materials in the simple-cycle gas turbine engine can provide large improvements by permitting turbine inlet temperatures to $2,500^{\circ} \mathrm{F}$ without the use of cooling air. The compound-cycle turbine diesel engine is projected to have a specific fuel consumption of 0.3 with a potential for 0.26 , resulting in a 40 -percent improvement in overall fuel consumption.

\section{Enhancing/Supporting Technology}

Internal Noise Although the external noise of tilt-rotor configurations are acceptably low in cruise, the interior noise levels can be excessive because of the close proximity of the rotors to the fuselage. Considerable work has been done to quiet turboprop airplanes, and this research should be examined for application to the tilt-rotor configuration.

An improvement in ride quality will require internal noise reduction of dynamic components supported by a comprehensive investigation of dynamic system component noise generation and propagation.

The Industry/Government Noise Reduction Program, sponsored by NASA and the four major U.S. civil helicopter manufacturers, is directed at developing the technology for resolving the external noise problem, but the work should be extended to encompass internal noise.

Advanced Cockpit/Flight Controls Advanced cockpit/flight control system designs can increase future helicopter mission effectiveness for both civil and military applications. The ever-growing speed and capacıty of digital processing hardware including sensor fusion technology and development of fly-by-wire technology could provide flight control design advantages in such areas as: weight/volume, reliability and maintainability, survivability, and electronic interference susceptibility. Just as important, the new technology could enable performance of complex missions with improved handling qualities and reduced pilot workload. 
Digital computation allows the easy implementation of complex flight control laws, including integration of propulsion controls to accomplish a wide variety of mission tasks and automatic flight modes. Handling qualities can be easily tailored or automatically varied as a function of flight condition, and future designs could allow flight control modes to be selected by an interactive voice control system rather than hand switches and buttons. Cockpit controls will be simplified, pilot ingress-egress improved, and added comfort provided via sidearm controllers integrated in the fly-by-wire flight control system. Elimination of manual trim requirements in favor of an inherently self-trimmed force controller will lead to reduced pilot workload as well as reduced parts count, weight, and maintenance, and will provide higher reliability.

Aerodynamics The payoff in Rotorcraft fuel reduction of 30 to 40 percent from advanced aerodynamic technology are projected. Studies have shown that drag reduction (12 percent) will provide the largest saving. The areas of greatest potential for drag reduction are the rotor hub, landing gear, and airframe.

Structures and Materials Forty to sixty percent of the Next Generation Helicopter should be composed of composite materials. There is a need to minimize the risks involved in applying these materials to realize their true potential. They must remain serviceable in an environment that includes the broad variations in moisture, temperature, manufacturing techniques, maintenance handling, and weapon and other damage. Structural characteristics and design of extremely high-aspect-ratio, forward- and rear-swept lifting surfaces will need to be understood for the $X$-wing concept. The requirements placed on advanced composite materials will be extensive and demanding. The research necessary to meet these requirements will have to include nondestructive testing and inspection techniques.

Avionics Current aircraft (civil and military) require three levels of avionics maintenance: on the aircraft, at the base, and at the depot. Two- and three-level maintenance is costly in components, material, and manpower. Clearly, efforts to achieve functional partitioning of avionics into low-cost, high-reliability, line replaceable units that incorporate dependable fault isolation techniques are needed to reduce the high cost of aircraft avionics support. Large-scale integration is leading to increased reliability. The increased computational power of very large scale integration and very high speed, integrated circuit technology offers the opportunity for thorough self-check, fault isolation, and fault tolerance to be included in designs without detracting from the reliability of and,-in fact, minimizing the need for line replaceable units. These technologies need to be developed and applied to all aircraft avionics in concert with simplified software maintenance techniques. Application of these technologies and increased emphasis on processor-based artificial intelligence techniques will have the potential to reduce avionics 
maintenance costs while providing better performance and reliability for all classes of aircraft, not just Rotorcraft.

Drive System Drive-train improvements should greatly increase safety, reliability, and survivability along with providing lower specific weight, acquisition cost, and noise. Advanced technologies will improve element performance and reliability. Specific enhancing technologies include:

- Better understanding of dynamic stress in gears and bearings. A significant forward step has been finite element analysis of gear strength. This technology should be extended to other major elements of the drive system and could, in time, provide a model for an entire transmission considering deflections and thermal effects.

- Enhanced knowledge of in-service condition of transmissions through health monitoring of systems considering response to debris, vibration, temperature, and noise and giving prognostic as well as diagnostic information.

- The characterization of both metallic and nonmetallic materials in terms of fatigue threshold or the ability to maintain integrity in the presence of a flaw.

- Lubrication to provide higher temperature capability with improved load-carrying capacity.

- Development of super alloys and production of clean steels to improve the specific weight of the drive system, as well as increased survivability in the case of the loss of lubrication. - Development of hot-hard materials with improved fracture toughness.

Alternate transmission concepts need to be explored for improvements in weight and reliability. A quantum reduction in transmission weight would be very desirable. One concept that shows potential is the split-torque transmission. This design is projected to have a 25-percent improvement in the weight-to-power ratio over state-ofthe-art transmissions.

Airframe motion feedback into the hub results in a rotor-airframe dynamic coupling that influences hub loads and vibration characteristics. This needs to be understood and reduced.

Vibration Research is needed to find ways to suppress the growth of vibratory rotor loads with speed. The research directed to understanding the source of aerodynamic vibratory loads and the definition of means to passively relieve them will be of value. Higher harmonic control holds promise for suppressing these vibratory forces at high speed. Initial flight tests have proven the concept at low helicopter speeds. Wind tunnel work on high harmonic control concept for the $X$-wing, mechanized through management of control pneumodynamics, have taken place. Further studies are indicated before this issue is resolved. 
Current work in the aerodynamic sources of rotor vibratory loads holds promise for a deeper understanding of the process and eventually a solution. Math modeling of the very complex rotor vortex wakes is not yet a workable technology. Once the aero modeling capability is in hand, rotor dynamics could be tailored to attenuate major portions of the loads through aeroelastic design. Then active, higher harmonic rotor control, managed by an onboard microprocessor, could drive the residual vibration to a nearly complete null.

The airframe response and its interaction (feedback) into rotor loads is the final link in the helicopter vibration path. Improved modeling of the airframe and forced vibration analysis is being pursued with emphasis on coupled rotor-airframe analysis, airframe damping modeling, and airframe optimization for minimum forced response.

Vibration levels should be low in the cruise configuration for Advanced High-Speed Rotorcraft, such as the tilt rotor, folding tilt rotor, and stopped rotor. However, in the rotor operating mode, vibration problems are expected to be the same as those of the conventional Rotorcraft, with the exception that the exposure will be reduced. Rotorcraft vibration research will be applicable.

Convertible Engines Convertible engine development will require comparative studies and testing of variable guide vanes and variable pitch fans to develop the technology and optimum designs. The completion of current demonstration programs (TF34 and Astafan) will support control and feasibility analyses for applicable vehicles. Design criteria for clutches and load compressors should be derived from demonstration vehicle data and help identify component technology development needs.

Program Implications

Flight research will be required because adequate technology development for these complex systems cannot be provided through analysis, simulation, and ground tests only. For example, flight data is needed to accurately model rotor aerodynamics in all flight regimes. It is also essential in determining rotor transient conditions and interactions between rotor and fuselage, particularly under maneuvering conditions. Flight research also is required to understand completely the interactive complex flows and control problems in low-speed regimes and in transient maneuvers.

Likewise, there is a need for a full-scale technology demonstrator to provide the technology data base for design of radical new concepts in a timely manner. Efforts on integrating and blending technologies into systems, in many instances will produce significantly greater gains than focused, individual component work. Such work is assessed to lower the cost and accelerate the application of advanced technology to new civil and military vehicles. 
Small performance improvements will continue to accrue from improvements in turbine engine components. The achievement of major engine improvements, however, will come from the careful design of complete propulsion systems that combine and synergistically integrate new cycle technology and advanced components.

Summary

Rotorcraft cover a broad range of aircraft that are of interest to both civil and military users. In general, higher performance, including speed, and reductions in noise and vibration are the key future design drivers. For the Next Generation Helicopters, new technology can provide vehicles with higher productivity, larger payload-to-weight ratios, larger payloads, longer range, better ride characteristics, and lower noise generation than current helicopters. The new vehicles will also have all-weather flight and precision hover capability with low pilot workloads.

The Advanced High-Speed Rotorcraft of the future will provide speed, range, and endurance capabilities beyond those of conventional or compound helicopters. The unique features of these aircraft (e.g., tilt, stopped, folding, and stowed rotors) will enable them to operate in forward flight like conventional subsonic aircraft and still retain efficient vertical takeoff and landing capability.

Future core engines for Rotorcraft are essentially the same as for Commuter Aircraft. Thus, turbine, rotary, and diesel engines all should be considered. Because high speed is the objective of the Advanced High-Speed Rotorcraft, the use of cruise engines thrusting horizontally rather than pitching the Rotorcraft to achieve forward flight is considered essential for all concepts. Hence, a convertible engine capable of decoupling from the rotor during cruise is very attractive.

If the possible improvements in key technology areas by the year 2000 can be realized, their application to advanced vehicles could provide the increased capabilities noted in Table 15 and the projected performance gains noted in Table 16.

In summary, these advances could be realized through these technology development activities:

- Vibration reduction for jet smooth ride and improved reliability.

- Noise source research for reduced noise levels.

- Automated cockpits with integrated flight controls for reduced pilot work load and improved performance.

- Composite stru'ctures for reduced weight and cost.

- Drive systems utilizing advanced materials for improved reliability.

- Convertible engines capable of efficient shaft and thrust power for improved performance and speed. 
TABLE 15 Performance Projections for Rotorcraft

\begin{tabular}{|ll|}
\hline & $\begin{array}{l}\text { Projected } \\
\text { Improvement } \\
\text { (Year 2000) }\end{array}$ \\
\hline Aechnology Factor & $-12 \%$ \\
Fuel efficiency & $+35 \%$ to $40 \%$ \\
Weight fraction reduction & $-30 \%$ \\
Noise level & $-5 \mathrm{EPNdB}$ \\
Vibration level & $-30 \%$ \\
Operating cost & $-50 \%$ \\
\hline
\end{tabular}

TABLE 16 Projected Performance Gains, Future Advanced Rotorcraft

Next Generation Helicopter

- 100 percent productivity

-- up to 225-250 knot speeds

-- 35 to 40 percent range increase or mission fuel reduction

- 30 percent weight fraction

- Lower external and internal noise, community acceptance, passenger and crew acceptance

- All-weather, zero-zero visibility operations

- "Jet smooth" vibration level

-- Passenger and crew comfort

- Elimination of vibrationrelated failure

-- Longer component life

- Improved safety

-- Lower pilot workload

-- Fail-safe structure

- Reduced operating cost (50 percent)
High-Speed Rotorcraft

- 100 percent to 200 percent speed and range increases (relative to conventional helicopters)

- 400-550 knot speeds

-- 600-1000 mile radius

-- Reasonable hover and low-speed performance

Large Helicopter

- 100 percent greater payload

- 5-fold increase in number of passengers 
Desirable and Possible Characteristics

By the year 2000, new lightweight propulsion and structural concepts will evolve to make possible the design and operation of very lightweight unmanned aircraft that could, in some cases, provide limited alternatives to satellites. Such vehicles flying at high altitudes could be positioned over selected positions on earth for long periods of time and would offer the capability for reuse and periodic payload change.

Manned aircraft such as the $T R-1$ and $U-2$ can provide a number of hours of continuous high altitude operation, and unmanned prototype vehicles have been built with similar capabilities. Satellites perform high-altitude earth surveillance, but the flexibility and resolution provided by their sensors are less than can be offered by aircraft.

The new lightweight vehicles will be able to sustain flight at altitudes of 60,000 to $100,000+$ feet at speeds of 300 knots or less. For military use, altitudes of 100,000 feet or greater will significantly enhance the survivability of these vehicles. However, altitude alone is insufficient to reduce detectability and guarantee survivability. The use of decoys and countermeasures and an ability to maneuver are highly desirable to provide a reasonable assurance of survivability of such military aircraft.

The aircraft will have sufficient airspeed to overcome high altitude winds and maintain a ground speed of 30 knots or greater. Endurance could range from days with chemical fuels to months with microwave-, solar-, or nuclear-powered propulsion systems. Launch and recovery modes for high-altitude aircraft are not clearly established at the present time. However, it is envisioned that takeoff and landing would be from conventional airfields.

Technology Needs

Essential Technology

There are two essential technologies that require considerable development in order for such vehicles to come to fruition: 1ongendurance and lightweight propulsive and energy storage systems and ultra-lightweight structures.

Propulsion The solar aircraft must have totally regenerative fuel cells; the combustible-fuel engine system must be very lightweight and highly efficient. All configurations must have an integrated system for storing, managing, utilizing, and/or acquiring their energy. 
Internal combustion engines, either turbine or highly supercharged intermittent combustion engines driving propellers, will power vehicles for the shorter flight durations: 3 or 4 days on station. Longer endurance aircraft will probably be powered by electric motors driving propellers. Although thrust requirements are generally small, the propellers must operate in a low density atmosphere requiring either high-rotational speeds or large diameters. Reynolds numbers at these altitudes will be very low. To design the propellers to operate relatively efficiently at cruise altitude may require them to operate inefficiently at off-design conditions, i.e., takeoff and climb.

Electric motors driving propellers and powered by solar, beamed microwave, or possibly nuclear energy appear to be the most practical way to obtain flight endurance greater than a few days.

A beamed microwave power receiver can be incorporated into the wing provided reasonable conversion efficiencies can be obtained. However, the power at the transmitting site will be many times the power required by the aircraft, and more than one transmitting station will be required if the aircraft is to move between separated points.

Solar electric systems have two major limitations when compared with the microwave system: the need to rely on seasonally varying radiation matched to sun and solar arrays and the need for high efficiency energy-storage. Reliable radioisotope generators have been developed for spacecraft. However, they have serious drawbacks. They are relatively heavy and inefficient, have low-power density, have poor cooling at altitude, and may be unacceptable from safety considerations.

Energy Storage Current battery technology is unsatisfactory for these applications. The technology for nonrechargeable high-energy-density batteries is emerging, and several different types of secondary storage batteries, such as nickel-iron, lithium-molysulfide, lead-acid, and aluminum-air batteries, could possibly be used in conjunction with other energy generating systems. Lithium batteries appear promising and experimental models have demonstrated high-energy densities. Fuel cell systems are generally lighter than batteries and are favored for long duration discharges. Fuel cells using hydrogen and oxygen are possible primary power sources, and regenerative fuel cell systems need to be explored.

Ultra-Lightweight Structure Aircraft operation at high altitude demands large area, high-aspect-ratio wings, with wing loadings typically varying from some 6 pounds per square foot (psf) for gliders, to 1 psf for man-powered flight concepts. These structural concepts can vary from conventional spar-stringer to truss, thin-skin construction. Candidate structural concepts include Nomex honeycomb core with metallic or nonmetallic facings, foam-core composites with an epoxy-bonded skin of Kevlar/graphite, or various graphite/epoxy combinations. Thermoplastics could be used in many understructure 
applications, especially in highly countoured parts where layered composites would be difficult to apply.

Enhancing/Supporting Technology

Enhancing/supporting technologies that would provide a superior vehicle are: low-Reynolds-number high lift to drag ratio airfoils for wings and propellers; a highly integrated flight control, guidance, and payload avionics system; highly reliable sensors and actuators; launch and recovery techniques; techniques for heat rejection at high altitude; very large, lightweight structural designs that provide acceptable flutter characteristics; and flutter suppression techniques. Further discussion is warranted regarding certain of these technologies.

This class of high-altitude operation is predicated on the ability to design an aircraft that can operate at low-dynamic pressures (on the order of 1- to 4-pounds psf). What is needed is low wing loading, low power loading, and high aerodynamic efficiency. Because low-speed, high-altitude aircraft will operate at very low Reynolds numbers, airfoil selection will require special attention, but there is promise here. Airfoils having lift-to-drag ratios exceeding 50 or 60 have been demonstrated for Reynolds numbers associated with high altitude flight, 1 million or less.

Aircraft conforming to these requirements generally resemble very high aspect ratio winged motor gliders or ultra-light aircraft. Lighter-than-air vehicles may be usable. They will tend to have very large, pressurized, voluminous hulls that have low aerodynamic drag. Airship contours with significant laminar flow may be essential.

It is anticipated that these aircraft will be unmanned to minimize weight and complexity. The minimum mission payload is expected to be approximately 200 pounds; however, payload requirements are mission dependent and the requirement could be considerably greater. For long-endurance missions, the aircraft must be equipped with advanced, autonomous avionics for guldance, control, and navigation. The system would be designed to accept updated information for these mission control functions. Most of the time, the aircraft will be under the control of its programmed autopilot and supervised by an attendant at a remote control center. An all-electric, high reliability flight control system will be used. The lightweight design of these vehicles may require the use of unconventional control techniques such as wing warping and segmented ailerons or upper-surface spoilers to avoid hinge jamming due to wing bending. These control configurations could complicate the aeroelastic flutter characteristics of these very large and lightweight aircraft structures. 
Program Implications

Technology integration is important. Current efforts to develop a totally regenerative fuel-cell system should account for the full spectrum of operating conditions of these vehicles (i.e., atmospheric instead of space application). Combustible-fuel engines need to be developed for the high-altitude environment. This work can focus on special fuels and lubricating systems; exotic regenerative cycles matched to ambient conditions; and ultra-lightweight, low-friction supercharging. A ground-based, bread-board assembly for electric systems, exclusive of energy acquisition arrays, should be developed to achieve high levels of efficiency and autonomy; also, a large-scale, phased-array microwave transmitter should be built and operated with a target vehicle.

Ultra-lightweight structures are essential for solar-powered vehicles. Materials and structures used in the Solar Challenger could be evaluated for high-altitude, long-endurance flight. Proposed structures should be evaluated by subjecting segments of high-aspect-ratio wings and fuselages to static and fatigue loads in laboratories.

A bread-board control system combined with a computer can be used to develop flight management software. Sensors loaded by laboratory equipment can add the requisite realism to the simulation of flightcontrol, guidance, payload, and other systems. Laboratory tests of sensors and actuators could establish the reliability of integrated systems. These tests could explore the dynamics of fatigue-related failure modes.

Computational simulations can help in the development of launch and recovery techniques of aircraft with very low wing loading. Small-scale tests can verify procedures associated with initial (self-energized) flight segments for solar and microwave aircraft, the inflation and launch for ultra-light blimps, and vehicle dynamics due to light overall weight but with concentrated loads (payloads, fuel cells, and propulsion units).

The problem of heat rejection at altitude for combustible-fuel engines must be resolved and the solution tested. Wind-tunnel tests at low air density will be needed to verify analytic modeling.

Regarding aeroelasticity, wind-tunnel tests of specific configurations can be combined with analyses to validate flutter alleviation methodology at low wing loading and high aspect ratio. Active controls may be essential for transitional flight through low altitudes.

Finally, a flight-test program should be conducted utilizing limited-endurance research aircraft. Potential conflicts between systems requirements can be resolved without risking all of the final systems hardware. For example, the flight management system may have to address significantly different concerns at low altitudes and at high altitudes due to different levels of turbulence and propeller efficiency. 
Summary

The Extremely High Altitude Aircraft that will be possible with projected propulsion, aerodynamic, and structures technology advances represents a new, unique class of aircraft for civil and military use. They will be capable of flying at extremely high altitude, at low speed, and for long duration. Although the concepts are heavierthan-air aircraft, 1ighter-than-air designs are also possible. These aircraft could function as alternatives to satellites, provide reconnaissance and intelligence data, collect atmospheric samples, and support search and rescue missions.

The technology matrix shown in Figure 39 presents the essential and the enhancing/supporting technology areas for the Extremely High Altitude Aircraft. These aircraft could depend on revolutionary propulsion concepts (such as solar and microwave power) and ultralight structures. Figure 40 presents the essential and enhancing technologies for the candidate propulsion systems. Aircraft sizing for several power systems is summarized in Figure 41. Possible improvements by the year 2000 in major parameters, providing adequate resources will be available, are noted in Table 17.

\begin{tabular}{|c|c|c|c|c|}
\hline \multirow{2}{*}{ TECHNOLOGY } & \multicolumn{4}{|c|}{ CRITICALITY } \\
\hline & $\begin{array}{l}\text { SOLAR } \\
\text { AIRPLANE }\end{array}$ & $\begin{array}{l}\text { MICROWAVE } \\
\text { AIRPLANE }\end{array}$ & $\begin{array}{l}\text { COMBUSTIBLE } \\
\text { FUEL AIRPLANE }\end{array}$ & BLIMP \\
\hline ENERGY STORAGE & Q & & & \\
\hline ENERGY SYSTEM INTEGRATION & 10 & OUIIIII & OUIIIII & 8 \\
\hline ULTRA LIGHTWEIGHT STRUCTURES & & & & \\
\hline LOW-RN AIRFOILS & & & & \\
\hline AUTONOMOUS FLIGHT MANAGEMENT & & & & \\
\hline SYSTEMS RELIABILITY & & & & \\
\hline LAUNCH/RECOVERY TECHNIQUES & & & & \\
\hline HEAT REJECTION AT ALTITUDE & & & & \\
\hline AEROELASTICITY & & & & \\
\hline
\end{tabular}

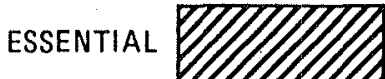

ENHANCING/SUPPORTING

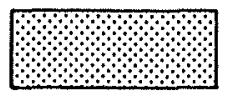

FIGURE 39 Technology matrix, Extremely High Altitude Aircraft. 


\begin{tabular}{|c|c|}
\hline TECHNOLOGY & CRITICALITY \\
\hline \multicolumn{2}{|l|}{ COMBUSTION SYSTEMS } \\
\hline \multicolumn{2}{|l|}{ Cycles with High $\eta$ at Altitude } \\
\hline \multicolumn{2}{|l|}{ High PR Turbochargers with Intercoolers for IC Engines } \\
\hline \multicolumn{2}{|l|}{ Advanced Thermal Barrier Coatings } \\
\hline \multicolumn{2}{|l|}{ Propellers with High $\eta$ at Low Reynolds No. } \\
\hline \multicolumn{2}{|l|}{ Composite Materials } \\
\hline \multicolumn{2}{|l|}{$\begin{array}{r}\text { Advanced Electronics - Manned } \\
\text { Unmanned }\end{array}$} \\
\hline \multicolumn{2}{|l|}{ Heat Exchangers } \\
\hline \multicolumn{2}{|l|}{ NON-COMBUSTION SYSTEMS } \\
\hline \multicolumn{2}{|l|}{ Very High $\eta$ Energy Storage Capability } \\
\hline \multicolumn{2}{|l|}{ Lightweight Gearboxes } \\
\hline Lightweight, Efficient Solar Collectors & \\
\hline
\end{tabular}

ESSENTIAL

ENHANCING/SUPPORTING

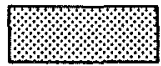

FIGURE 40 Technology matrix, Extremely High Altitude Aircraft propulsion systems.

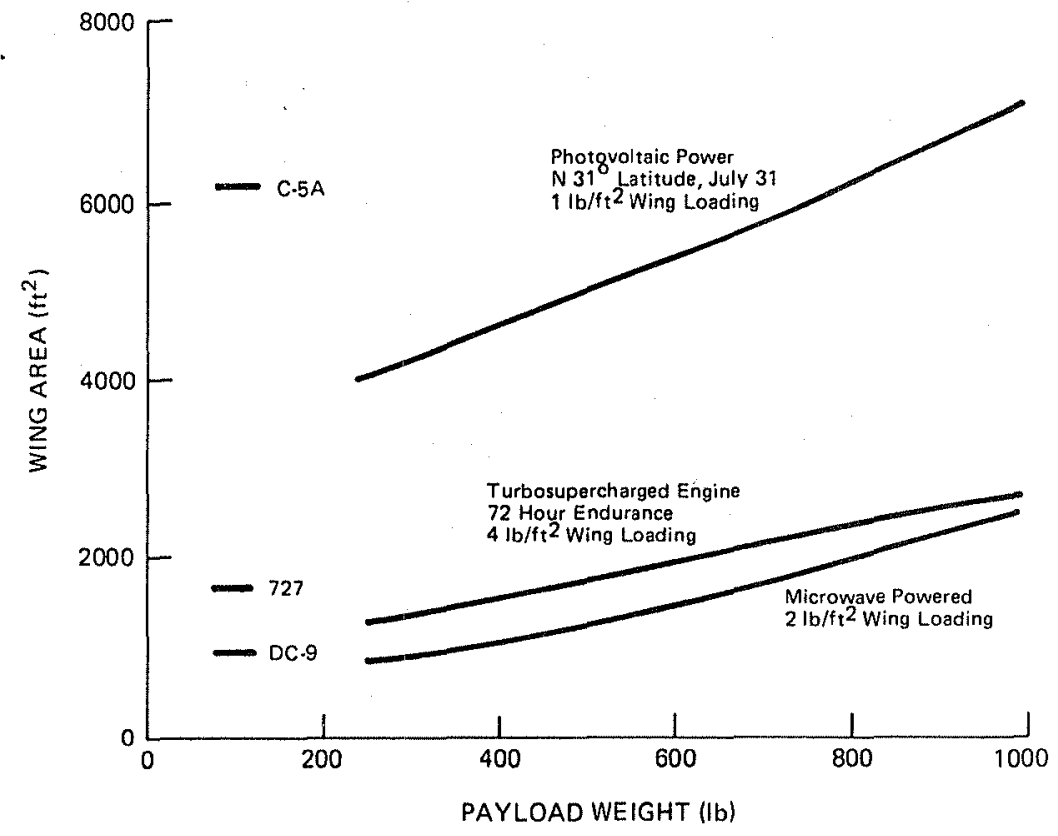

Source: NASA Langley Research Center

FIGURE 41 Aircraft sizing for various power systems for operation at 60,000 feet. 
TABLE 17 Performance Projections for Extremely

High Altitude Aircraft

\begin{tabular}{|ll}
\hline Technology Factor & $\begin{array}{l}\text { Projected } \\
\text { Improvement } \\
\text { (Year 2000) }\end{array}$ \\
\hline Regenerative fuel cells (Long & Attainment at $10 \mathrm{w} / 1 \mathrm{~b}$ and \\
endurance, high cycle count) & $200 \mathrm{~W}-\mathrm{hr} / 1 \mathrm{~b}$ \\
Total microwave system & Attainment \\
operation & $20 \%$ internal combustion \\
Engine SFC at altitude & engine, $30 \%$ gas turbine \\
Structural weight efficiency & $200 \%$ \\
Flight hour between inspection & $10,000 \%$
\end{tabular}

\section{TRANSATMOSPHERIC VEHICLE}

Desirable and Possible Characteristics

There is no current equivalent to the Transatmospheric Aircraft (TAA)/Aerospace Vehicle. The projected TAA is best described as a space-capable aircraft able to operate in earth orbit as a spacecraft or as an airplane in the earth's atmosphere-an aerospace vehicle. It could serve both civil and military interests. The Space Shuttle is a technology precursor, but its operational flexibility and maneuverability is far short of that of a potential TAA. TAA concepts range from Space Shuttle-like configurations to high lift-to-drag ratio configurations that could act as boost stages or as an advanced orbiter aircraft.

This aircraft class could include a number of possible aircraft systems. The distinguishing characteristics of such aircraft are that they could operate in the lower edge of space, reach velocities high enough to allow coasting flight over global distances, and operate from and to bases on Earth. Figures 42 and 43 illustrate two potential concepts for such a vehicle.

A desired characteristic of the TAA that distinguishes it from the Space Shuttle transportation system is on-demand launch capability. Accomplishing a mission within a period of hours rather than weeks is desired for normal operations, and operation from an alert or standby status may be desired for missions that need to be initiated within minutes of a decision. The desire for rapid response leads to a requirement for launch in adverse weather. 


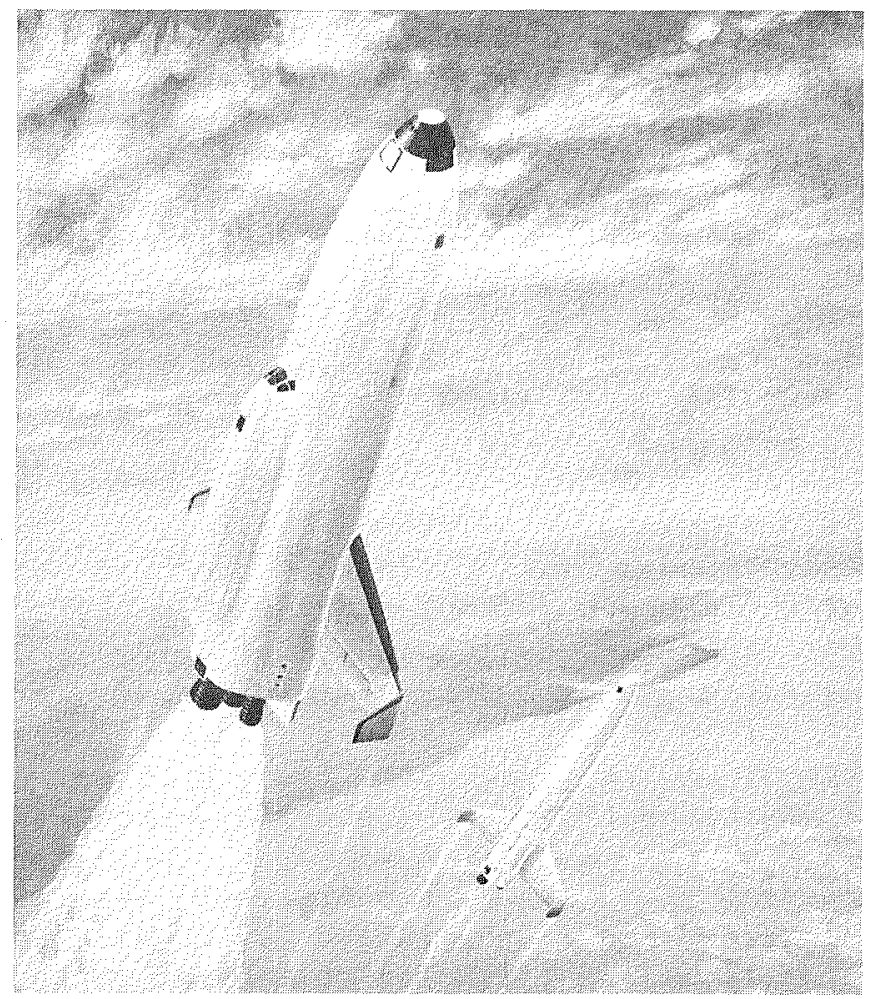

FIGURE 42 TAA/Aerospace Vehicle, vertical-takeoff concept.

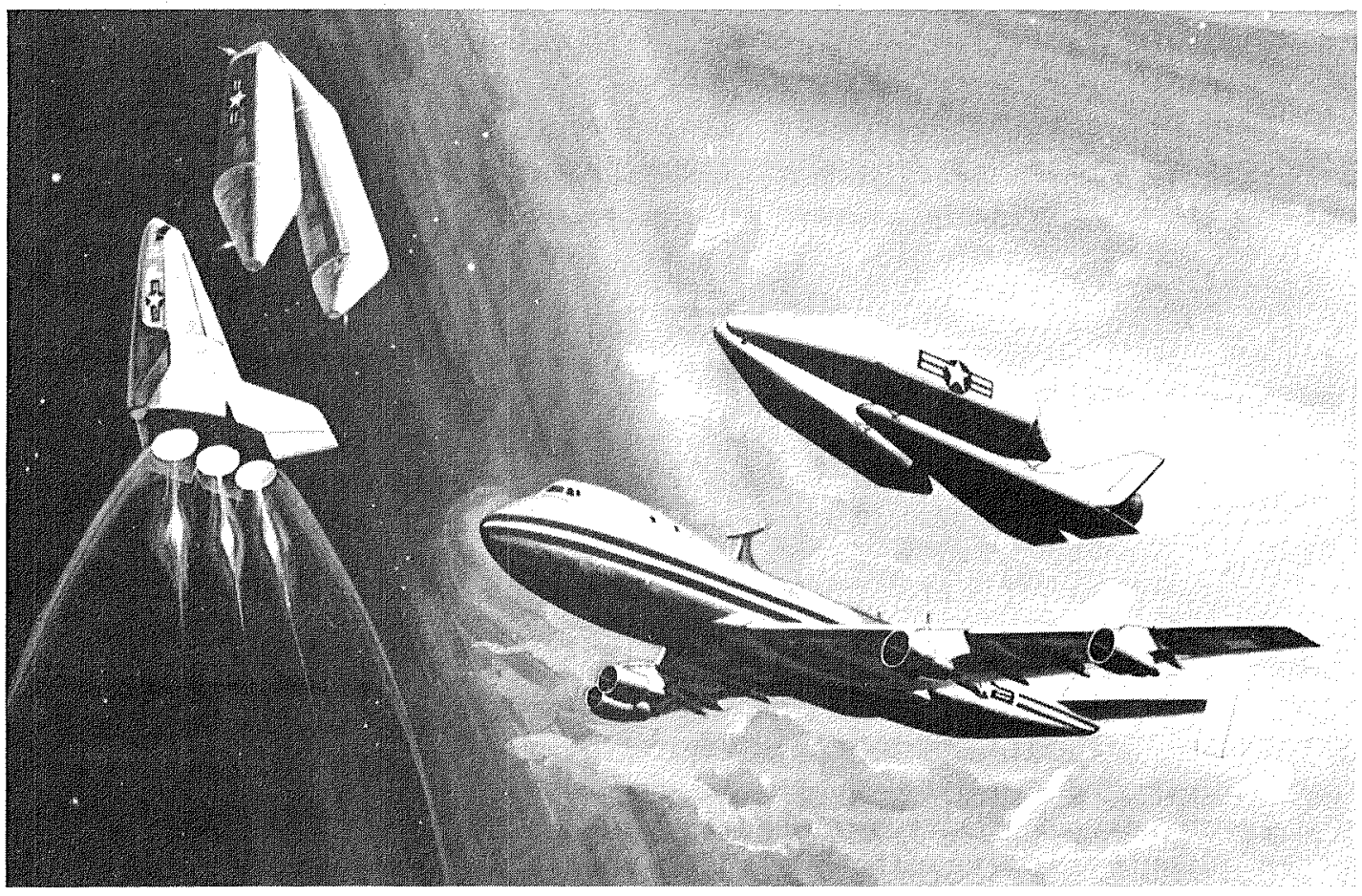

FIGURE 43 TAA/Aerospace Vehicle, air-launched concept. 
The on-demand (quick response) operation means that the aircraft does not require refurbishment between flights. Advances in avionics, software, and data management and presentation should make it possible for a crew of two to operate this class of aircraft for civil or military applications.

A second desired characteristic is an ability to reach a wide range of orbital conditions--for example, rendezvous with existing spacecraft in various orbits. The desire for both a wide range of orbital conditions and rapid response leads to the requirement for offset launch capability. Offset launch involves flying toward an orbital plane before launching into it.

For some missions, maneuverability on orbit is desired, which requires propulsive input. This could come from leaving orbit, turning with the help of the atmosphere, and returning to orbit. In other cases, a maneuver capability during ascent or entry is desired. To help the vehicle achieve some orbits rapidly, an offset cruise capability during ascent is desired. Maneuvers during entry allow return from a wide range of orbits to selected landing sites, and require careful control of the heating during entry and manuevering.

Another desired characteristic is operational flexibility. Several aspects are of interest, including inland launch sites, launch from sites with minimal facilities, landing at many airports, rapid ferry, recall after launch, and movement of vehicles from a location in danger to a safe location for a later launch.

Characteristics desired from economic considerations are reasonable development and life-cycle costs and low technological risk.

This new class of aircraft is projected to have lower operating costs than those associated with the present Shuttle. Airbreathing propulsion systems, from Hypersonic Aircraft, would reduce oxidizer requirements dramatically. Short turnaround times, and operational flexibility would make this advanced aerospace vehicle a much more effective vehicle than the Shuttle, and reuse without substantive refurbishment would mean conventional aircraft-like operations with service crews.

If the TAA is a multistage vehicle, the in-flight system weight and stringent requirements on the structural weight fraction can be reduced. Launch complexity, however, could be expected to increase.

\section{Technology Needs}

Essential Technology

The areas of technology that are essential to the development of a transatmospheric aircraft include airbreathing propulsion, materials, and controls, including computer-assisted operations. Vehicles incorporating all the desirable features are theoretically possible, 
but the technology base is insufficient to say that design commitments could be made by the year 2000 with high confidence. Vehicles with some of the key features, but not all, could be developed earlier if the technology base development is vigorously pursued.

Propulsion Only rocket propulsion systems are currently suitable for the TAA. The TAA represents a new class of aeronautical system. An initial rocket-powered TAA could be essentially a rocket-powered Hypersonic Aircraft. Operation within the atmosphere, if desired, would be based on airbreathing propulsion systems developed for Hypersonic Aircraft.

Airbreathing Transatmospheric Aircraft would utilize multicycle propulsion systems for various flight regimes. Cycles such as the air turbo ramjet/rocket, hydrogen expansion engine/cryojet, injector $\mathrm{ram} / \mathrm{scramjet}$, and rocket/scramjets are candidates.

Among proposed systems for the future are concepts with one- or two-stages to orbit. For the first stage of two-stage systems, the combined cycle air-breathing propulsion system concepts, discussed in the section on Hypersonic Aircraft, in combination with rocket propulsion are applicable. The ultimate propulsion systems for TAA would allow operation from earth-to-orbit with a single stage and sustained operation in the earth's atmosphere after reentry.

For single-stage-to-orbit vehicles, propulsion performance levels are more critical than those for staged vehicles. The structural mass fraction and the allowable payload is strongly dependent on propulsion system performance and the propellent fraction.

Aerodynamics/structures If one of the functions of a TAA is to perform sustained cruise within the earth's atmosphere, cryogenic fuel-cooled structures are required to handle the thermal loads. In any case, lightweight structures and materials, including thermal protection systems, are essential. Cooled structures, ceramic composites, and carbon-carbon materials will be used in addition to cryogenic fuel cooling. A hypersonic lift-to-drag ratio of 3 or more is necessary to have rapid recall from any orbit and to land in the United States. Also the capability to integrate the airframe and propulsion system into a high lift, high thrust, low drag controllable system constitutes a major challenge.

Research and technology developments described for Hypersonic Aircraft could also provide the data base to design hot primary structures with sufficient durability and thermal protection. This could be expected to replace, to some degree, the "cool" structural concepts (external radiation panels, insulation, and phase change materials) in use today. 
Most of the more attractive vehicle concepts require integral cryogenic tanks. The tank system will be not only the containment tank, but also a thermal system.

The weight of both tank and nontank structures can be reduced by technology improvements, and these reductions are extremely important for these vehicles. Both structural concepts and materials improvements should be pursued. For tanks, metal-matrix composite materials offer the possibility of significant weight savings. For nontank structures, "warm" composite materials or "hot" structures may be the lightest weight solution.

Engine weight should also be reduced wherever possible. Engines are often located near the aft end of the vehicle and cause the center of gravity to be so far aft that the design is compromised, so engine weight reductions have more benefit than other reductions of equal magnitude.

Controls and Integrated Avionics The design limitations and maneuver requirements of these vehicles will require that they have automated guidance and control. This capability will enhance vehicle performance in that load alleviation can be designed into the system to reduce structural loads while providing the ability to fly optimal trajectories.

The crew and the vehicle hardware interface will be integrated to place the crew in a decision mode rather than in a control mode. Most mission and control functions will be automated with special attention to combined control of airframe and propulsion systems. It will be possible to employ fault-tolerant and fault-fixing systems to maximize mission success.

The on-demand launch requirements will require that many vehicle systems be monitored automatically and will be automated to take corrective action in the event an incipient failure is detected. This capability will minimize manual checks and reports that reduce turnaround time and increase operating costs.

Computational technology development, similar to that for Hypersonic Aircraft will be required, such as computer-assisted piloting, sensor data integration, automated pilot/crew stations, fully integrated systems with programmable processors, and software development/ maintenance/change capability. However, these systems will be required to handle a broader range of conditions those for Hypersonic Aircraft.

Enhancing/Supporting Technology

Durable Thermal Protection The Transatmospheric Aircraft must be protected from heating beyond the capability of the surface structure. The thermal protection system of the Shuttle may not be acceptable for TAAs because it can be expected that they will have sharper leading 
edges to improve aerodynamic performance. Also, a more durable system would be required to reduce refurbishment time and operating costs. Heat pipes could be used on leading edges, and metallic tiles filled with fibrous insulation could be used on much of the other surfaces. Hot structures could reduce the weight of airframe elements such as control surfaces.

Aerothermodynamic Prediction Techniques The inherent capability of a design will depend on how well the aerothemodynamics can be predicted. Prediction of boundary-layer transition, surface catalitic effects, and interactions of surface or jet controls should be improved. Improvements in computational techniques and test facilities and methods should be pursued.

Design Integration Improvements in the design process, such as computer-alded design and manufacturing, have the potential of improving the vehicle design by allowing a more nearly optimum approach of design and cost objectives.

Program Implications

The technology development program for Transatmospheric Aircraft will build-on the technology developments described for Hypersonic Aircraft, but TAA technology also could be developed independently if the Hypersonic Aircraft technology was not pursued. The technical areas of interest are essentially the same but TAAs will need to fly faster, exit the atmosphere, and return from earth orbital flight. A program to develop integral fuel tank technology will be needed and should include materials tests and subscale tank construction, including insulation and thermal cycling. The key program in the long run to improve performance is to develop air-breathing propulsion to at least Mach 12 for a first stage system and/or support single stage to orbit concepts. Rocket engine development programs should include modification of the Space Shuttle main engine to increase life and should include development of hydrocarbon engine technology. An entry research vehicle flight experiment, deployed from the payload bay of the Shuttle, would provide a method for developing important technologies such as aerothermodynamics, flight control, and thermal protection systems.

An incremental approach would be appropriate for the long-term development of the technology base for Transatmospheric Aircraft.

The system controls work and other activity to hold costs down, discussed in the hypeHsonic Aircraft program, applies here as well. In summary, the technology areas common to the two programs are:

- Practical airbreathing propulsion systems.

- Integrated airframe-propulsion systems.

- Thermally protected cool primary structures. 
- "Intuitive" pilot-crew station/sensor data fusion.

- Logistics/supply of cryogenic fuels.

- Cryogenic reaction control/orbital maneuver systems.

- All electric force devices and activation systems.

- Al1-up system (airframe, propulsion, controls) integration.

Summary

The major areas of technology development considered essential for TAA are identified in Figure 44. Representative TAA would build on the hypersonic vehicle technology, but extended to allow achievement of orbital operation. Key features are on-demand launch, earth return with airplane-1ike turnaround, and good atmospheric maneuverability. These capabilities will be realized through the application of advanced technology in the areas of propulsion, aerodynamics, flight control, integrated avionics, and materials and structures.

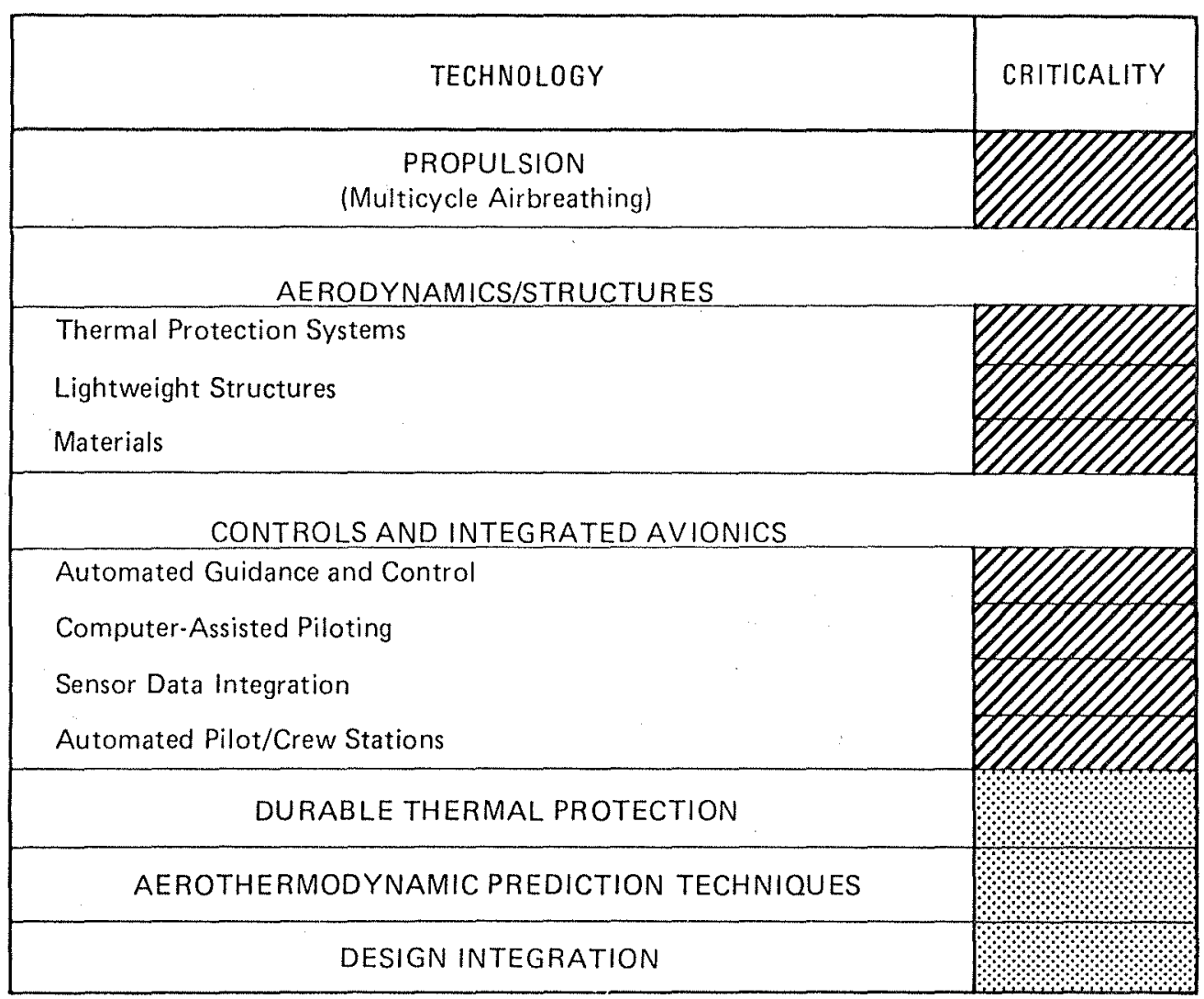

ESSENTIAL

ENHANCING/SUPPORTING

FIGURE 44 Technology matrix, Transatmospheric Aircraft. 
The essential and enhancing technologies for the TAA propulsion system are shown in Figure 45.

If the technology developments addressed here are pursued, performance improvements, shown as a percentage of capability available today in Table 18, are projected as being achievable.

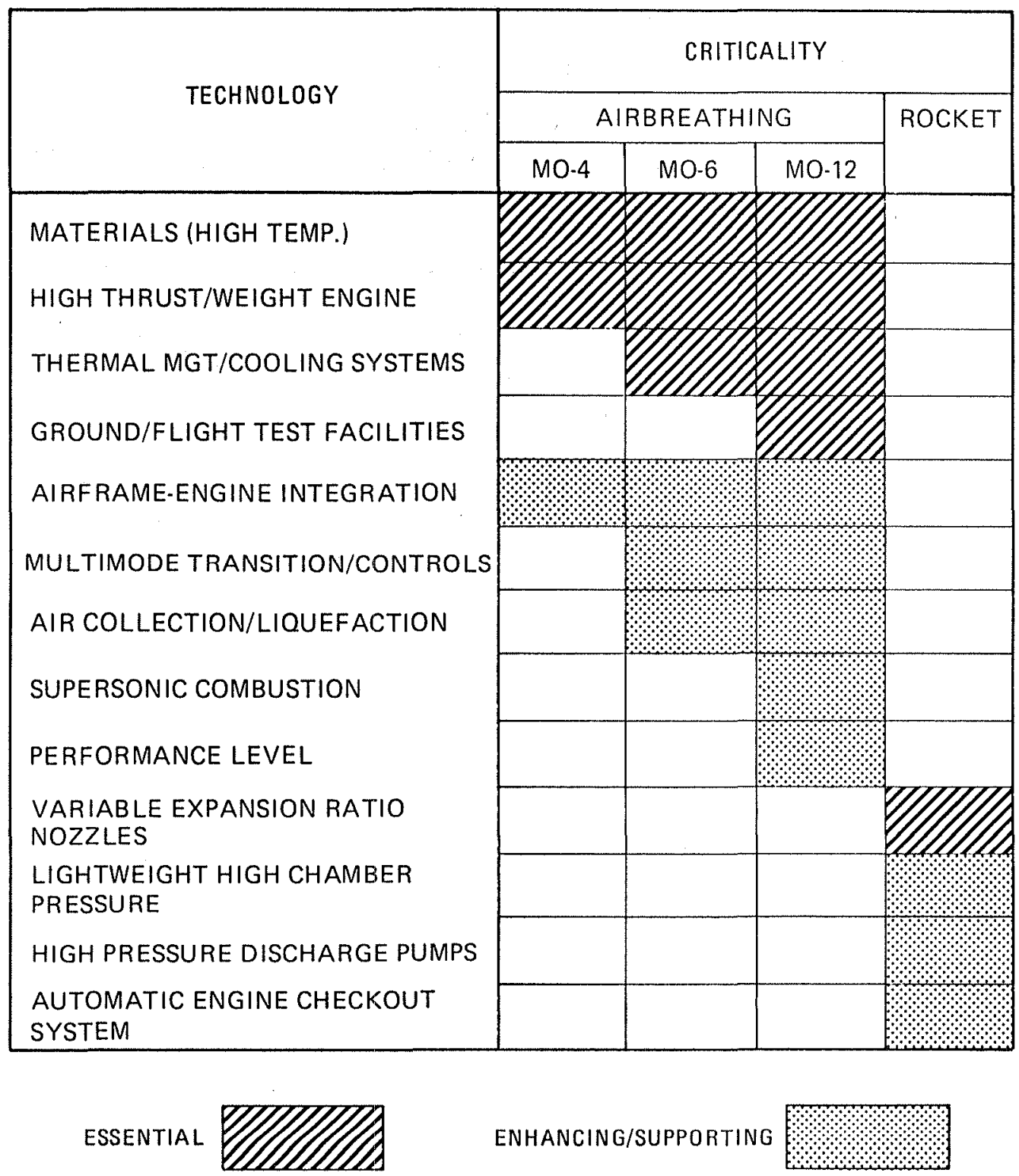

FIGURE 45 Technology matrix, Transatmospheric Aircraft propulsion systems . 
TABLE 18 Performance Projections for Transatmospheric Aircraft

Projected

Improvement

Technology Factor

(Year 2000)

Hypersonic 1 ift-to-drag ratio

$+300 \%$

Cross range for reentry

$+500 \%$

Integrated propulsion specific impulse $+1,000 \%$

Thermal protection system durability

$+500 \%$

Payload fraction to orbit

Structural weight fraction

$+300 \%$

$-30 \%$ 
End of Document 